\title{
WestVirginiaUniversity
}

THE RESEARCH REPOSITORY @ WVU

Graduate Theses, Dissertations, and Problem Reports

2009

\section{Numerical modeling of nitrogen injection into gas condensate reservoir}

\author{
Candace L. Subero \\ West Virginia University
}

Follow this and additional works at: https://researchrepository.wvu.edu/etd

\section{Recommended Citation}

Subero, Candace L., "Numerical modeling of nitrogen injection into gas condensate reservoir" (2009). Graduate Theses, Dissertations, and Problem Reports. 2021.

https://researchrepository.wvu.edu/etd/2021

This Thesis is protected by copyright and/or related rights. It has been brought to you by the The Research Repository @ WVU with permission from the rights-holder(s). You are free to use this Thesis in any way that is permitted by the copyright and related rights legislation that applies to your use. For other uses you must obtain permission from the rights-holder(s) directly, unless additional rights are indicated by a Creative Commons license in the record and/ or on the work itself. This Thesis has been accepted for inclusion in WVU Graduate Theses, Dissertations, and Problem Reports collection by an authorized administrator of The Research Repository @ WVU. For more information, please contact researchrepository@mail.wvu.edu. 


\title{
NUMERICAL MODELING OF NITROGEN INJECTION INTO GAS CONDENSATE RESERVOIR
}

\author{
Candace L. Subero \\ Thesis Submitted to the \\ College of Engineering and Mineral Resources \\ At West Virginia University \\ In partial fulfilment of the requirements \\ For the degree of \\ Master of Science \\ In \\ Petroleum and Natural Gas Engineering
}

Khashayar Aminian, Ph.D. Chair

Ilkin Bilgesu, Ph.D.

Samuel Ameri, M.S

Department of Petroleum and Natural Gas Engineering

Morgantown, West Virginia

2009

Keywords: Petroleum and Natural Gas Engineering, Gas Condensate, Nitrogen

Injection, Numerical Reservoir Modelling.

Copyright 2009 Candace L. Subero 


\section{ABSTRACT \\ NUMERICAL MODELING OF NITROGEN INJECTION INTO GAS CONDENSATE RESERVOIR}

\section{Candace L. Subero}

Gas-condensate reservoirs differ from dry-gas reservoirs. Gas condensate production is predominantly gas from which a quantity of liquid is condensed; the amount condensed being based on the gas-oil-ratio, GOR, in surface separators. Condensate dropout occurs in the reservoir as the pressure falls below dew-point, as a result of which, the liquid production decreases significantly and the condensate formed in the reservoir is also unrecoverable. Injection and cycling of dry natural gas has been used to enhance the condensate production from these reservoirs. However natural gas has become more valuable and alternative gases must be investigated. One of such gas is nitrogen which is inert and can be generated inexpensively at the well site.

The purpose of this research study was to develop a gas condensate reservoir model to determine the effects that nitrogen injection has on the condensate recovery. In order to build a realistic reservoir model, data from a deep high pressure gas condensate field was used. The results of this study indicated that for original well pattern, nitrogen injection did not show an overall benefit to condensate recovery. However alternative development plan for the reservoir showed increased condensate producibility and thus the viability of nitrogen injection. 


\section{ACKNOWLEDGEMENTS}

Thank you God for the many opportunities your have given me. I know that through You all things are possible.

I am especially grateful to my advisor and professor, Dr. Kashy Aminian, for his continuous supervision during my graduate program. I respect and admire your professionalism and appreciate your guidance throughout my program.

I would also like to extent my appreciation and gratitude to Prof. Sam Ameri for his support, continuous motivation and uncanny ability to always put a smile on my face. I also appreciate your participation and enthusiasm to be part of my committee.

My gratitude is also extended to Dr. Ilkin Bilgesu for his help and support. Thank you for your involvement and commitment towards being a part of my committee.

Special thanks to all the faculty and staff of the department of Petroleum and Natural Gas Engineering, with special mention of Ms. Beverley Matheny who was always so helpful and welcoming.

I am also eternally grateful to the Fulbright organisation without which I would not have had the opportunity to pursue my Masters degree. Thank you for your support and guidance during my stay in the United States; special thanks to Renee and Megan who were always there when I needed advice.

I will like to express special thanks and gratitude to all the friends I have made here and for the many memories I will carry with me. Many thanks to Richard for "laughing with me”.

I dedicate my work to my family back home. Thank you for all your love and constant support.

"I have had dreams and I have had nightmares, but I have conquered my nightmares because of my dreams.” Dr. Jonas Salk 


\section{TABLE OF CONTENTS}

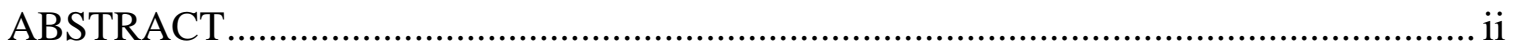

ACKNOWLEDGEMENTS ............................................................................... iii

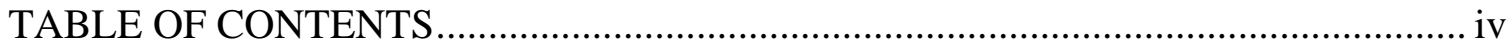

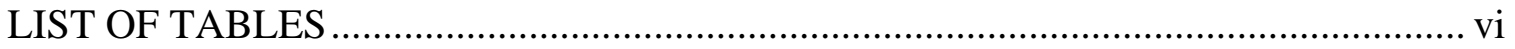

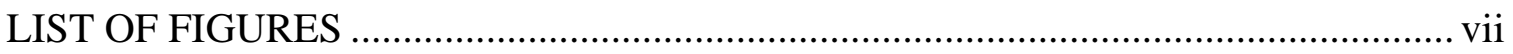

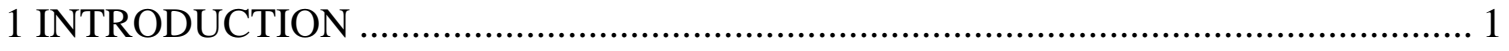

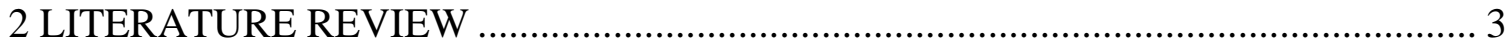

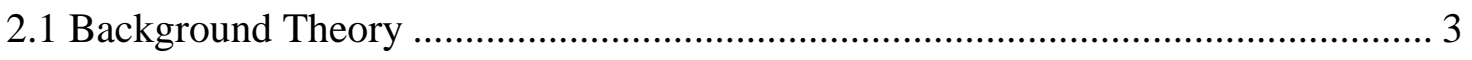

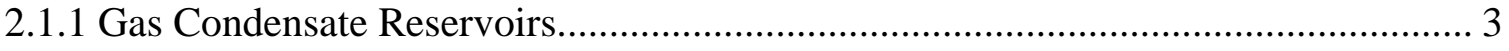

2.1.2 Recovery from Gas Condensate Reservoirs ....................................................... 4

2.1.3 Gas Condensate Reservoir Frequency of Occurrence .......................................... 5

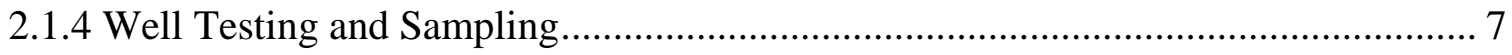

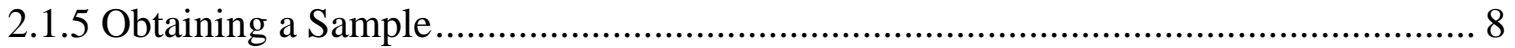

2.1.6 Well Conditioning and Sampling Procedures .................................................... 8

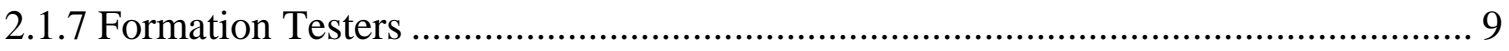

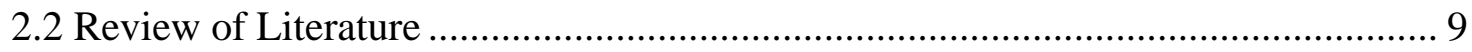

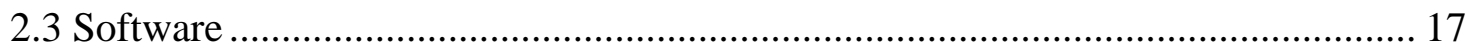

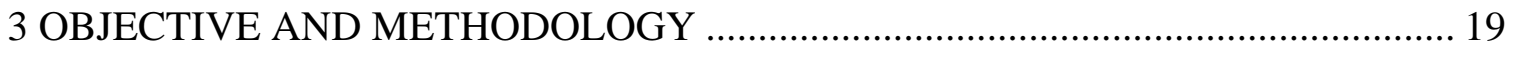

3.1 Pressure-Volume-Temperature (PVT) Analysis.............................................. 19

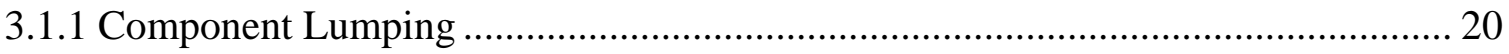

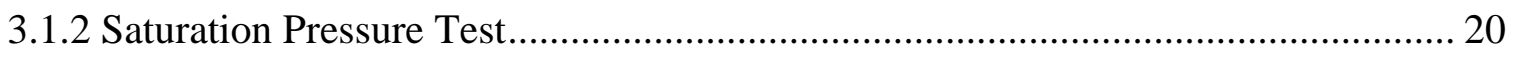

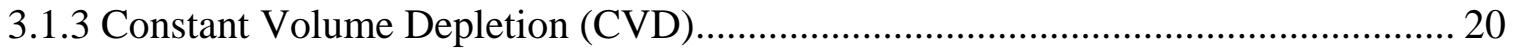

3.1.4 Constant Composition Expansion (CCE) …...................................................... 20

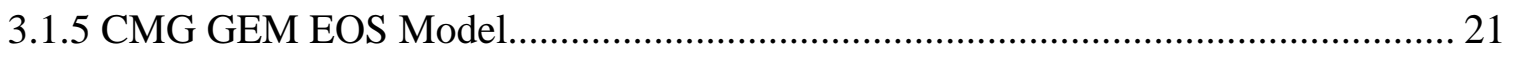

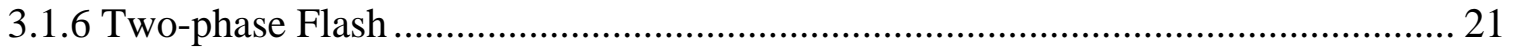

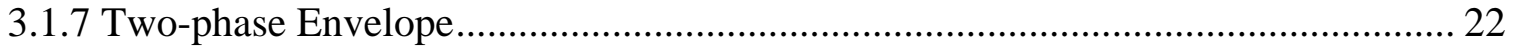

3.2 Development of the Reservoir Model.............................................................. 22 
3.2.1 Data Entry into Builder .......................................................................................... 24

3.2.2 Relative Permeability ......................................................................................... 25

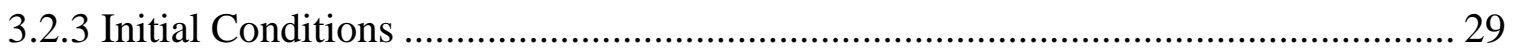

3.2.4 Wells, Well Constraints and Production Time ……………………………............ 30

3.3 Initial Reservoir Conditions and Fluid Properties ..................................................... 31

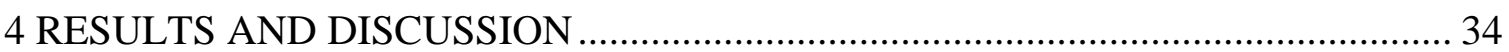

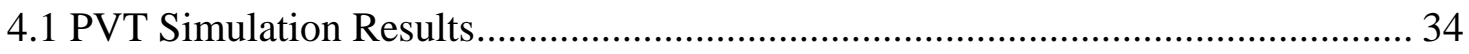

4.1.1 Constant Volume Depletion.................................................................................. 34

4.1.3 Two-phase Flash ................................................................................................ 35

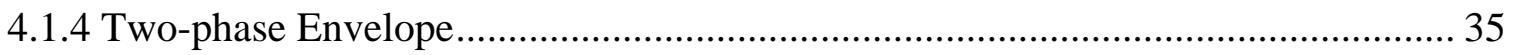

4.1.2 Constant Composition Expansion......................................................................... 37

4.2 Nitrogen Effect on Reservoir Fluid Dew Point.................................................... 38

4.3 Pressure Depletion and Nitrogen Injection Results ................................................. 38

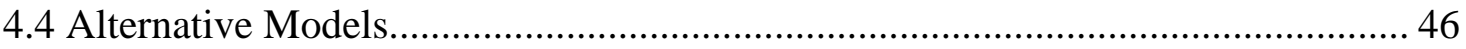

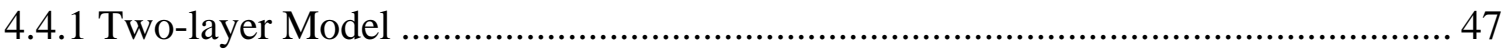

4.4.2 Nitrogen Injection Starting Time .................................................................... 54

4.4.3 Location of Injection Point ................................................................................ 59

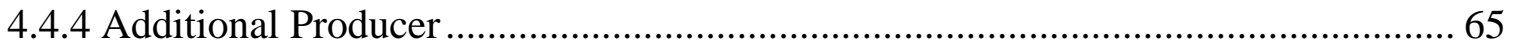

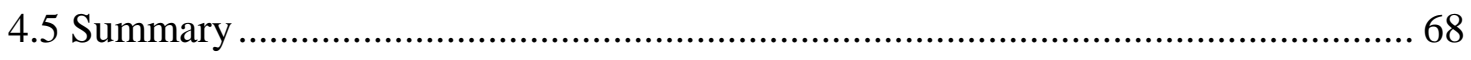

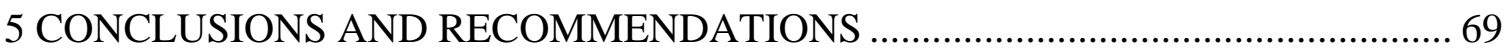

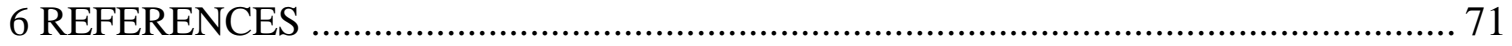

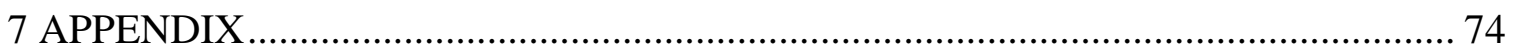

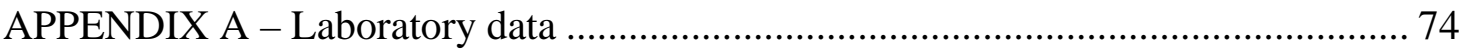

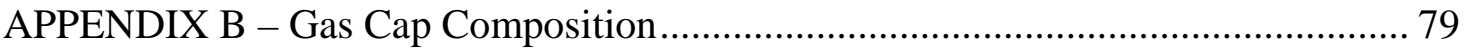

APPENDIX C - Comparison of saturations of single layer and two-layer model

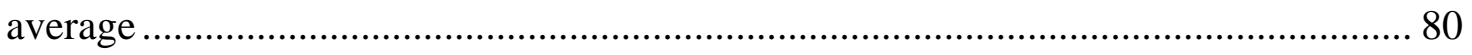

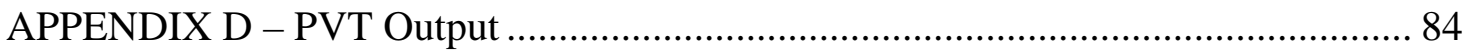

APPENDIX E - PHASE Program Example Input and Output Files.............................. 88 


\section{LIST OF TABLES}

TABle 1-1: TyPiCAL COMPOSITION AND PROPERTIES OF FIVE SINGLE PHASE RESERVOIR FLUID (DATA FROM NATURAL GAS ENGINEERING ${ }^{10}$ ) ........................................... 5

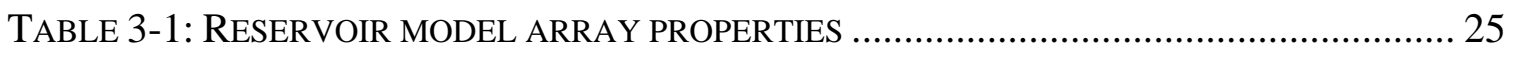

TABLE 3-2 INITIAL GAS-WATER RELATIVE PERMEABILITY ASSUMPTION ........................... 25

TABLE 3-3 WATER-GAS RELATIVE PERMEABILITY TABLE ............................................. 26

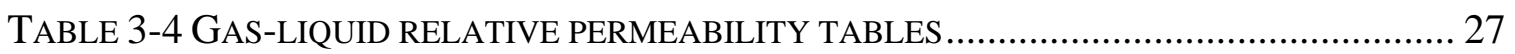

TABLE 3.5 INITIAL RESERVOIR CONDITIONS CALCULATED BY GEM SiMULATOR .............. 32

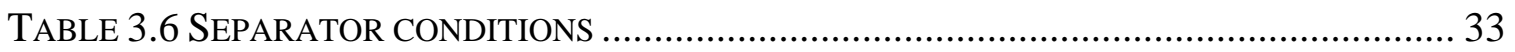

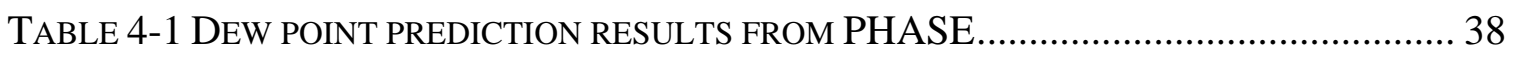

TABle 4-2 Cumulative CONDENSATE PRODUCTIONS FOR DIFFERENT LOCATIONS OF

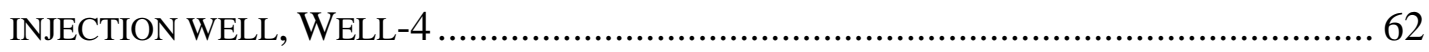

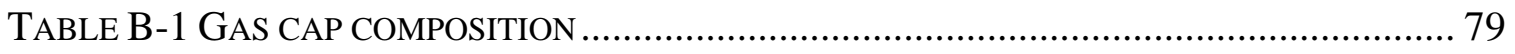

TABLE C-1 AVERAGE GAS AND OIL SATURATIONS OF TOP AND BOTTOM LAYER ................. 80

TABLE C-2 SINGLE LAYER MODEL GAS AND OIL SATURATIONS ...................................... 81

TABle C-3 Numeric DIFFERENCE BETWEEN TWO-LAYER AND SINGLE LAYER MODELS

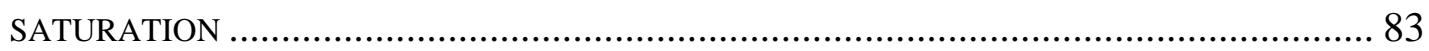




\section{LIST OF FIGURES}

FIGURE 1-1 DisCOVERY FREQUENCY OF OIL AND GAS OR GAS-CONDENSATE RESERVOIRS VERSUS DEPTH, FOR 17 PARISHES IN SOUTHWEST LOUISIANA, 1952-1956, INCLUSIVE.

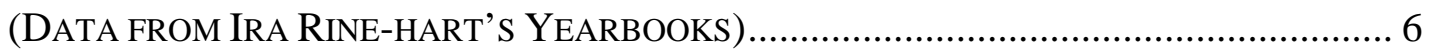

FIGURE 1-2 PLOT SHOWING TREND OF INCREASE OF GAS-OIL RATIO VERSUS DEPTH, FOR 17 PARISHES IN SOUTHWEST LOUISIANA, 1955. (DATA FROM IRA RINE-HART'S

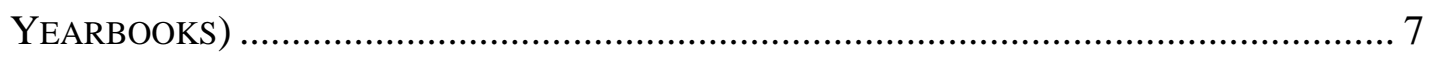

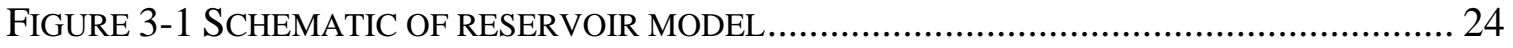

FIGURE 3-2 INITIAL GAS-WATER RELATIVE PERMEABILITY CURVES ................................ 28

FIGURE 3-3 FINAL GAS-LIQUID RELATIVE PERMEABILITY CURVES ................................... 28

FIGURE 3-4 GAS-OIL-RATIO COMPARISON BETWEEN SIMULATION AND FIELD RESULTS ..... 29

FIGURE 3-5: WINPROP GENERATED PHASE PROPERTY - LIQUID PHASE VOLUME PERCENT AT

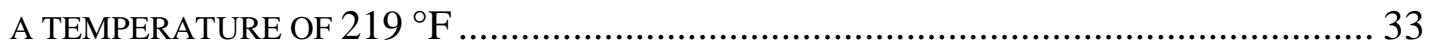

FiguRE 4-1: LiQuid VOLUME PERCENTAGE MATCH OF SIMULATED AND LABORATORY

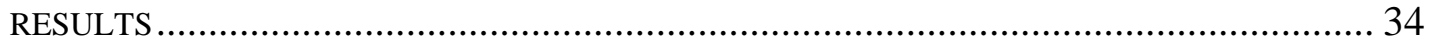

FIGURE 4-2: WINPROP TWO-PHASE FLASH RESULTS SHOWING THE PREDICTED TWO-PHASE

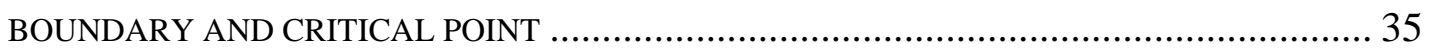

FIGURE 4-3: WINPROP GENERATED PHASE PROPERTY - LIQUID PHASE VOLUME PERCENT AT

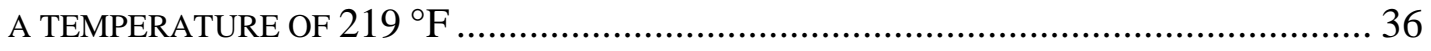

FIGURE 4-4: WINPROP GENERATED PHASE PROPERTY - VAPOR PHASE VOLUME PERCENT AT A TEMPERATURE OF $219^{\circ} \mathrm{F}$ 36

Figure 4-5: WinPROP CCE SimULATION MATCH OF LABORATORY RELATIVE VOLUME DATA.

FIGURE 4-6 WELL BLOCK PRESSURES DURING THE PRESSURE DEPLETION OF RESERVOIR .. 40

FIGURE 4-7 SURFACE CONDENSATE PRODUCTION RATES FOR MODEL UNDER PRESSURE

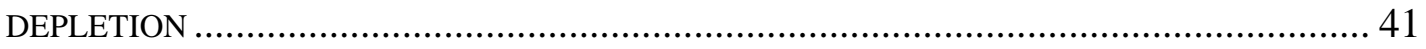

FIGURE 4-8 SURFACE GAS OIL RATIOS FOR PRESSURE DEPLETION .................................. 41

FIGURE 4-9 CUMULATIVE SURFACE CONDENSATE PRODUCTION FOR PRESSURE DEPLETION

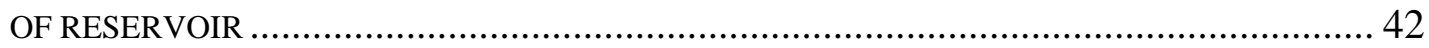


FIGURE 4-10 OIL AND GAS SATURATION TRENDS FOR PRODUCTION GRID-BLOCKS .. 42

FIGURE 4-11 WELL BLOCK PRESSURE COMPARISON BETWEEN NITROGEN INJECTION (SOLID

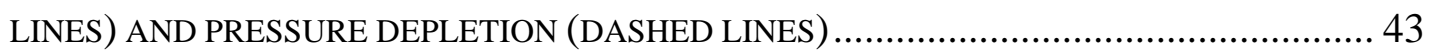

FIGURE 4-12 SURFACE PRODUCTION RATES FOR FIELD UNDER NITROGEN INJECTION.......... 43

FIGURE 4-13 SURFACE GAS OIL RATIOS FOR RESERVOIR WHEN NITROGEN IS INJECTED...... 44

FiguRE 4-14 CUMULATIVE SURFACE CONDENSATE PRODUCTION COMPARISON BETWEEN NITROGEN INJECTION (SOLID LINES) AND PRESSURE DEPLETION (DASHED LINES) ...... 44

FIGURE 4-15 GOR AND BLOCK SATURATIONS FOR WELL-1 1.......................................... 45

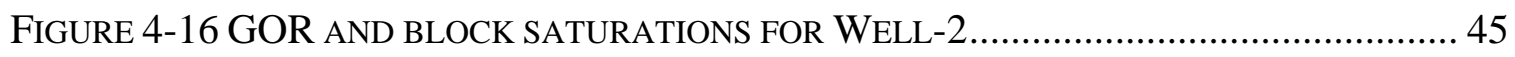

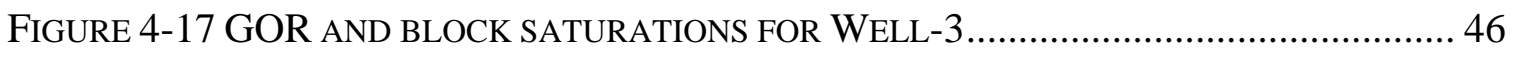

FIGURE 4-18 WELL BLOCK PRESSURES FOR TWO-LAYER MODEL COMPARING PRODUCTION WITH NITROGEN INJECTION (SOLID LINES) AND PRESSURE DEPLETION (DASHED LINES) .48

FIGURE 4-19 SURFACE CONDENSATE PRODUCTION RATES FOR TWO-LAYER MODEL UNDER PRESSURE DEPLETION. 49

FigURE 4-20 SURFACE CONDENSATE PRODUCTION RATES FOR TWO-LAYER MODEL WITH NITROGEN INJECTION 49

FIGURE 4-21 SURFACE GAS-OIL-RATIOS FOR TWO-LAYER MODEL UNDER PRESSURE DEPLETION 50

FIGURE 4-22 SURFACE GAS-OIL-RATIOS FOR TWO-LAYER MODEL WITH NITROGEN INJECTION 50

Figure 4-23 CUMUlative CONDENSATE PRODUCTIONS FOR TWO-LAYER MODEL COMPARING PRODUCTION WITH NITROGEN INJECTION (SOLID LINES) AND UNDER

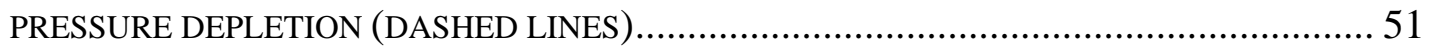

FIGURE 4-24 CMG RESULTS TOP LAYER GAS SATURATION PROFILE AFTER 25 YEARS....... 52

FIGURE 4-25 CMG RESULTS BOTTOM LAYER GAS SATURATION PROFILE AFTER 25 YEARS 52 FIGURE 4-26 CMG RESULTS TOP LAYER OIL SATURATION PROFILE AFTER 25 YEARS ........ 53 FIGURE 4-27 CMG RESULTS BOTTOM LAYER OIL SATURATION PROFILE AFTER 25 YEARS 53 FIGURE 4-28 WELL BLOCK PRESSURES COMPARISON BETWEEN INJECTION STARTING AT YEAR 7 (SOLID LINES) AND YEAR 10 (DASHED LINES) .......................................... 55 
FIGURE 4-29 SURFACE CONDENSATE PRODUCTION RATES FOR INJECTION PLAN STARTING AT

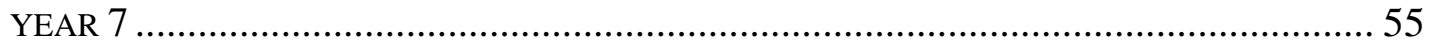

FIGURE 4-30 GAS-OIL-RATIOS FOR INJECTION PLAN STARTING AT YEAR 7 ....................... 56

FIGURE 4-31 CUMULATIVE CONDENSATE PRODUCTIONS COMPARISON BETWEEN INJECTION STARTING AT YEAR 7 (SOLID LINES) AND YEAR 10 (DASHED LINES) .......................... 56

FIGURE 4-32 WELL BLOCK PRESSURES COMPARISON BETWEEN INJECTION STARTING AT YEAR 13 (SOLID LINES) AND YEAR 10 (DASHED LINES)........................................ 57

FIGURE 4-33 SURFACE CONDENSATE PRODUCTION RATES FOR INJECTION PLAN STARTING AT

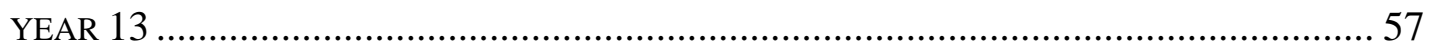

FIGURE 4-34 GAS-OIL-RATIOS FOR INJECTION PLAN STARTING AT YEAR 13..................... 58

FIGURE 4-35 CUMULATIVE CONDENSATE PRODUCTIONS COMPARISON BETWEEN INJECTION STARTING AT YEAR 13 (SOLID LINES) AND YEAR 10 (DASHED LINES) ......................... 58

FIGURE 4-36 GAS-OIL-RATIOS FOR INJECTION AT GRID-BLOCK 2,4,1 ............................ 59

FiguRE 4-37 CUMULATIVE CONDENSATE PRODUCTIONS COMPARISON BETWEEN INJECTION AT GRID-BLOCK 2,4,1 (SOLID LINES) AND GRID-BLOCK 2,5,1 (DASHED LINES) ........... 60

FIGURE 4-38 GAS-OIL-RATIOS FOR INJECTION AT GRID-BLOCK 2,7,1 ........................... 61

FIGURE 4-39 CUMULATIVE CONDENSATE PRODUCTIONS COMPARISON BETWEEN INJECTION AT GRID-BLOCK 2,7,1 (SOLID LINES) AND GRID-BLOCK 2,5,1 (DASHED LINES) ........... 61

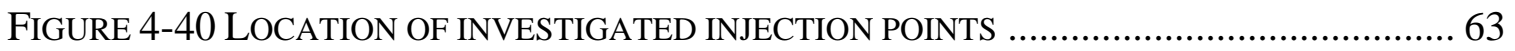

FIGURE 4-41 GAS-OIL-RATIOS FOR INJECTION AT GRID-BLOCK 3,9,1 ............................. 64

FIGURE 4-42 CUMULATIVE CONDENSATE PRODUCTIONS COMPARISON BETWEEN INJECTION AT GRID-BLOCK 3,9,1 (SOLID LINES) AND GRID-BLOCK 2,5,1 (DASHED LINES) ........... 64

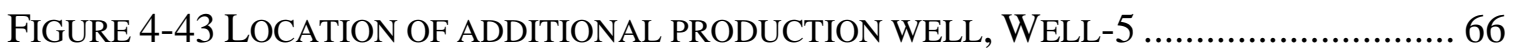

FigURE 4-44 ALTERNATE LOCATION OF ADDITIONAL PRODUCTION WELL, WELL-5........... 66

FiguRE 4-45 CUMULATIVE SURFACE CONDENSATE PRODUCTION FOR FIELD UNDER NITROGEN INJECTION WHERE WELL-3 SURFACE GAS RATE WAS INCREASED TO 1 MMSCFD (SOLID LINES) COMPARED TO PRESSURE DEPLETION WITH WELL-3 AS A LOW PRODUCER (DASHED LINE)

FIGURE A-1 RESERVOIR FLUID COMPOSITION BASED ON SEPARATOR FLUIDS RECOMBINATION 74 
FIGURE A-2 HYDROCARBON ANALYSIS OF SEPARATOR PRODUCTS AND CALCULATED WELL

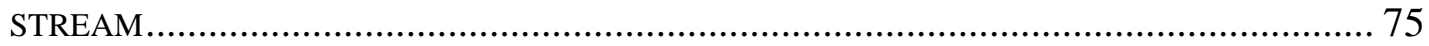

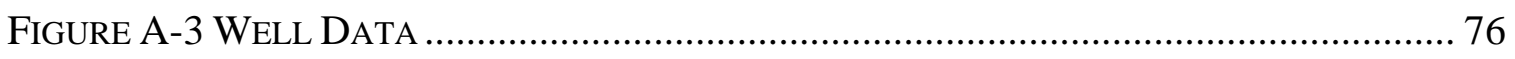

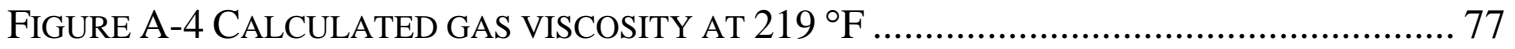

FigURE A-5 RETROGRADE CONDENSATION DURING GAS DEPLETION AT $219^{\circ} \mathrm{F}$................. 78

FIGURE D-1: WINPROP CVD SIMULATION RESULTS FOR GAS COMPRESSIBILITY................ 84

FIGURE D-2: WinPROP CCE SIMULATION OIL AND GAS VISCOSITY PREDICTIONS ............. 84

FIGURE D-3: WinPROP CCE SIMULATION PREDICTIONS FOR LIQUID VOLUME PERCENT ... 85

FIGURE D-4: WinPROP CCE SiMULATION PREDICTIONS FOR GAS AND OIL Z-FACTORS ..... 85

Figure D-5: WinPRoP CCE SiMUlATION PREDICTIONS FOR SINGLE PHASE OIL

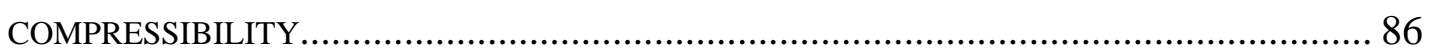

FIGURE D-6: WinPRoP CCE SIMULATION PREDICTIONS FOR GAS AND OIL DENSITIES....... 86 FIGURE D-7 WINPROP GENERATED P-T DIAGRAM SHOWING INDIVIDUAL COMPONENT KVALUES 


\section{INTRODUCTION}

At the time of discovery, a typical gas-condensate reservoir pressure might be above or close to the critical pressure. At this time there exists only single-phase gas. However as the production is carried out, there is isothermal pressure decline and as the bottom hole pressure in a flowing well falls below the dew-point of the fluid a liquid hydrocarbon phase is formed. Retrograde condensation occurs in gas condensate reservoirs when the pressure falls below the dew point pressure. This leads to low recoveries as the liquid dropout is capillary trapped or left behind due to the low relative permeability.

Retrograde condensation can be prevented by maintaining the reservoir pressure above the dew point pressure by injection of gas. The physical properties of dry hydrocarbon gases make it very suitable for injection gas. However, dry gas is expensive and is not always available for re-injection. An alternative could be nitrogen, which is available everywhere, relatively cheap and has favorable injection characteristics (safe, noncorrosive, environment-friendly).

The disadvantage of nitrogen is that liquid drop-out occurs in the mixing zone between the injected nitrogen and the gas condensate. In a homogeneous reservoir this occurs only at the displacement front.

The purpose of this research study was to develop a gas condensate reservoir model to determine the impact that nitrogen injection has on the condensate recovery. The research investigation comprised several phases: Estimating extended compositional analysis of the original reservoir using PVT analysis, developing a realistic gas condensate reservoir model, developing a feasible nitrogen injection plan and investigating the impact of injecting nitrogen to enhance condensate recovery.

In order to build a realistic reservoir model, data from a deep, high pressure gas condensate field was used and where needed, estimates were made for any unknown reservoir properties. The intended plan was for simultaneously injection to and production from the reservoir. This differs from previous studies done on nitrogen 
injection where injection and production was done consecutively in a production cycle or the injected gas was a mixture of nitrogen and dry natural gas. Our study will use a threedimensional compositional simulator to run the model. By using this as opposed to PVT simulator, we were able to incorporate uneven mixing of the reservoir fluid and injection gas within the reservoir.

It was intended that at the end of this study we would be able to determine the positive and negative aspects of nitrogen injection into gas condensate reservoirs and be able to apply the knowledge learnt to further perfect this method of enhancing condensate recovery. 


\section{LITERATURE REVIEW}

\subsection{Background Theory}

\subsubsection{Gas Condensate Reservoirs}

Gas condensate production may be thought of as being an intermediate between oil and gas production. Gas condensate production is predominantly gas from which a quantity of liquid is condensed; the amount condensed being based on the GOR, in surface separators. The liquid is sometimes referred to by and older name of distillate or oil.

Gas condensate reservoirs may be approximately defined as those that produce light colored or colorless stock tank liquids with gravities above $45{ }^{\circ} \mathrm{API}$. Condensate reservoirs include both wet gas and retrograde condensate types. In both types, fluid exists at a single phase state initially in the reservoir. The difference being that liquid is formed in the reservoir of retrograde types. Most known gas condensate reservoirs occur within a range of 3000 to $6000 \mathrm{psi}$ and 200 to $400{ }^{\circ} \mathrm{F}$. This combined with wide compositional ranges give numerous conditions that would alter the gas condensate deposit's physical behavior. A rough classification, which is based on the reservoir's performance at initial conditions is given as follows,

- Initial GOR $>15,000 \mathrm{scf} / \mathrm{bbl}$, Pressure $\leq 8,000 \mathrm{psia}$, Temperature $\leq 225{ }^{\circ} \mathrm{F}$. It is likely that no liquid is formed in this reservoir.

- $6,000 \mathrm{scf} / \mathrm{bbl}<$ Initial GOR $<15,000 \mathrm{scf} / \mathrm{bbl}$. It is likely that there is retrograde behavior, a representative reservoir sample should be obtained and Pressure Volume Temperature (PVT) analysis conducted.

- $3,000 \mathrm{scf} / \mathrm{bbl}<$ Initial GOR $<6,000 \mathrm{scf} / \mathrm{bbl}$. It is likely that this is a volatile oil or retrograde gas condensate. The distinction is made by using gas sampling and PVT analysis. This analysis is important since these two types of reservoirs will require different development plans. 
- Initial GOR $>3,000 \mathrm{scf} / \mathrm{bbl}$. It is likely that the reservoir fluid is oil, probably a volatile oil.

\subsubsection{Recovery from Gas Condensate Reservoirs}

Once the initial hydrocarbon in place is calculated, the gas and condensate recovery can be determined. These recoveries will be based on a selected abandonment pressure. As pressure drops below the dew point, liquid drop-out will occur in the reservoir, which is mostly unrecoverable. This drop-out causes the surface composition of heavy hydrocarbons to be reduced as the reservoir is depleted.

An estimate of recovery by depletion must be made before determining the feasibility of pressure maintenance by a chosen method.

The table below shows the typical composition and properties of five (5) single phase reservoir fluids. Lean or dry gas is commonly described as having a GOR > 100,000 $\mathrm{scf} / \mathrm{bbl}$, however this value is not set in stone. The volatile oil is the intermediate between black oil and gas condensate (sometimes called wet gas). The gas-oil-ratios are used as a good indication of a reservoir fluid overall composition, thus high GORs represent low pentane plus compositions.

As pressure declines in black oil, volatile oil and gas condensate reservoirs there is a general upward trend observed in GOR due to the reservoir mechanism that controls the flow of oil and gas to the wellbore. This increase in GOR can be observed in two-phase reservoirs depending on the reservoir conditions. If a well is completed in the oil zone and the oil and gas zones are only several feet in thickness, downward coning of gas from the overlaying gas cap can occur, leading to an increase in GOR. 
Table 1-1: Typical composition and properties of five single phase reservoir fluid (data from Natural Gas Engineering ${ }^{10}$ )

\begin{tabular}{|c|c|c|c|c|c|}
\hline \multicolumn{6}{|c|}{ Mole composition and other properties of typical single-phase reservoir fluids } \\
\hline Component & $\begin{array}{c}\text { Black } \\
\text { Oil }\end{array}$ & $\begin{array}{c}\text { Volatile } \\
\text { Oil }\end{array}$ & $\begin{array}{c}\text { Gas- } \\
\text { Condensate }\end{array}$ & Dry Gas & Gas \\
\hline$C_{1}$ & 48.83 & 64.36 & 87.07 & 95.85 & 86.67 \\
\hline$C_{2}$ & 2.75 & 7.52 & 4.39 & 2.67 & 7.77 \\
\hline$C_{3}$ & 1.93 & 4.74 & 2.29 & 0.34 & 2.95 \\
\hline$C_{4}$ & 1.60 & 4.12 & 1.74 & 0.52 & 1.73 \\
\hline $\mathrm{C}_{5}$ & 1.15 & 2.97 & 0.83 & 0.08 & 0.88 \\
\hline$C_{0}$ & 1.59 & 1.38 & 0.60 & 0.12 & \\
\hline $\mathrm{C}_{2}^{+}$ & 42.15 & 14.91 & 3.80 & 0.42 & \\
\hline & 100.00 & 100.00 & 100.00 & 100.00 & 100.00 \\
\hline Mol. wt. $C_{7}^{+}$ & 225 & 181 & 112 & 157 & \\
\hline GOR, SCF/bbl & 625 & 2000 & 18,200 & 105,000 & Inf. \\
\hline Tank gravity, ${ }^{\circ} \mathrm{API}$ & 34.3 & 50.1 & 60.8 & 54.7 & \\
\hline Liquid color & $\begin{array}{l}\text { Greenish } \\
\text { black }\end{array}$ & $\begin{array}{c}\text { Medium } \\
\text { orange }\end{array}$ & $\begin{array}{l}\text { Light } \\
\text { straw }\end{array}$ & $\begin{array}{l}\text { Water } \\
\text { white }\end{array}$ & \\
\hline
\end{tabular}

\subsubsection{Gas Condensate Reservoir Frequency of Occurrence}

In the 1950's when deeper drilling began in many areas, there was a higher chance of gas and gas condensate reservoir discoveries. Most oil discoveries occurred at depths above $8,000 \mathrm{ft}$ whereas gas and gas condensate dominated below 10,000 ft. the figures below show the discovery trend for Louisiana in the 1950's. The reservoirs were described as oil, gas and gas condensate based on gas-oil-ratio and produced liquid API from well tests. 


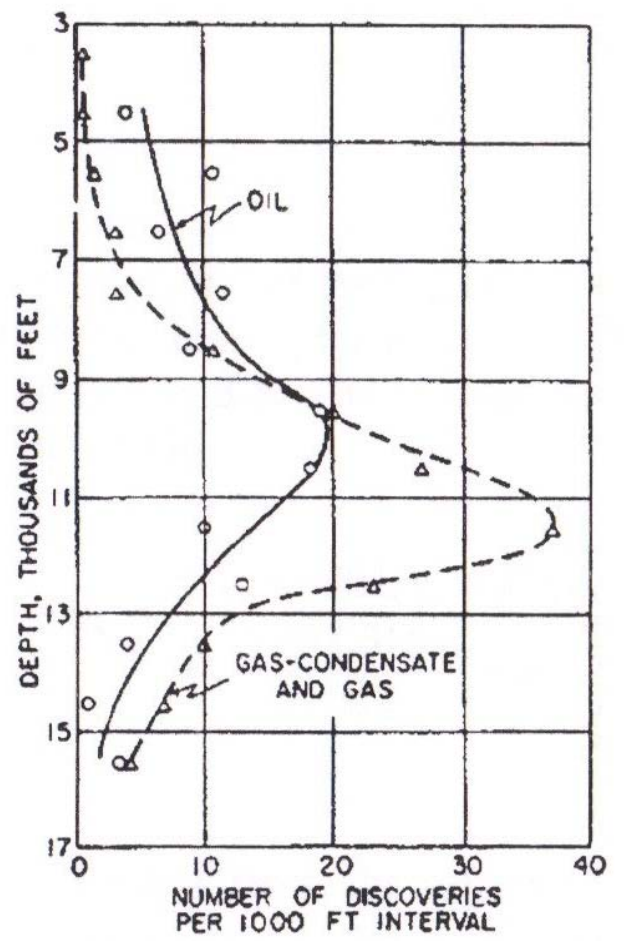

Figure 1-1 Discovery frequency of oil and gas or gas-condensate reservoirs versus depth, for 17 parishes in southwest Louisiana, 1952-1956, inclusive. (Data from Ira Rine-hart's Yearbooks)

A single phase gas reservoir if depleted at constant temperature would remain in the gas phase, however due to cooling and wellbore and surface facilities pressure drop there is hydrocarbon condensing. Retrograde gas condensate reservoirs initially exist in the single phase region above the two-phase boundary and at temperatures between the critical point and cricondentherm. The presence of a large percentage of $C_{2}$ to $C_{6}$ allows retrograde gas condensate reservoirs to be found initially very close to or at the dew point pressure. Another common feature is a volatile oil rim in the reservoir; in this case the gas would be exactly at the dew point pressure. 


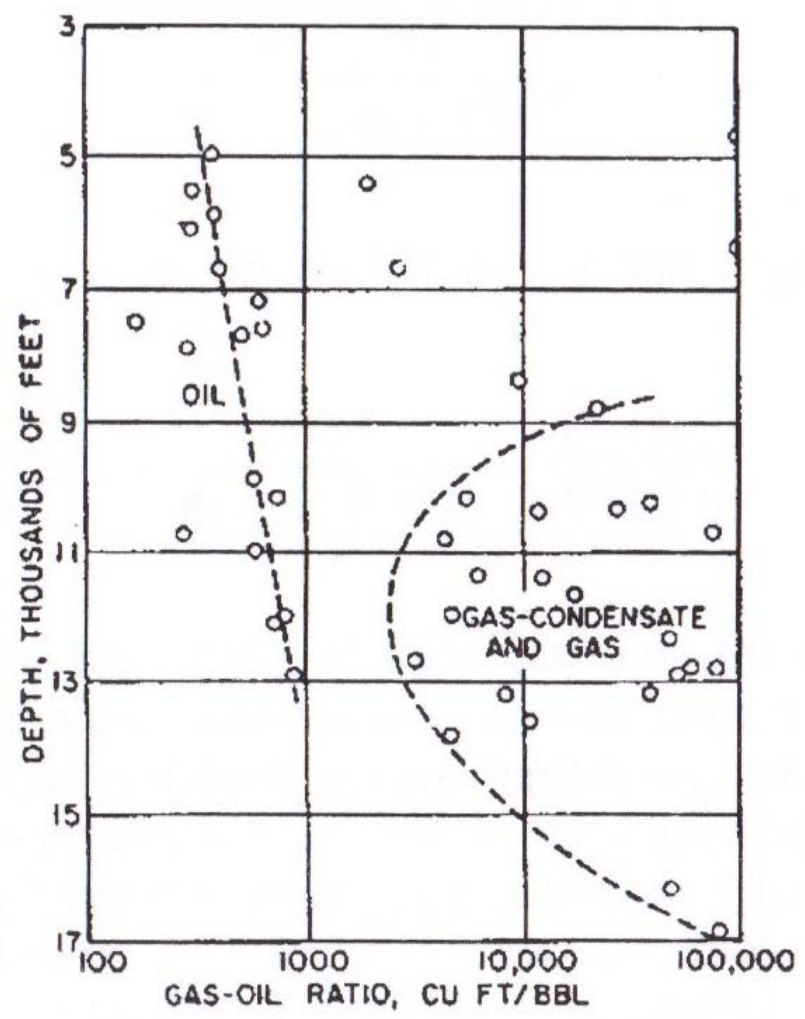

Figure 1-2 Plot showing trend of increase of gas-oil ratio versus depth, for 17 parishes in southwest Louisiana, 1955. (Data from Ira Rine-hart’s Yearbooks)

\subsubsection{Well Testing and Sampling}

In order to design the best production plan for a gas condensate reservoir, to determine the phase conditions and amount of hydrocarbons present at reservoir temperature and pressure, proper testing and sampling is imperative. Tests are made on gas condensate wells for the following specific purposes:

- To obtain representative samples for laboratory determination of reservoir fluid composition and properties.

- To make field determinations of gas and liquid properties.

- To determine formation and well characteristics, including producibility and injectivity. 


\subsubsection{Obtaining a Sample}

There is a considerably higher level of difficulty in obtaining a representative sample from a gas condensate than a black oil reservoir. This is due to the fact that the liquid may condense from the reservoir fluid during sampling process. An erroneous representative composition can be calculated if proper sample proportions of liquid and gas are not recovered. Typically surface sampling techniques are used in gas condensate reservoirs after a long stabilized flow period. Gas and liquid produced volumes from surface separators are accurately measured and fluid samples are recombined in these proportions.

The selection of the well to be sampled also needs to be taken into consideration. The well should be an acceptable distance away from any liquid portions (if present) to minimize any chance of the liquid oil phase entering the well during the test period. Also the selected well should have high productivities so that a minimum drawdown will occur in acquiring the reservoir fluid samples.

\subsubsection{Well Conditioning and Sampling Procedures}

There are several desirable conditions needed for obtaining a representative sample from the gas condensate reservoir. One should employ the lowest rate that gives smooth well operations and the most reliable surface product measurements. These should be minimum drawdown during the conditioning period with a relatively constant produce gas-liquid ratio for several days; the length of time depending on the reservoir permeability.

Recombined separator samples are considered more representative of the original fluid than bottom-hole samples. There can be a liquid layer adhering to the tubing walls for gas condensate wells, making it very difficult to obtain a reliable bottom-hole sample. Also a surface sample provides the larger sample quantities required for laboratory testing.

Recently methods have been developed for down hole sampling. These methods are only practical and desirable if the wellbore flowing pressure is above the dew point pressure. They are not recommended if the tubing pressure at any point is lower than the dew point 
pressure. If this condition occurs there is a two-phase flow in the wellbore giving rise to separation of any liquid formed in the tubing. The liquid drops out at the bottom of the tubing, where the bottom-hole sample is collected, leading to a potentially unrepresentative sample with larger amounts of heavier components.

\subsubsection{Formation Testers}

The formation testers have improved significantly over the past decade. The MDT, Modular Formation Dynamic Tester, has a probe that is pressed against the uncased borehole well and withdraws a fluid sample from the formation. The LFA, Live Fluid Analyzer module on the tool measures the cleanup of oil-based drilling or completions fluids contamination minimizing the wait time and assuring quality samples. This detector also provides a measure of the light components, such as methane, and liquids. Thus the ratio of methane to liquid provides a measure of the condensate to gas ratio which is an important consideration for early economic evaluation of a prospective. The analysis can also show zones with varying composition or composition gradients as well as reservoir pressure. Measured data from the MDT is transmitted to the surface immediately.

For gas condensates that are at pressures above the dew point in the reservoir, it is important to capture and maintain a single-phase fluid. If the fluid pressure drops below the dew point it may take a long time to recombine the sample, or changes may be irreversible. The LFA measurements provide evidence for when a fluid goes through its dew point which can give an indication of when the pressure difference is too large and should be reduced before sampling to keep the pressure above the dew point.

\subsection{Review of Literature}

There are several published papers dealing with different aspects of nitrogen injection and gas condensate reservoir properties. 
In a paper presented at the 2001 SPE Middle East Oil Show, A. A. Humoud and M. A. Al-Marhoun presented a new empirical correlation for the prediction of gas condensate dew point pressure. This correlation related gas condensate fluid dew point pressure directly to the following available properties:

- Reservoir temperature

- Pseudo-reduced pressure and temperature

- Primary separator gas oil ratio

- Primary separator pressure and temperature

- Relative densities of separator gas

- Heptane-plus fraction

The data was obtained from different Middle East gas reservoir gas condensate representative samples and the correlation was based on field and PVT laboratory analysis of these samples. Error statistical analysis method and additional separate data sets were used for validation of the developed model.

Some background for their work included work done by Sage and Olds, 1947, in which a rough correlation was developed relating retrograde dew point to a specific range of gasoil-ratios, temperature and stock tank API gravity. A predictive correlation for saturation pressures (dew point and bubble point) for gas condensate and volatile oil reservoir fluids was presented by Organick and Golding in 1952. In this study the saturation pressure was related directly to chemical composition of the mixtures using molar average boiling point and modified average equivalent molecular weight. This work was presented in fourteen (14) working charts of saturation pressure against temperature for specific equivalent molecular weights.

In the Humoud/Al-Marhoun study, experimental dew point pressures were determined using Constant Mass Expansion (CME) tests performed on samples made available. Data 
set dew point ranged from 2700 psia to 7465 psia for lean and rich gases of varying acidity. This dew point correlation was developed based on a multiple least-square linear/nonlinear regression. Two (2) types of independent variables, one based on pressure and temperature conditions and the other on gas condensate fluid composition were used for the model. Statistical and graphical analyses were used to compare this Hamoud/Marhoun correlation with the Organick and Golding correlation and the Nemeth and Kennedy correlation. The analyses showed that the new correlation better predicted the Middle East fields' dew points. The reason for this being that it was developed based on a large number of data sets from these fields. A new correlation to estimate pseudocritical properties as a function of gas relative density (specific gravity) was also developed for the Middle East field data. These provided a better estimate than that provided by Standing.

Another correlation developed by Adel M. Elsharkawy (SPE 2001) describes the dew point as being dependent on the Equation of State(s), the number of pseudo-components and the characterization of plus fractions. The final empirical model estimated dew point pressure using reservoir temperature, $\mathrm{C}_{1}-\mathrm{C}_{6}$ and $\mathrm{C}_{7+}$ compositions (mole fractions), $\mathrm{C}_{7+}$ molecular weight, $C_{7+}$ specific gravity and with constants ranging from $A_{0}$ through $A_{18}$.

The model was compared to earlier correlations as well as Equation of States. The comparison indicated that this correlation had the best accuracy for the samples considered. Also when tested using extreme conditions of reservoir temperature and $\mathrm{C}_{7+}$ molecular weight and density, the model matched the Equation of State trend for predicting the change in dew point pressure with gas composition.

A paper presented by Marruffo et al in 2002 used statistical forecast models to determine retrograde dew point pressure and $\mathrm{C}_{7+}$ percentage of gas condensate reservoir on the basis of easily accessible production field parameters of the Eastern Venezuelan fields. This new correlation was based on condensate API gravity, gas/condensate production ratio and sometimes separator gas gravity and reservoir temperature. These PVT data were validated through consistency tests and a non linear regression was applied to fit models to the data. It was found that the main parameters for the determination of the dew point 
pressure are the $\mathrm{C}_{7+}$ content and the gas condensate ratio; these two parameters were inversely proportional in the Eastern Venezuelan gas condensate. The correlation did not require knowledge of the gas condensate composition which can prove difficult to get without a PVT analysis. Two new correlations were developed to estimate the $\mathrm{C}_{7+}$ content at dew point conditions based on either gas condensate ratio or on specific gas separator gravity. This new retrograde dew point correlation is seen to improve on Nemeth and Kennedy's when applied to the Eastern Venezuelan field and forecasts dew point pressure without the use of PVT information.

Ovalle et al presented four (4) correlations in 2005 for dew point pressure, surface yield, reservoir gas specific gravity and heptanes plus composition which are based only on field data. This study was an advancement to the Marruffo et al and the correlations were also based on a wider selection of data sets that had worldwide origins.

A non-parametric approach was taken for estimating the optimal transformations of petrophysical data, in order to obtain the maximum correlation between the observed variables. Average relative error and average absolute relative error were used as measures of the correlations accuracy and precision when compared with the experimental values. The four (4) correlations for dew point pressure, surface yield, reservoir gas specific gravity and heptanes plus composition had great accuracy and compared well with experimentally measured values.

Niemstschik et al also developed a correlation to determine gas condensate composition. The correlation related well stream effluent composition at any depleted state to the retrograde composition at the initial dew point pressure as a function of the fraction the reservoir is depleted, reservoir temperature and the specific gravity of the retrograde gas condensate at its initial dew point pressure. Well stream effluent composition, initial reservoir composition, the compositional history or the initial and well stream effluent specific gravity are calculated using the correlation once all other parameters were known. The correlation developed had high internal consistency and excellent results from statistical analysis. 
The two-phase compressibility factor should be used in material balance calculations for rich gas condensate systems. The paper presented by Reyes et al presented a correlation to calculate this factor from field data. The procedure included: calculating the pseudoreduced properties of the produced gas from the well stream gas composition or well stream gas specific gravity, calculating the two-phase compressibility factor if the $\mathrm{C}_{7+}$ concentration $\geq 4 \mathrm{~mol} \%$, or if the gas specific gravity $>0.911$. This was done using the final form of the correlation,

$$
Z_{2 P}=A_{0}+A_{1}\left(P_{r}\right)+A_{2}\left(\frac{1}{T_{r}}\right)+A_{3}\left(P_{r}\right)^{2}+A_{4}\left(\frac{1}{T_{r}}\right)^{2}+A_{5}\left(\frac{P_{r}}{T_{r}}\right)
$$

For $0.7 \leq \mathrm{P}_{\mathrm{r}} \geq 20.0$ and $1.1 \leq \mathrm{T}_{\mathrm{r}} \geq 2.1$, where $\mathrm{A}_{0}$ to $\mathrm{A}_{5}$ are constants.

The use of this correlation was also verified for rich gases with large amounts of $\mathrm{CO}_{2}$, $\mathrm{H}_{2} \mathrm{~S}$ and $\mathrm{N}_{2}$. Further investigation also showed that for $\mathrm{C}_{7+}$ concentrations $\leq 4 \mathrm{~mol} \%$ or well stream gas specific gravity $<0.911$, the single phase gas compressibility factor should be used in $\mathrm{P} / \mathrm{Z}$ material balance plots.

Firoozabadl examined several cubic Equations of States (EOS) and their use in predicting vapor liquid equilibrium (VLE) and volumetric behavior of reservoir fluids. An EOS could be defined as an algebraic equation that can describe the relationship between pressure, volume and temperature and volumetric behavior for both pure substances and mixtures. It may be used to describe solid, liquid and gas states. There are several families of EOS. The van der Waals family has a simple cubic form with only two (2) constants. The non-cubic EOS, with numerous constants, could more precisely represent PVT data of pure components.

Firoozabadl looked at the following cubic EOS for estimating phase behavior and volumetric properties of complex reservoir fluid systems,

- Zudkevitch-Joffe-Redlich-Kwong EOS

- Soave-Redlich-Kwong EOS 
- Peng-Robinson EOS

- Schmidt-Wenzel EOS

He found that the EOSs were reliable in predicting phase behavior of complex reservoir crude and gas condensate systems away from the critical and retrograde regions. The same K-value was predicted by each EOS; however each equation gave different volumetric predictions.

Bourblaux presented a parametric study of gas condensate reservoir behavior during depletion as a guide for development planning. Specifically the results of systematic compositional simulations of gas condensate depletion in a radial and cross-sectional reservoir model were presented.

Bourblaux analyzed and quantified the effects on productivity, recoveries and fluid distribution while changing various parameters. He intended the study's results to be used as a guide during the development planning of a gas condensate field to estimate the quantitative role played by key rock fluid parameters during future exploitation and to define the most relevant core-fluid measurements and simulation studies for reduced uncertainties related to field performance predictions. For this study a hypothetical field situated at a depth of $3000 \mathrm{~m}$ (9843 ft) was considered. The reservoir model was a cylinder with 14 radial and 5 vertical grid-blocks and no associated aquifer.

There were several conclusions drawn from this study. These were all based on the findings that the near wellbore condensate accumulation and productivity index (PI) drop are more important in relative value for lean fluids than for rich fluids. Also that gas PI is higher for rich fluids due to higher interfacial tension (IFT). In addition, the occurrence of gravitational effects was suspected for rich fluids with high IFT and dropout effects on recovery was seen to be more detrimental to rich fluids than leaner ones.

In 1988, Hagoort et al presented a conceptual study on the development of an offshore gas-condensate reservoir by nitrogen injection versus pressure depletion. For this study the fluid was a rich gas condensate and the reservoir heterogeneity was varied. Nitrogen 
injection was started once the dew point was reached and injection was done to maintain the pressure above dew point. The results of the study indicated nitrogen injection to be a realistic alternative to pressure maintenance, once the reservoir was not too heterogeneous and the fluid rich enough in condensate. Economically the study showed nitrogen injection to be a risky venture at the time. Nitrogen had to be stored on land and transported to the offshore rig, leading to extensive additional costs. Currently high purity nitrogen can be generated from air on site at a much reduced cost; this greatly reduces the risk that there once was.

Another economic evaluation of cycling gas-condensate reservoirs using nitrogen as a substitute for natural gas was presented by Donohoe et al. They used cryogenically generated nitrogen to maintain the reservoir pressure during cycling operations. The paper identified prices, stock tank liquid content of the reservoir gas and the degree of reservoir heterogeneity as the three main factors affecting the use of nitrogen. A minimum limit of $100 \mathrm{bbl} / \mathrm{MMSCF}$ condensate content was also identified for the potential success of cycling gas-condensate reservoirs with nitrogen gas.

For our study the initial condensate content was $238 \mathrm{bbl} / \mathrm{MMSCF}$, which was far above the limit. However the nitrogen injection for our study was continuous once started and production and injection took place simultaneously, thus the mixing that would take place was different due to the continuous flow of reservoir fluid.

Ulysses de Ribeiro Augusto Lino conducted compositional and phase behavior experimental and theoretical work on the mixing of three types of hydrocarbon mixtures with several solvents; carbon dioxide, nitrogen and two flue gases. The series of experiments consisted of constant composition expansion, multiple-contact processes and constant volume depletion. The solvents were analyzed by their hydrocarbon recovery efficiency. The theoretical work dealt with developing a mathematical model that was able to more accurately reproduce the compositional and phase behavior of multiplecontact processes.

The results from the study showed that carbon dioxide was the only solvent to develop miscibility by a mechanism of vaporization with the rich gas condensate mixture. The 
injection of nitrogen and the two flue gases into the rich gas condensate was an immiscible process but showed the capability to significantly enhance the recovery of hydrocarbon from the liquid phase. This study was done using PVT analysis only thus recovery was based on the mixing of streams. The intended use of CMG's GEM simulator would look at the recovery process in a realistic gas condensate reservoir model and determine whether nitrogen injection really does improve recovery and what factors affect the effectiveness of the injection.

Siregar et al investigated the possibility of using nitrogen injection as opposed to gas cycling in a rich (API gravity = 58.6) retrograde gas/condensate reservoir. The study was done using a PVT simulator to formulate the fluid and a compositional one-dimensional simulator. The gas-condensate was only defined with methane, butane, tetradecane and nitrogen. The results showed that there were two factors which caused lower recovery when nitrogen was injected. These were higher liquid drop-out due to dispersion and lower evaporating capacity. However when the reservoir was simulated to relate to field conditions, nitrogen was seen as a potential alternative to gas cycling in condensate reservoirs. The conclusions drawn in this study was limited due to the use of a onedimensional simulation. The authors recommended using two- and three dimensional simulations to verify the results obtained.

Previous studies use PVT analysis and in some cases one or two dimensional simulators thus the results obtained were limited to an assumption of uniform mixing or a model described as a flat plane. The intended use of CMG's GEM 3-D simulator would look at the recovery process in a realistic gas condensate reservoir model. We would be able to model the non-uniform mixing within the reservoir, we can see the effects that well pattern and point of injection has on the recovery and thus determine whether nitrogen injection really does improve recovery and what factors affect the effectiveness of the injection.

For our study the initial condensate content was $238 \mathrm{bbl} / \mathrm{MMSCF}$, which was in a range that was investigated by several of the studies reviewed. However our approach towards nitrogen injection was different from previous studies. Previous studies compared natural 
depletion or gas cycling to nitrogen injection, but injection and production were consecutive. Our nitrogen injection was continuous once started and production and injection took place simultaneously, thus there would be a different impact on condensate recovery.

\subsection{Software}

CMG (Computer Modeling Group Ltd.) is a computer software engineering and consulting firm engaged in the development, sale and technology transfer of reservoir simulation software. Their software was used for this research. The programs used include WinProp, Builder, GEM, Results 3D and Results Graph.

WinProp is CMG's Windows based package for modeling the phase behavior and properties of reservoir fluids. It is a comprehensive equation of state engineering tool that determines the reservoir characteristics and compositional variations of fluids for use with CMG's reservoir simulators.

WinProp can be used for:

- Component characterization

- $\quad$ PVT matching

- Miscibility studies,

- Modeling of laboratory experiments

- Prediction of wax and asphaltenes production

- Surface separation facilities modeling

- Generation of PVT data for CMG simulators

The Builder series is a set of applications used in the preparation of reservoir simulation models. It provides a Windows interface which organizes data into individual sections for building the reservoir model.

GEM is CMG's general equation-of-state (EOS) based compositional reservoir simulator for modeling the flow of three-phase, multi-component fluids. GEM is described as a robust, fully compositional simulator used to model any type of reservoir where the 
importance of the fluid composition and their interactions are essential to the understanding of the recovery process.

GEM provides extensive well management options, plus a flexible set of surface separator facilities, including EOS and gas plant separator stages, enabling the modeling of flow from the sand face to the outlets of the separator trains.

GEM simulates a variety of structurally complex and varying fluid combinations beyond the conventional black oil simulators as well as K-value compositional simulators. GEM can be used for modeling:

- Single and multi-component CBM recovery

- Gas condensate recovery

- Volatile oil reservoirs

- $\mathrm{CO}_{2}$ and hydrocarbon injection

- Gas cycling and re-cycling

- WAG processes

- Numerous other reservoir management processes

"Results" is CMG's set of post-processing applications designed for visualizing and reporting simulator output. Results can efficiently analyze the output from CMG simulators, prepare 2D and 3D plots, generate various informative graphs, and prepare tables of required information to be included in a study report.

"Results" is currently composed of three modules:

- Results 3D - 2D and 3D views.

- Results Graph - user-definable XY graphs

- Results Report - user-definable tabular reports 


\section{OBJECTIVE AND METHODOLOGY}

The objective of this research was to model nitrogen injection into a gas condensate reservoir using a compositional simulator. This will be done in order to evaluate the impact of nitrogen injection on condensate recovery. The following methodology was developed to achieve the objective:

1. Estimating extended compositional analysis of the original reservoir using available data from the laboratory tests performed on a well in a gas condensate field. The PVT analysis included Constant Volume Depletion Test and Constant Composition Expansion Test.

2. Development of a practical gas condensate reservoir model producing through three (3) vertical wells with one (1) injection well.

3. Development of a feasible nitrogen gas injection plan.

4. Investigation of the impact of nitrogen gas injection on production.

5. Determination of the impact of using nitrogen to enhance the productivity of a gas condensate reservoir.

\subsection{Pressure-Volume-Temperature (PVT) Analysis}

PVT Analysis was done using WinProp to best match the limited data available. Tests that were run were chosen based on the data available. The following programs were run;

- Saturation Pressure

- Constant Volume Depletion

- Constant Composition Expansion

- GEM 
- Two-phase Flash

- Two-phase Envelope

\subsubsection{Component Lumping}

This option is invoked by selecting Characterization / Component Lumping. The lumping scheme was entered and components $\mathrm{C}_{20}$ to $\mathrm{C}_{30}$ were lumped to give one pseudo-component whose critical property was estimated using the mixing rules of Lee and Kesler.

\subsubsection{Saturation Pressure Test}

The laboratory dew point was entered as an initial estimate for this test. The test result was based on the fluid composition with the heavier components lumped to form $\mathrm{C}_{20+}$. The saturation test gave a dew point pressure of 3,581 psia which was a good match to the laboratory dew point of 3,505 psia.

\subsubsection{Constant Volume Depletion (CVD)}

This procedure is usually performed for a gas condensate to simulate the conditions encountered in the reservoir. The sample of reservoir liquid in the laboratory cell is brought to the dew-point pressure, and the temperature is set to the reservoir temperature.

Pressure is reduced by increasing the cell volume. Part of the gas is expelled from the cell until the volume of the cell equals the volume at the dew point. The gas collected is sent to a multistage separator. The process is repeated for several pressure steps

The laboratory data included a constant volume depletion test run at a constant temperature of $219^{\circ} \mathrm{F}$ (Appendix A), giving the depletion pressures with corresponding liquid saturation (Appendix A). This data was inputted into the WinProp CVD simulation and the separator conditions were defined with three stages starting at the separator pressure used for the laboratory runs.

\subsubsection{Constant Composition Expansion (CCE)}


For this laboratory procedure a sample of the reservoir fluid is placed in a laboratory cell. Pressure is adjusted to a value equal to or greater than the initial reservoir pressure. Temperature is set to the reservoir temperature. Pressure is reduced by increasing the volume of the cell in increments. No gas or liquid is removed from the cell.

At each step, the pressure and total volume of the reservoir fluid (oil and gas) are measured. Additional data that can be determined include the liquid phase volume, oil and gas densities, viscosities, compressibility factors or single phase compressibility above the saturation pressure. The procedure is also called flash vaporization, flash liberation, flash expansion or constant mass expansion.

Data entry required for the CCE simulation included the experimental results from the laboratory data; pressure levels and corresponding relative volumes (Appendix A), and the temperature and saturation pressure estimate. The results included a simulation match of the relative volume as well as plots of oil and gas viscosities, densities and Z-factors and liquid volume percentage.

\subsubsection{CMG GEM EOS Model}

This writes the CMG GEM EOS Simulator model data to be used in developing the reservoir model. The only input required for this was the reservoir temperature.

\subsubsection{Two-phase Flash}

The two-phase flash was set to run from 14.7 psia with six 1000 psia pressure steps at a constant temperature of $219^{\circ} \mathrm{F}$. The phase volume fraction, phase mole fraction and Kvalues $(\mathrm{y} / \mathrm{x})$ were selected to be plotted with the results. This test was run before the $\mathrm{C}_{20+}$ component lumping was done.

The Flash type may be set to either QNSS/Newton or Negative. Selecting QNSS/Newton specifies that the two-phase flash equations will be converged initially using a QuasiNewton successive substitution (QNSS) algorithm, followed by Newton's method to refine the roots. If the system is in the single-phase region, properties for that phase will be reported, and k-values will not be calculated. 


\subsubsection{Two-phase Envelope}

The two-phase envelope calculation generates the boundaries between the single-phase and two-phase regions. The bubble point envelope corresponds to the boundary between a single-phase liquid region and a two-phase vapor-liquid region; the dew point envelope corresponds to the boundary between the single-phase vapor region and the two-phase region. There are two main classes of diagrams that can be generated: $\mathrm{X}-\mathrm{Y}$ phase diagrams and pseudo-ternary phase diagrams.

The XY phase diagrams were chosen for this two-phase envelope laboratory test. X-Y phase diagrams are displayed on regular Cartesian coordinates. The types of envelopes or diagrams that can be generated are:

- $\quad$ Pressure-Temperature (PT) diagram

- $\quad$ Pressure-Composition (PX) diagram

- Temperature-Composition (TX) diagram

In the process of constructing the envelope, WinProp also calculates the location of critical points through interpolation.

\subsection{Development of the Reservoir Model}

The parameters chosen for the development of the reservoir model were based on limited data available from a deep high pressure gas condensate field (Appendix A).

Two sets of data are available for the field. Each set is taken at a different time interval.

One shows the components breakdown of the reservoir fluid based on the reconstitution of the separator gas and liquid (Appendix A). This breakdown shows that the composition of the gas is primarily nitrogen and is characteristic of the reservoir at the latter stages of depletion with nitrogen injection. There are high concentrations of heavier hydrocarbons present at the time of the analysis. 
The second set of data shows a condensed well stream analysis which combines heavier hydrocarbons as heptanes plus (Appendix A). There is also a 1.68 mole \% of nitrogen present with the bulk of the reservoir fluid being principally methane. This sample is representative of the well in its earlier stage of depletion where methane content is still favorable. This data set also gives the specific gravity and molecular weight of the recombined well stream analysis.

Input data that was required for building of the model, but not available were inferred as practical values in keeping with ranges typical for gas condensate reservoirs. The model was built using BUILDER.

The model developed was a rectangular $3 \times 9$ grid that was one (1) layer thick. The model was developed as a homogeneous reservoir with each grid block having constant parameters. The permeability was kept constant in the $\mathrm{i}, \mathrm{j}$, and $\mathrm{k}$ directions for each case.

Three (3) production wells were placed in grid blocks 1,5,1, 2,2,1 and 2,9,1 and an injection well in grid block 2,5,1. The spacing of these wells was chosen to best correspond to the well spacing in the gas condensate field. 


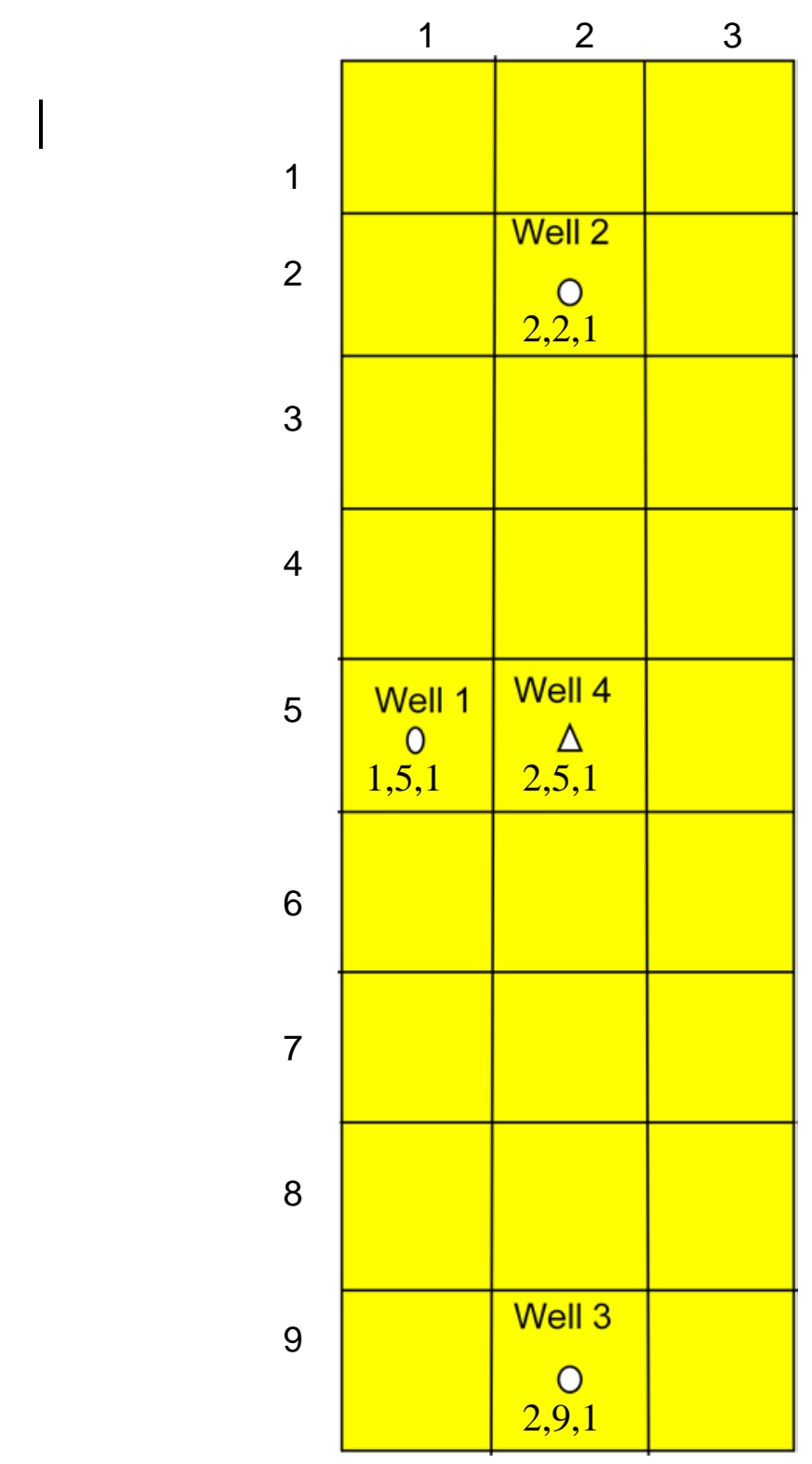

Figure 3-1 Schematic of reservoir model

\subsubsection{Data Entry into Builder}

Data entry for model development included a definition of the grid and grid properties, rock properties, a definition of components and equation of state, entering initial conditions and appointment of well operating properties. 
The grid developed was a Cartesian rectangular $3 \times 9$ grid that was one (1) layer thick. The array properties were chosen to be analogous with data available from the deep gas condensate field. The array properties entered are shown in Table 3-1.

Table 3-1: Reservoir model array properties

\begin{tabular}{|l|c|}
\hline Array Property & Value \\
\hline Grid Top & $13784 \mathrm{ft}$ \\
\hline Grid Thickness & $90 \mathrm{ft}$ \\
\hline Porosity & $10 \%$ \\
\hline Permeability I & $20 \mathrm{md}$ \\
\hline Permeability J & $20 \mathrm{md}$ \\
\hline Permeability K & $20 \mathrm{md}$ \\
\hline
\end{tabular}

The permeability was reduced from 50 md to 20 md while fine-tuning the model for a more realistic reservoir.

The rock compressibility was unknown and a value of $0.00021 / p s i$ was assumed in order for the model to run. Other component properties were imported from the WinProp model developed previously. The Peng-Robinson equation of state was used for this model with a reservoir temperature of $219^{\circ} \mathrm{F}$.

\subsubsection{Relative Permeability}

Definition of the rock type included rock type properties, relative permeability tables and hysteresis modeling. No data was available to define the rock fluid properties. The gaswater relative permeability tables were based off of a water saturation of $24 \%$. The initial assumed relation was as follows,

Table 3-2 Initial gas-water relative permeability assumption

\begin{tabular}{|c|c|c|}
\hline $\mathbf{S}_{\mathbf{w}}$ & $\mathbf{k}_{\mathbf{r w}}$ & $\mathbf{k}_{\text {row }}$ \\
\hline 0.24 & 0 & 1 \\
\hline 0.62 & 0.5 & 0.5 \\
\hline 1 & 1 & 0 \\
\hline
\end{tabular}

This was further detailed using the "Smooth Table" tool available. The model was developed with no associated aquifer thus the table was further modified to minimize the amount of water produced from the reservoir. The resulting table and graph is shown in 
Table 3-3 and Figure 3-2. The gas-liquid relative permeability was also assumed based on relative permeability values from Table 3-2. The initial detailed table generated is shown in Table 3-4. Numerous modifications were made to the gas-liquid relative permeability curves in order to find the best match that would give production similar to the deep gas condensate field and to ensure that the liquid saturation was affected by the pressure decline. The likeness between the simulated and field gas oil ratios were used as a measure of the accuracy of the relative permeability curves. The final choice for the gasliquid relative permeability curves is shown in Figure 3-3 and the gas-oil-ratio match is shown in Figure 3-4

Table 3-3 Water-gas relative permeability table

\begin{tabular}{|c|c|c|}
\hline $\mathbf{S}_{\mathbf{w}}$ & $\mathbf{k}_{\mathbf{r w}}$ & $\mathbf{k}_{\text {row }}$ \\
\hline 0.240 & 0.000 & 1.000 \\
\hline 0.255 & 0.000 & 0.980 \\
\hline 0.286 & 0.000 & 0.940 \\
\hline 0.315 & 0.000 & 0.902 \\
\hline 0.331 & 0.001 & 0.880 \\
\hline 0.357 & 0.003 & 0.846 \\
\hline 0.377 & 0.005 & 0.820 \\
\hline 0.399 & 0.009 & 0.791 \\
\hline 0.427 & 0.036 & 0.754 \\
\hline 0.455 & 0.083 & 0.718 \\
\hline 0.483 & 0.150 & 0.680 \\
\hline 0.514 & 0.202 & 0.640 \\
\hline 0.539 & 0.257 & 0.607 \\
\hline 0.559 & 0.294 & 0.580 \\
\hline 0.580 & 0.333 & 0.552 \\
\hline 0.608 & 0.381 & 0.515 \\
\hline 0.636 & 0.427 & 0.478 \\
\hline 0.666 & 0.485 & 0.440 \\
\hline 0.696 & 0.546 & 0.400 \\
\hline 0.720 & 0.604 & 0.368 \\
\hline 0.742 & 0.650 & 0.340 \\
\hline 0.762 & 0.687 & 0.313 \\
\hline 0.790 & 0.724 & 0.276 \\
\hline 0.818 & 0.761 & 0.239 \\
\hline 0.848 & 0.800 & 0.200 \\
\hline 0.878 & 0.840 & 0.160 \\
\hline 0.902 & 0.871 & 0.129 \\
\hline
\end{tabular}




\begin{tabular}{|l|l|l|}
0.924 & 0.900 & 0.100 \\
\hline 0.944 & 0.926 & 0.074 \\
\hline 0.972 & 0.963 & 0.037 \\
\hline 1.000 & 1.000 & 0.000 \\
\hline
\end{tabular}

Table 3-4 Gas-liquid relative permeability tables

\begin{tabular}{|c|c|c|}
\hline $\mathbf{S}_{\mathbf{I}}$ & $\mathbf{k}_{\mathbf{r g}}$ & $\mathbf{k}_{\mathbf{r o g}}$ \\
\hline 0.2400 & 1.00 & 0.00 \\
\hline 0.2552 & 0.98 & 0.02 \\
\hline 0.2704 & 0.96 & 0.04 \\
\hline 0.3008 & 0.92 & 0.08 \\
\hline 0.3312 & 0.88 & 0.12 \\
\hline 0.3616 & 0.84 & 0.16 \\
\hline 0.3920 & 0.80 & 0.20 \\
\hline 0.4224 & 0.76 & 0.24 \\
\hline 0.4528 & 0.72 & 0.28 \\
\hline 0.4832 & 0.68 & 0.32 \\
\hline 0.5136 & 0.64 & 0.36 \\
\hline 0.5440 & 0.60 & 0.40 \\
\hline 0.5744 & 0.56 & 0.44 \\
\hline 0.6048 & 0.52 & 0.48 \\
\hline 0.6352 & 0.48 & 0.52 \\
\hline 0.6656 & 0.44 & 0.56 \\
\hline 0.6960 & 0.40 & 0.60 \\
\hline 0.7264 & 0.36 & 0.64 \\
\hline 0.7568 & 0.32 & 0.68 \\
\hline 0.7872 & 0.28 & 0.72 \\
\hline 0.8176 & 0.24 & 0.76 \\
\hline 0.8480 & 0.20 & 0.80 \\
\hline 0.8784 & 0.16 & 0.84 \\
\hline 0.9088 & 0.12 & 0.88 \\
\hline 0.9392 & 0.08 & 0.92 \\
\hline 0.9696 & 0.04 & 0.96 \\
\hline 1.0000 & 0.00 & 1.00 \\
\hline & & \\
\hline
\end{tabular}




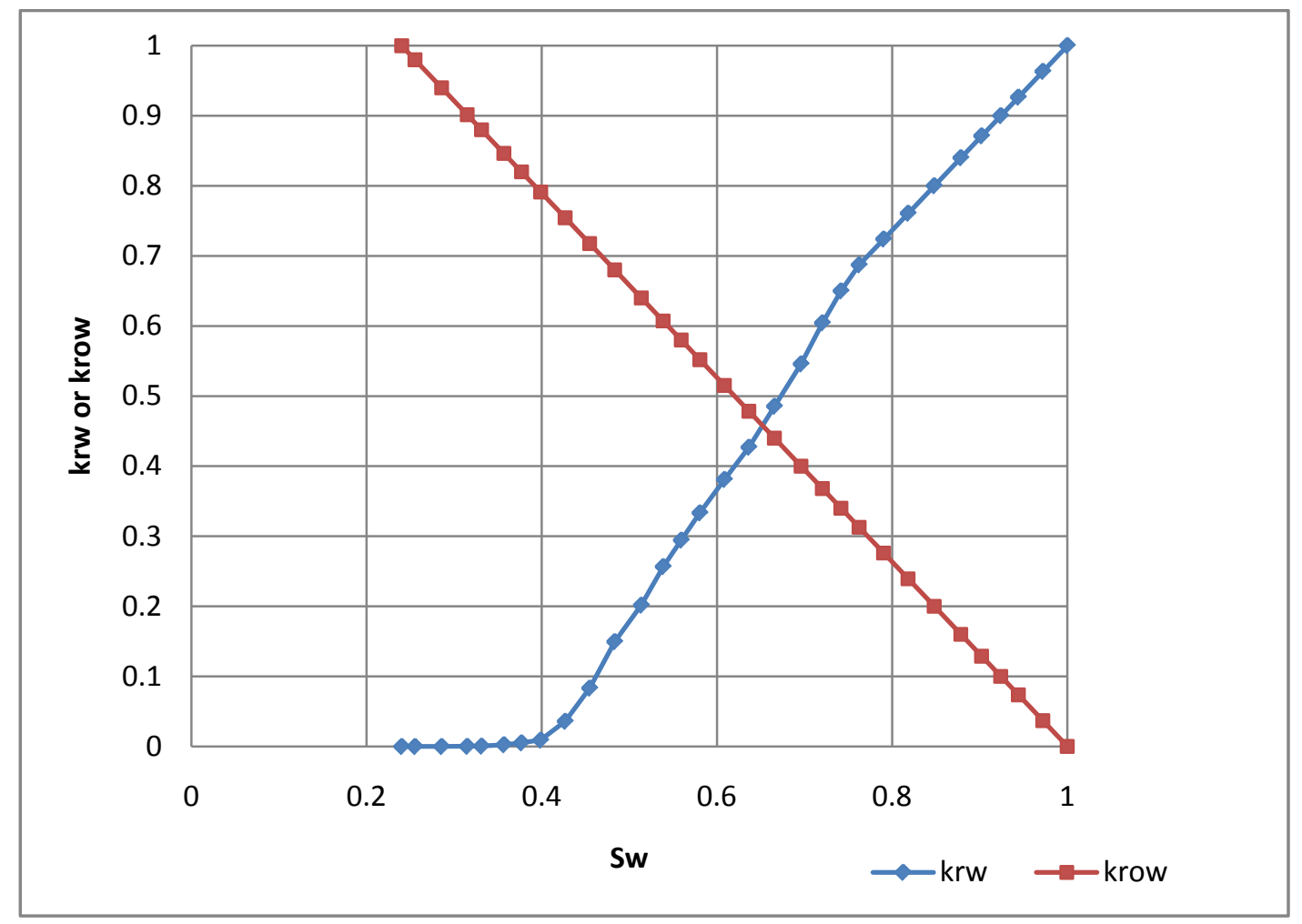

Figure 3-2 Initial Gas-water relative permeability curves

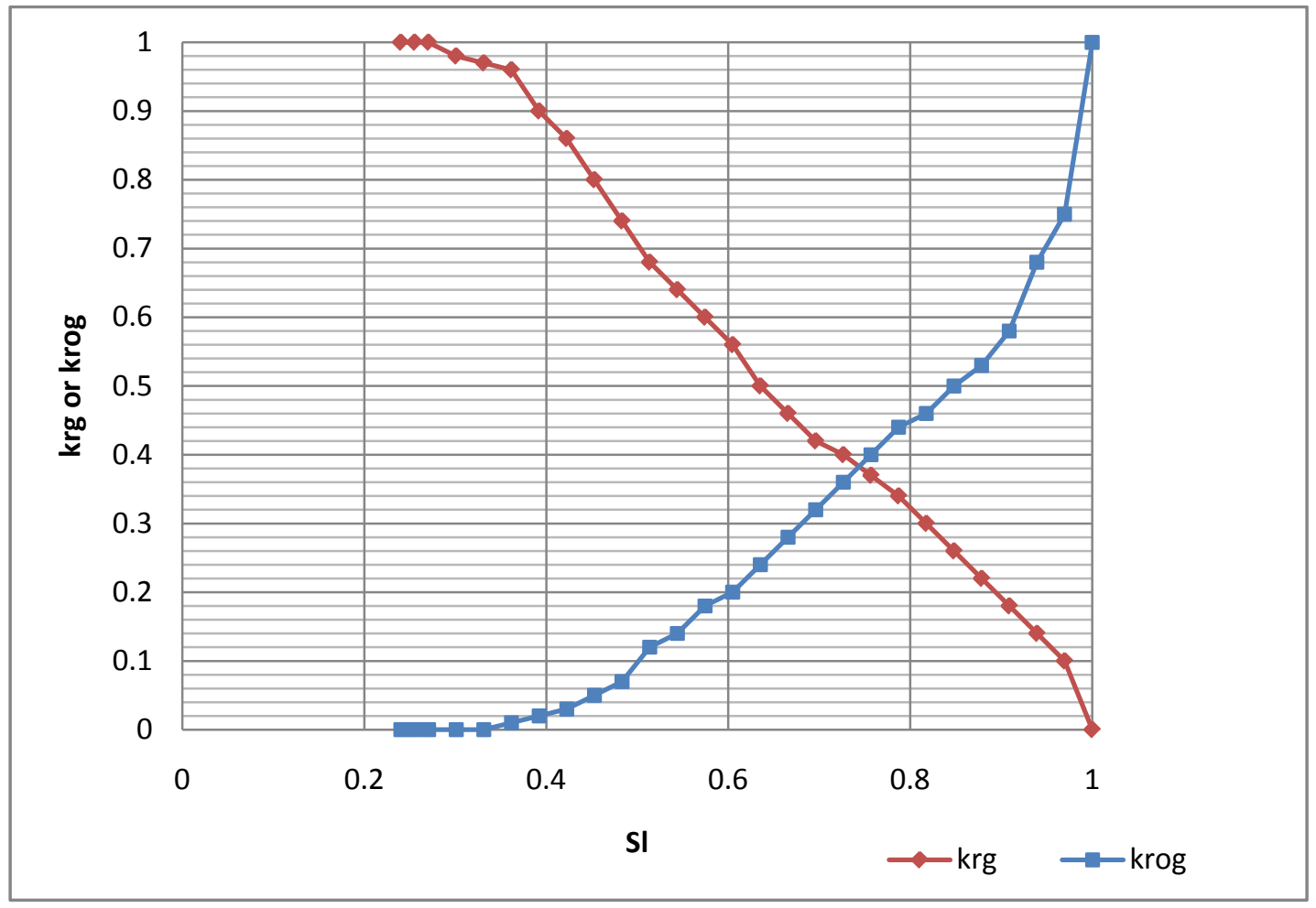

Figure 3-3 Final Gas-liquid relative permeability curves 


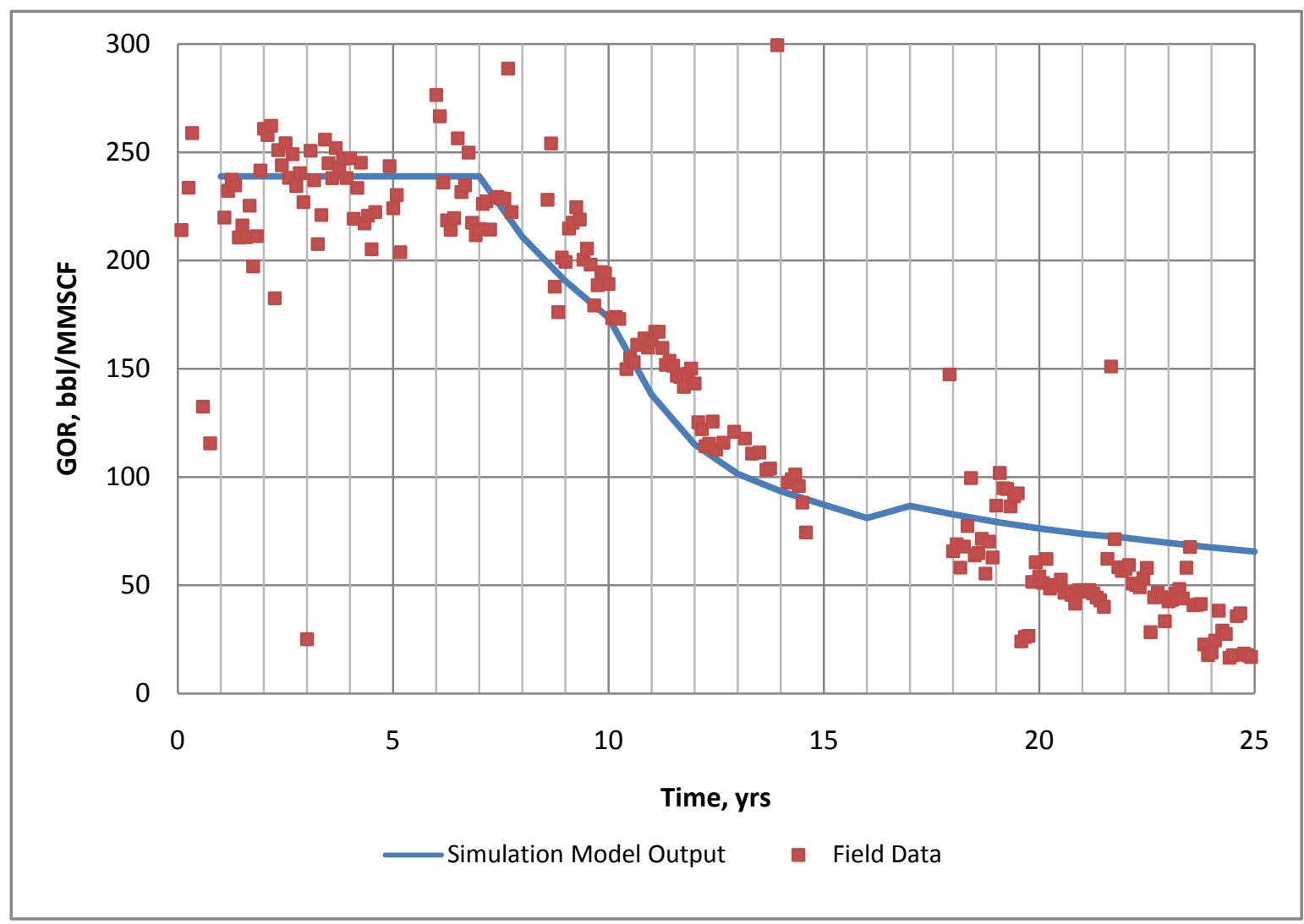

Figure 3-4 Gas-oil-ratio comparison between simulation and field results

\subsubsection{Initial Conditions}

The calculation methods were set as "Block saturation at each grid block average over the depth interval spanned by the grid block”. The gravity-capillary equilibrium was performed for a reservoir initially containing water and gas. Also no transition zone was assumed between the water and gas. Phase pressure correction was added, as a default, to ensure that the reservoir was initially in gravitational equilibrium. 
The following initialization region parameters were entered as well,

\begin{tabular}{|l|c|l|}
\hline \multicolumn{1}{|c|}{ Parameter } & Value & \\
\hline Reference pressure, psi & 5715 & \\
\hline Reference depth, $\mathrm{ft}$ & 13784 & \\
\hline Water-Gas phase contact depth, $\mathrm{ft}$ & 15,000 & $\begin{array}{l}\text { A contact depth was chosen that } \\
\text { was lower than the grid bottom, to } \\
\text { ensure that there was no water } \\
\text { attached to the gas pay-zone. }\end{array}$ \\
\hline Water saturation below water-oil contact & 0.24 & \\
\hline
\end{tabular}

The gas cap composition was also entered. These were taken from the imported WinProp model (Appendix B).

\subsubsection{Wells, Well Constraints and Production Time}

At this point the well and dates specifications were entered. Four (4) wells were created as specified previously and were perforated throughout the entire layer. Operating constraints were selected on a trial and error basis. Constraints used for the three (3) producers were minimum bottom hole or wellhead pressures, maximum surface gas rate and maximum drawdown. In order to calculate the wellhead pressure, the wellbore model was defined to be $13,874 \mathrm{ft}$ in length and depth with a radius of $0.245 \mathrm{ft}$ with a relative roughness of 0.0006 .

The minimum bottom-hole pressure and minimum wellhead pressure constraints caused a very rapid drop in pressures; the bottom-hole pressure dropping drastically below the dew point pressure within the first two (2) or three (3) years of production. The drawdown constraint allowed the well to decline at a slightly slower rate but initial gas production rates were too high and more than $95 \%$ of the reservoir was produced in less than ten (10) years with the well bottom-hole pressure dropping to atmospheric pressure.

The selected constraint for this model was the maximum surface gas rate. The production wells were each set to follow a gas flow rate averaged from the available field data. For the deep gas condensate field, Well-1 was the highest producer with an average surface gas flow rate of 1.4 MMSCFD and Well-2 averaged 0.8 MMSCFD. Well-3 had poor completion, it was shut in after four (4) years and was re-completed and opened twelve 
(12) years later and only averaged 0.25 MMSCFD. The injector, Well-4, was also controlled by surface gas rate. The injected rate was set to match the rate of gas being produced, thus when all three (3) producers were open the injection rate was 2.45 MMSCFD.

All wells were completed with no skin factor. The production period was set at twentyfive (25) years with injection starting at year ten (10). Well-3 was shut in at year four (4) and reopened at year sixteen (16).

\subsection{Initial Reservoir Conditions and Fluid Properties}

The simulator calculated initial reservoir conditions which are summarized in Table 3.5 below. A three stage separator was used for fluid-in-place calculations. The separator conditions are shown in Table 3.6.

The initial GOR calculated was 4,186 scf/bbl. This identifies the reservoir as either a volatile oil or retrograde gas condensate. The PVT analysis was used to identify this. Figure 3-5, which presented the liquid phase volume percent from the two-phase envelope test, showed an increase in liquid phase content when the pressure dropped from the dew point of 3,581 psia to around 3,000 psia. After 3,000 psia the liquid phase volume percent declined. Based on this and the initial GOR, the reservoir fluid was identified as a rich retrograde gas condensate. 
Table 3.5 Initial reservoir conditions calculated by GEM Simulator

\begin{tabular}{|c|c|}
\hline Reservoir & \\
\hline Ave. Pressure, psia & 5,720 \\
\hline Ave. Porosity & 0.1 \\
\hline Total Bulk Reservoir Volume, res $\mathrm{ft} 3$ & $2.43 \times 10^{9}$ \\
\hline Total Pore Volume, res ft3 & $2.43 \times 10^{8}$ \\
\hline Total Hydrocarbon Pore Volume, res ft3 & $1.85 \times 10^{8}$ \\
\hline \multicolumn{2}{|l|}{ Oil Phase } \\
\hline Ave. oil saturation & 0 \\
\hline Total moles, mol & 0 \\
\hline \multicolumn{2}{|l|}{ Gas Phase } \\
\hline Ave. gas saturation & 0.76 \\
\hline Ave. gas phase pressure, psia & 5,720 \\
\hline Ave. gas phase $\mathrm{Z}$ factor & 1.08 \\
\hline Shrinkage factor, OGIP/std vol of free gas & 0.842 \\
\hline Total moles, mol & $6.11 \times 10^{10}$ \\
\hline \multicolumn{2}{|l|}{ Water Phase } \\
\hline Ave. water saturation & 0.24 \\
\hline Total moles of dissolved hydrocarbon, mol & 0 \\
\hline Total moles, mol & $9.33 \times 10^{10}$ \\
\hline \multicolumn{2}{|l|}{ Fluid Properties } \\
\hline Relative oil volume, res bbl/std bbl & 0 \\
\hline Relative gas volume, res ft3/std ft3 & $4.35 \times 10^{3}$ \\
\hline Solution gas-oil-ratio, std ft3/std bbl & 0 \\
\hline \multicolumn{2}{|l|}{ Original Oil in Place, OOIP, std bbl } \\
\hline In Oil Zone & 0 \\
\hline Condensate in Gas Zone & $1.01 \times 10^{7}$ \\
\hline Dissolved in Water Zone & 0 \\
\hline Total OOIP & $1.01 \times 10^{7}$ \\
\hline \multicolumn{2}{|l|}{ Original Gas in Place, OGIP, std ft3 } \\
\hline In Gas Zone & $4.24 \times 10^{10}$ \\
\hline Dissolved Gas in Oil Zone & 0 \\
\hline Dissolved Gas in Water Zone & 0 \\
\hline Total OGIP & $4.24 \times 10^{10}$ \\
\hline Original Water in Place, OWIP, std bbl & $1.06 \times 10^{7}$ \\
\hline
\end{tabular}


Table 3.6 Separator conditions

\begin{tabular}{|c|c|c|c|c|c|c|}
\hline Stage & Type & Set or Table & Pressure & Temperature & \multicolumn{2}{|c|}{$\begin{array}{c}\text { Output } \\
\text { Destinations }\end{array}$} \\
\hline & & & psia & degF & Liquid & Vapor \\
\hline 1 & EOS & 1 & 880 & 88 & 2 & GAS \\
\hline 2 & EOS & 1 & 65 & 88 & 3 & GAS \\
\hline 3 & EOS & 1 & 14.7 & 60 & OIL & GAS \\
\hline
\end{tabular}

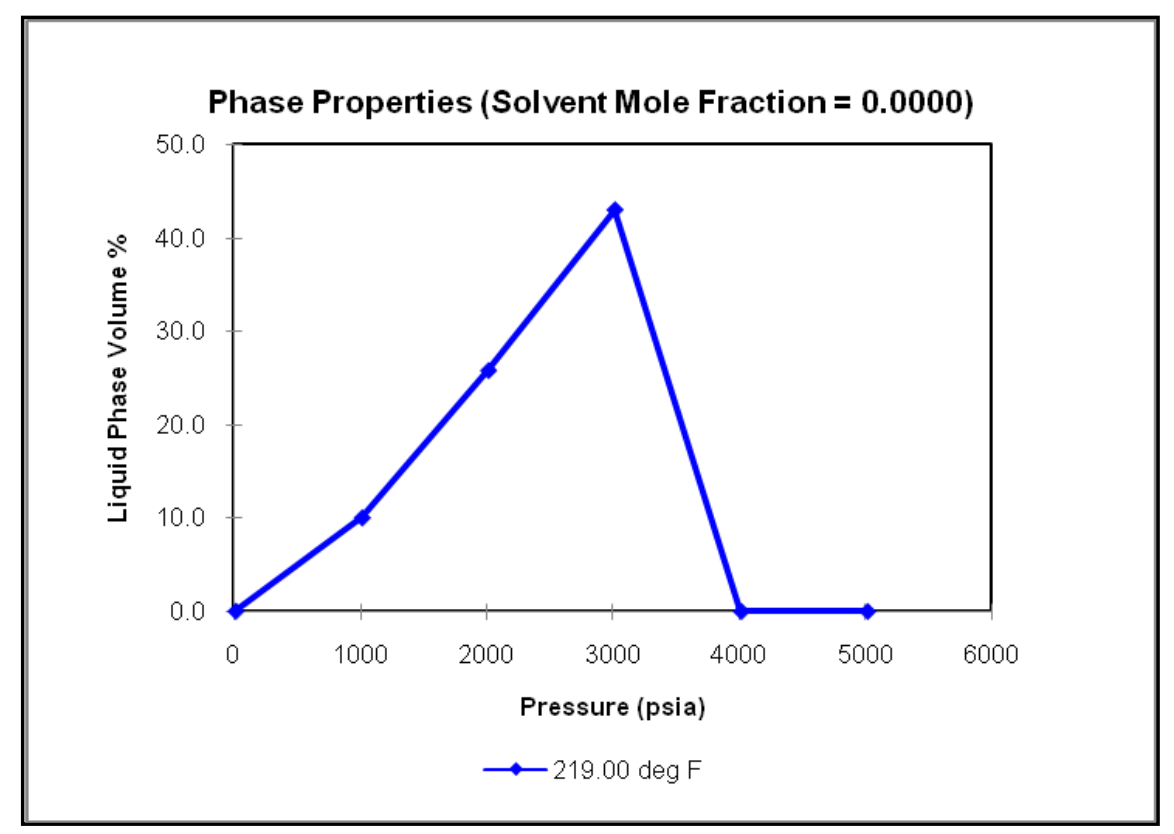

Figure 3-5: WinProp generated phase property - liquid phase volume percent at a temperature of $219^{\circ} \mathrm{F}$ 


\section{RESULTS AND DISCUSSION}

\subsection{PVT Simulation Results}

Graphical results for the PVT analyses done using WinProp are given in Figures 4-1 to 45 for the following tests:

\subsubsection{Constant Volume Depletion}

The constant volume depletion test done in WinProp developed a match for the available laboratory data. Figure 4-1 shows that the simulation produced a better match of liquid volume percent at lower pressures.

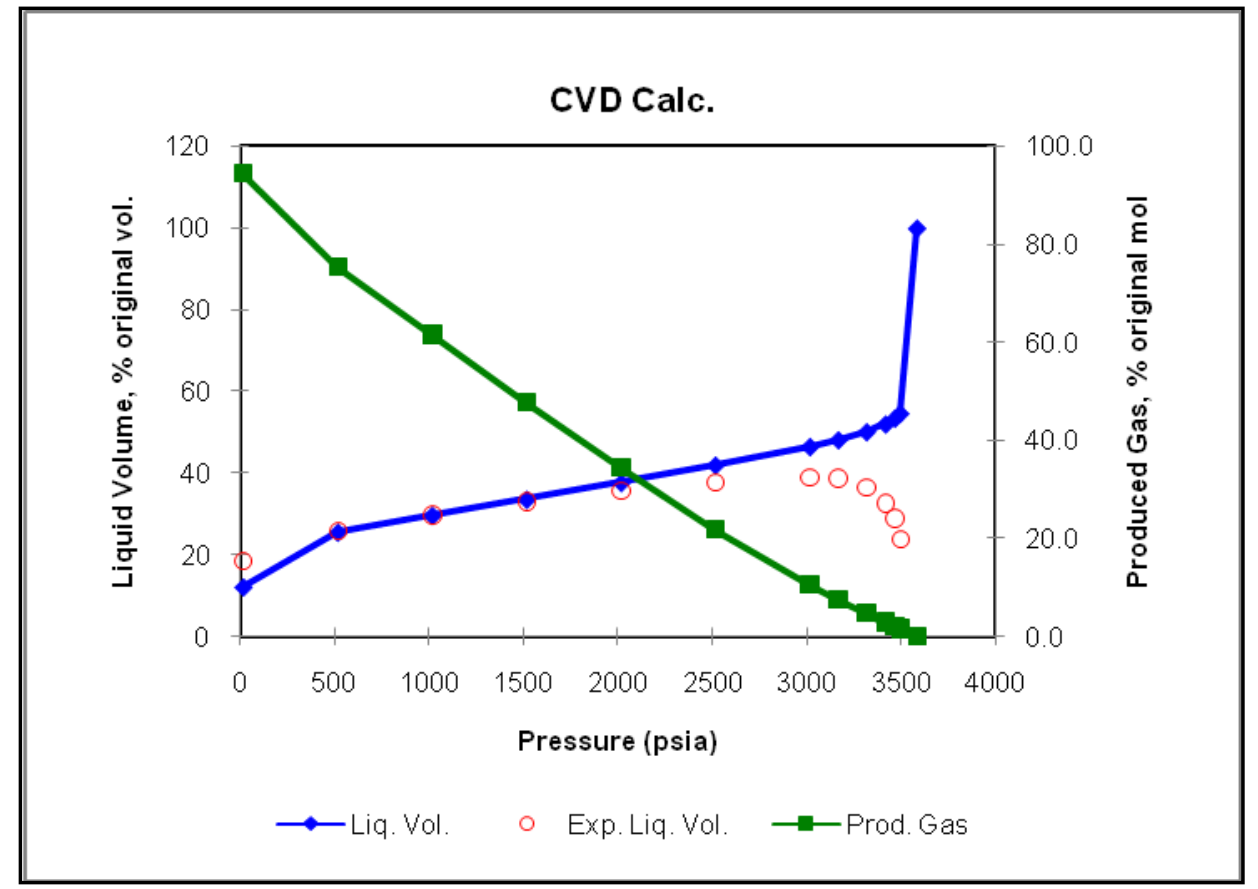

Figure 4-1: Liquid volume percentage match of simulated and laboratory results 


\subsubsection{Two-phase Flash}

This test gave the simulation prediction of the Pressure-Temperature two-phase boundary for the reservoir fluid composition. The critical point was estimated at 3,593 psia and 229 ${ }^{\circ} \mathrm{F}$.

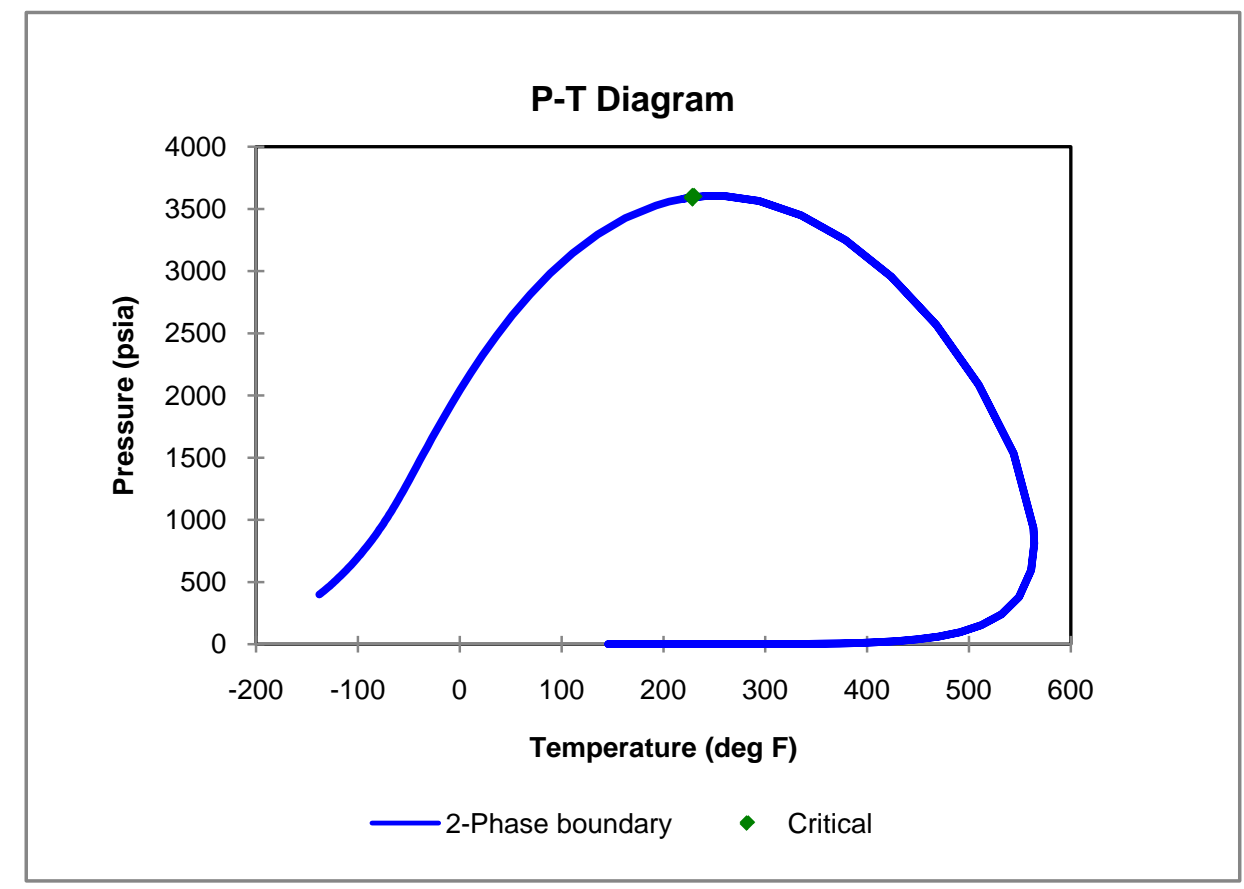

Figure 4-2: WinProp two-phase flash results showing the predicted two-phase boundary and critical point

\subsubsection{Two-phase Envelope}

The two-phase envelope results were typical of a gas condensate reservoir fluid. The liquid phase volume percent was zero above the dew point pressure and after the dew point there was an initial increase in liquid phase volume percent as some liquid drop-out occurs. However after the pressure declines below 3,000 psia the liquid phase volume decreases as re-vaporization of the condensed liquid occurs. The phase properties are shown in Figures 4-3 and 4-4. 


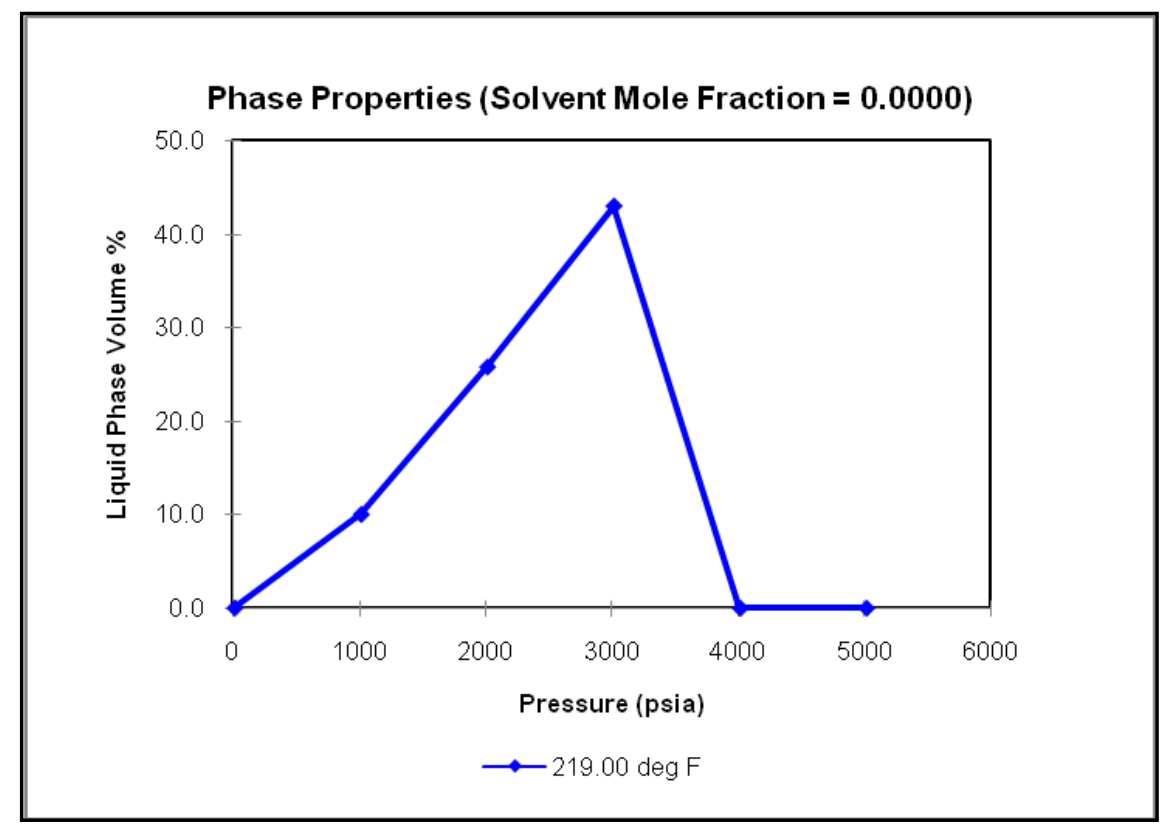

Figure 4-3: WinProp generated phase property - liquid phase volume percent at a temperature of $219^{\circ} \mathrm{F}$

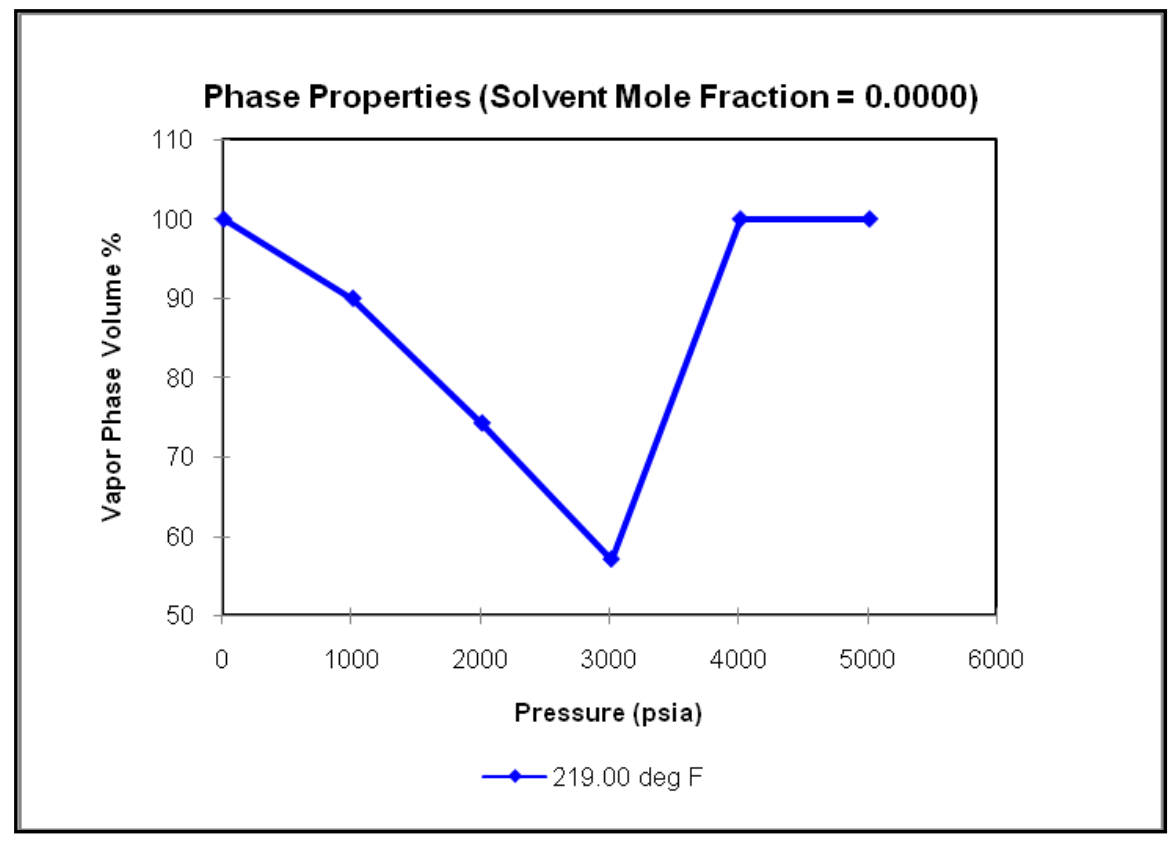

Figure 4-4: WinProp generated phase property - vapor phase volume percent at a temperature of $219^{\circ} \mathrm{F}$ 


\subsubsection{Constant Composition Expansion}

The Constant Composition Expansion test showed a better match of the laboratory data than the CVD. The simulation matched the experimental values of relative volume for the entire pressure range examined as seen in Figure 4-5.

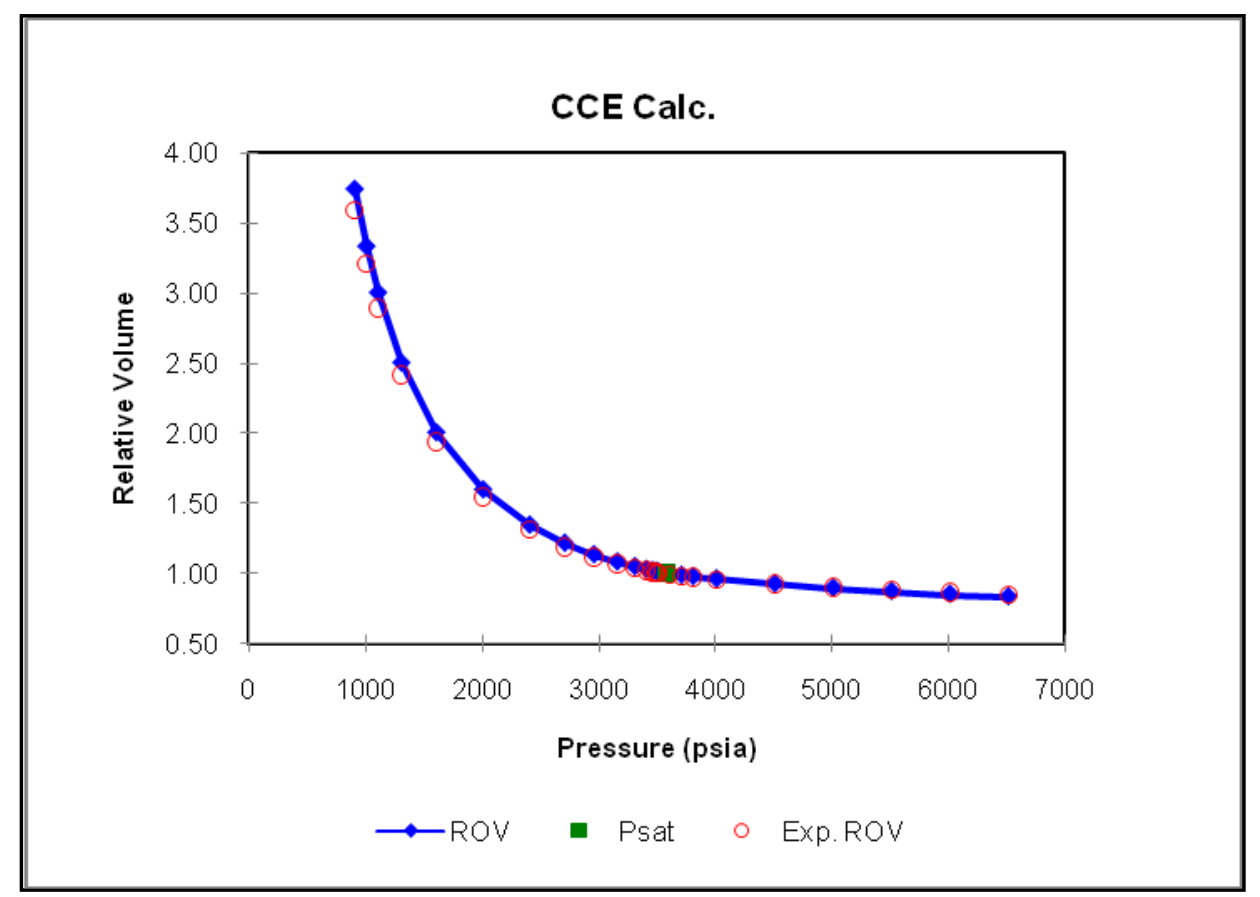

Figure 4-5: WinProp CCE Simulation match of laboratory relative volume data

Additional WinProp output for the prediction of other fluid properties such as oil and gas viscosity and compressibility are shown in Appendix D. 


\subsection{Nitrogen Effect on Reservoir Fluid Dew Point}

PHASE, a phase behavior simulation package was also used to determine the effect that the uniform mixing of nitrogen with the reservoir fluid has on the dew point. Runs were made with two streams, the reservoir fluid and nitrogen and the mixing ratio was varied to determine a trend. Runs were done using 2:8, 3:7 and 5:5 nitrogen gas: reservoir fluid ratio. An example of the input and output files are shown in Appendix E. The resulting dew point pressure for each case is compared to the original reservoir fluid dew point in Table 4-1 below,

Table 4-1 Dew point prediction results from PHASE

\begin{tabular}{|c|c|}
\hline $\begin{array}{c}\text { Nitrogen Gas and: Reservoir } \\
\text { Fluid Mixing Ratio }\end{array}$ & Dew Point Prediction, psia \\
\hline $0: 1$ & 3436 \\
\hline $1: 4$ & 5095 \\
\hline $3: 7$ & 6075 \\
\hline $1: 1$ & 8467 \\
\hline
\end{tabular}

It can be seen that uniform mixing of nitrogen significantly raises the dew point pressure. Also the more nitrogen introduced, the higher the dew point becomes. As the dewpoint pressures rises, the reservoir pressure will be lower than the dew point pressure. When this occurs, the liquid starts to drop-out in the reservoir and theoretically will lead to a lower of condensate recovery. This was not the case in the reservoir model that was developed since the GEM simulator would take into account the uneven mixing that is dependent on the well placement in the reservoir.

\subsection{Pressure Depletion and Nitrogen Injection Results}

The reservoir model was produced by pressure depletion. The surface gas rate was controlled and set at a maximum of 1.4 MMSCFD for Well-1, 0.8 MMSCFD for Well-2 and 0.25 MMSCFD for Well-3. Well-3 was also shut in from year 4 to year 16. This was done to better match the well constraints that were present in the field. Well-3 was not a successful completion and had low production rates and was shut-in after a couple years. 
It was then reopened after being re-completed. Wells 1 and 2 had higher producibility and thus higher surface gas rates. Figures 4-6 to 4-10 show the production as a result of this reservoir's depletion. The reservoir was produced for a total of 25 years.

The dew point was reached at year 7 , at this point there was a change in the rate of decline of the block pressures. The bottom-hole, well block and well head pressures were similar for all three (3) production wells. Wells 1 and 2 had a similar decline in rates after 7 years. Well-3 maintained a low rate before and after being shut-in. All wells, once opened, had very similar GOR trends and values. The GOR remained constant till year 7 when the reservoir pressure was above the dew point.

As is expected based on the condensate production rates, Well-1 had the highest cumulative production while Well-3 had the lowest. The total field production was 3.18 MMbbl.

Nitrogen injection commenced at the start of year ten (10) with a constant nitrogen injection rate of 2.2 MMSCFD until the start of year sixteen (16) when the rate was increased to 2.45 MMSCFD to accommodate Well-3 being opened. Figures 4-11 to 4-17 show the production as a result of the nitrogen injection. The results are shown in comparison to production under pressure depletion.

The well block pressure declined similarly for all three (3) production wells. However each had a different reaction to the nitrogen injection due to the location in the reservoir with respect to nearness to the injection well, Well-4.

At year 10 when nitrogen injection was started there was a change in the condensate production for Wells 1 and 2. There was a steeper decline in Well-1 production rate from year 10 to year 13, after which the rate leveled off. Well-2 had a slight increase in production rate from year 10 to 13 after which it gradually declined to a minimum at the end of production. Once Well-3 was re-opened at year 16, its production rate was higher than for the case of pressure depletion.

There was a drop in the overall field production when nitrogen was injected. This was due to the large decline in Well-1 condensate production. 
The GOR was also analyzed alongside the gas and oil saturations for each well gridblock.

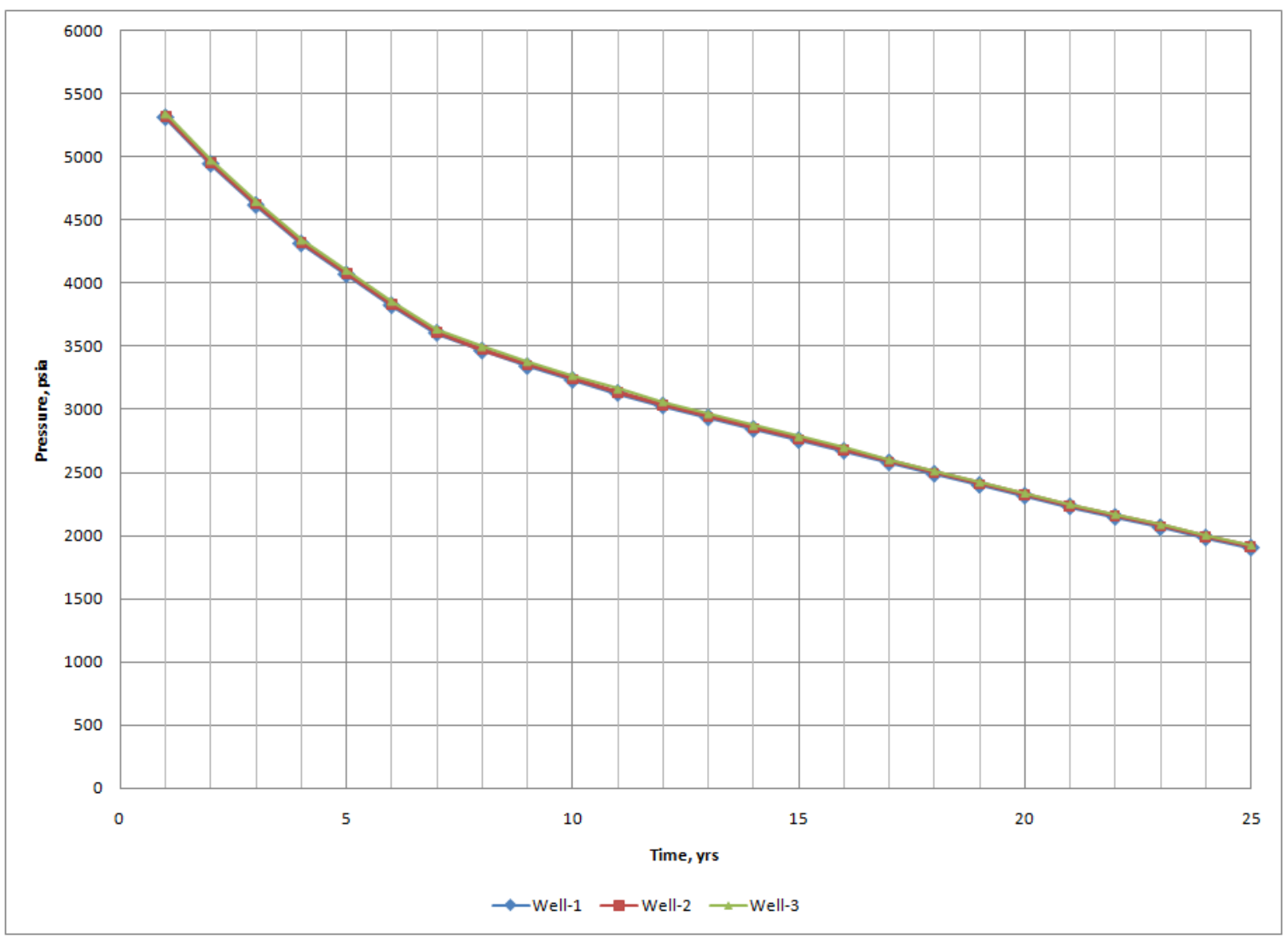

Figure 4-6 Well block pressures during the pressure depletion of reservoir 


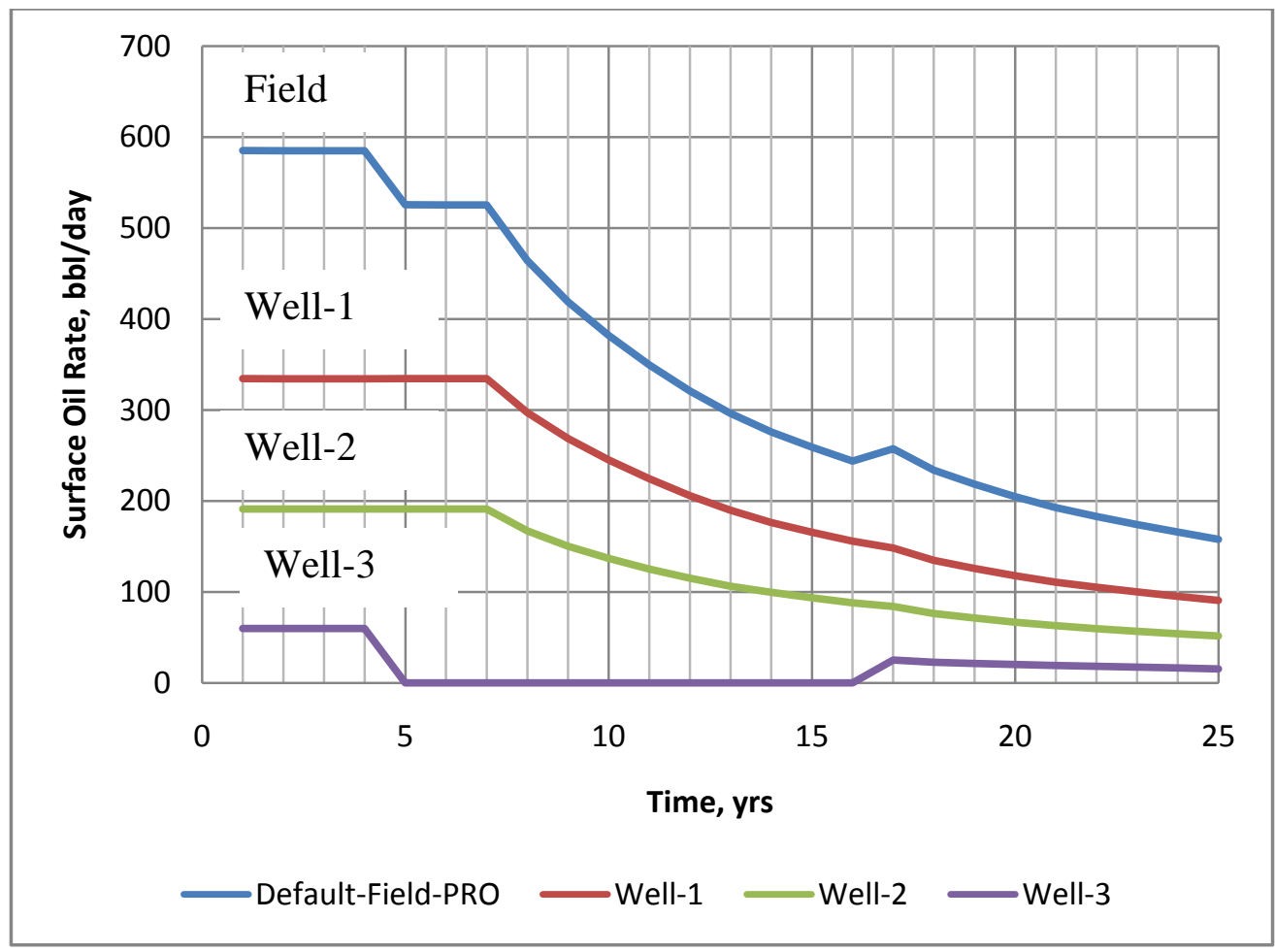

Figure 4-7 Surface condensate production rates for model under pressure depletion

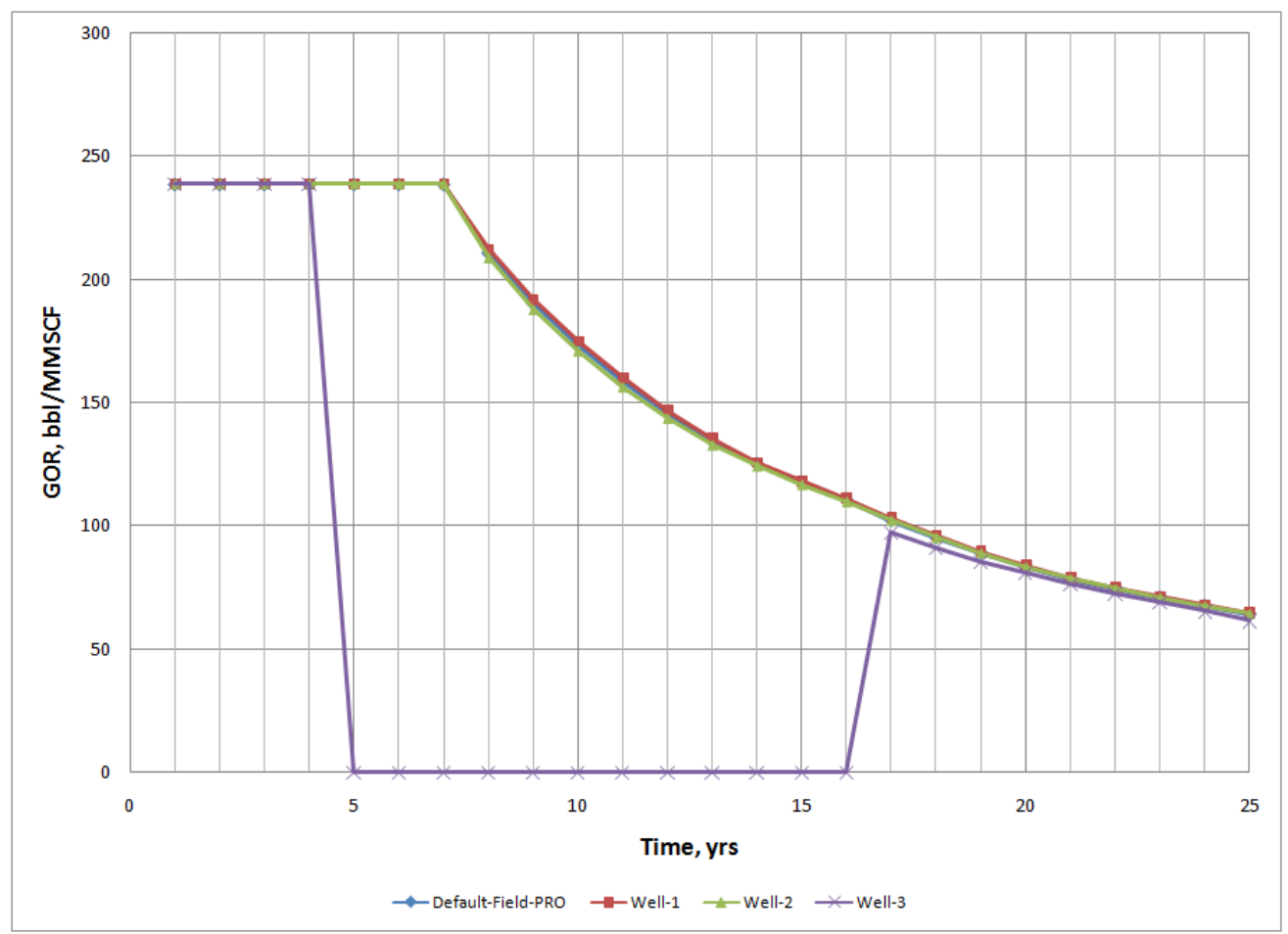

Figure 4-8 Surface gas oil ratios for pressure depletion 


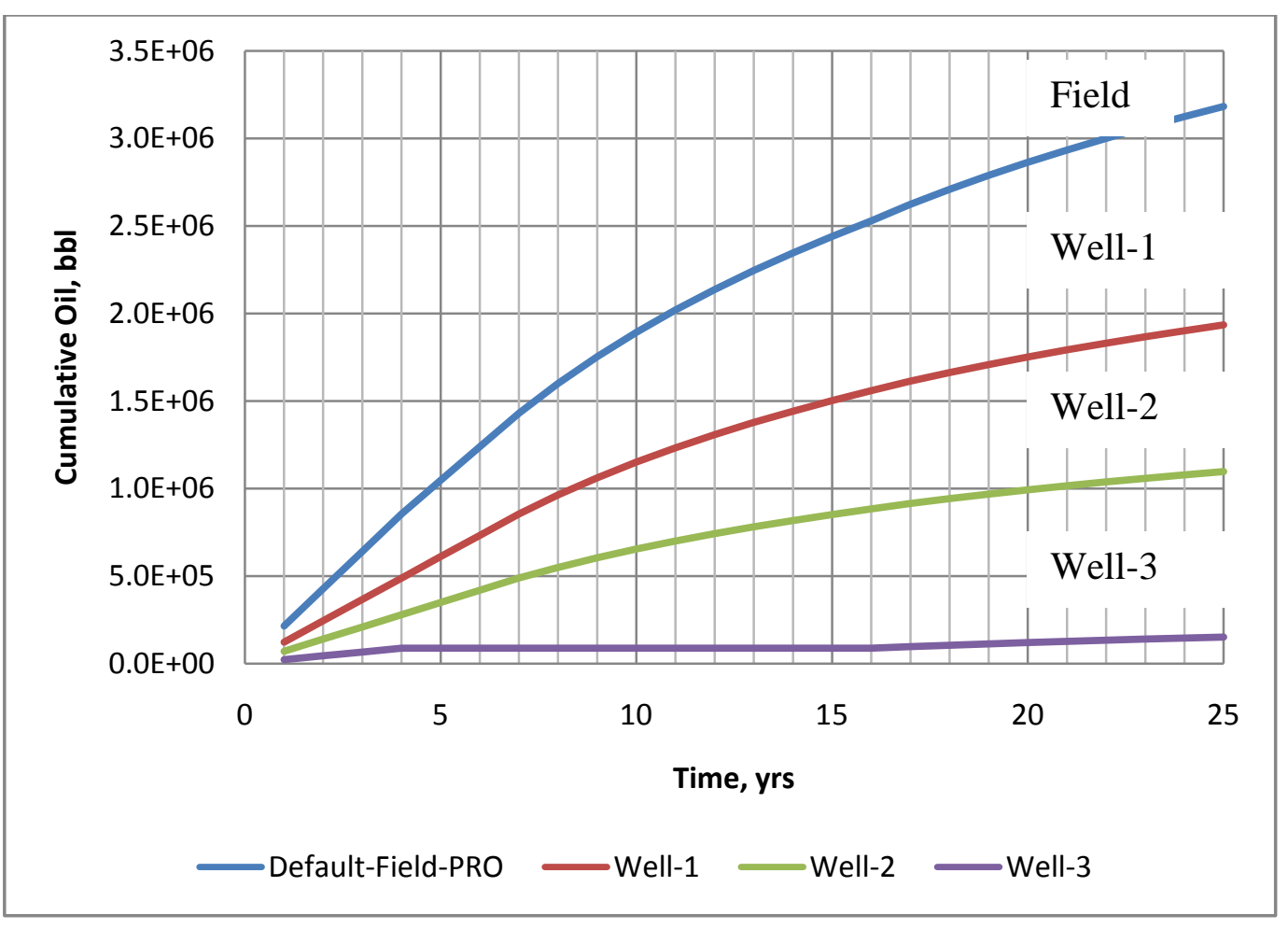

Figure 4-9 Cumulative surface condensate production for pressure depletion of reservoir

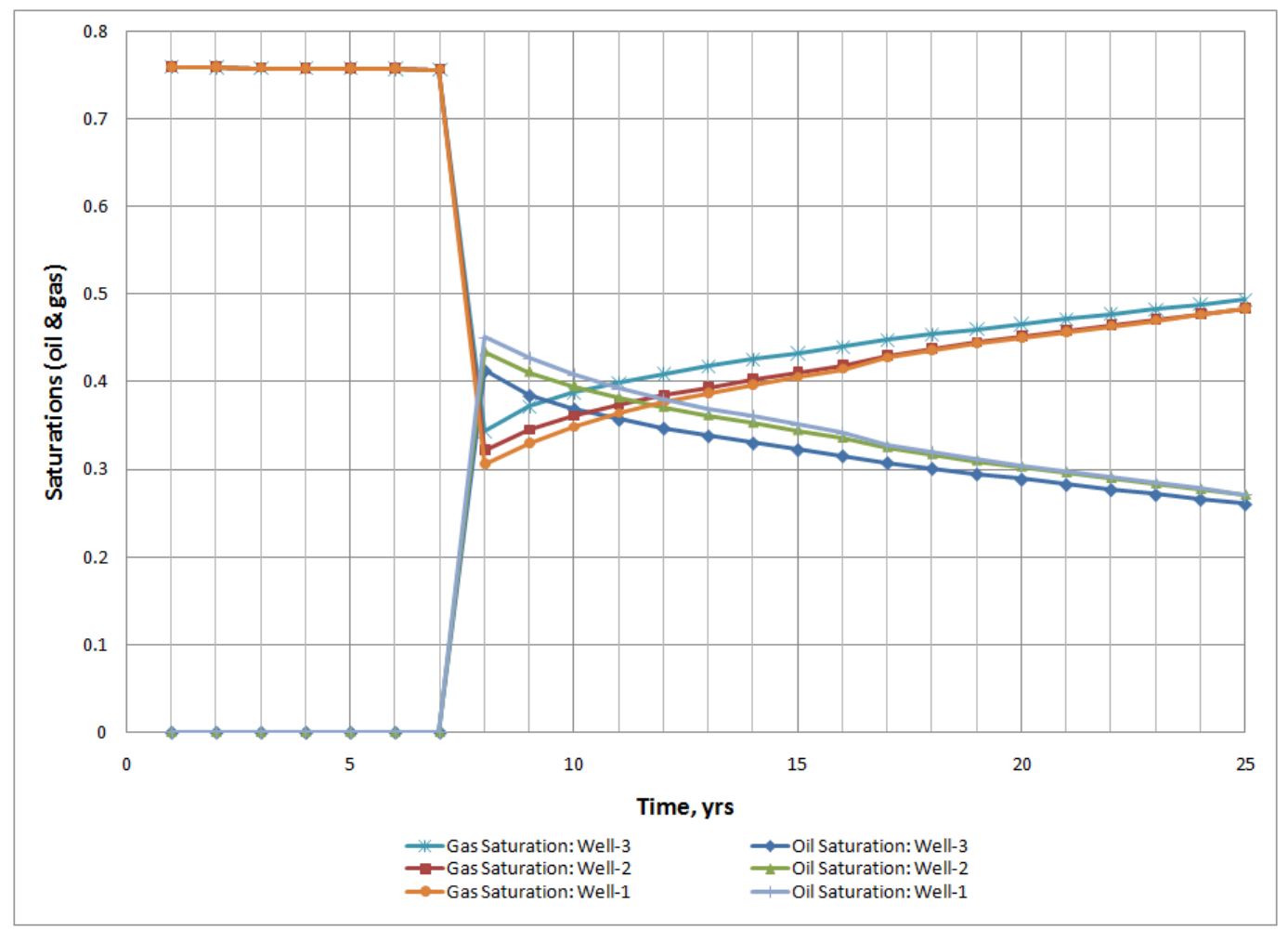

Figure 4-10 Oil and gas saturation trends for production grid-blocks 


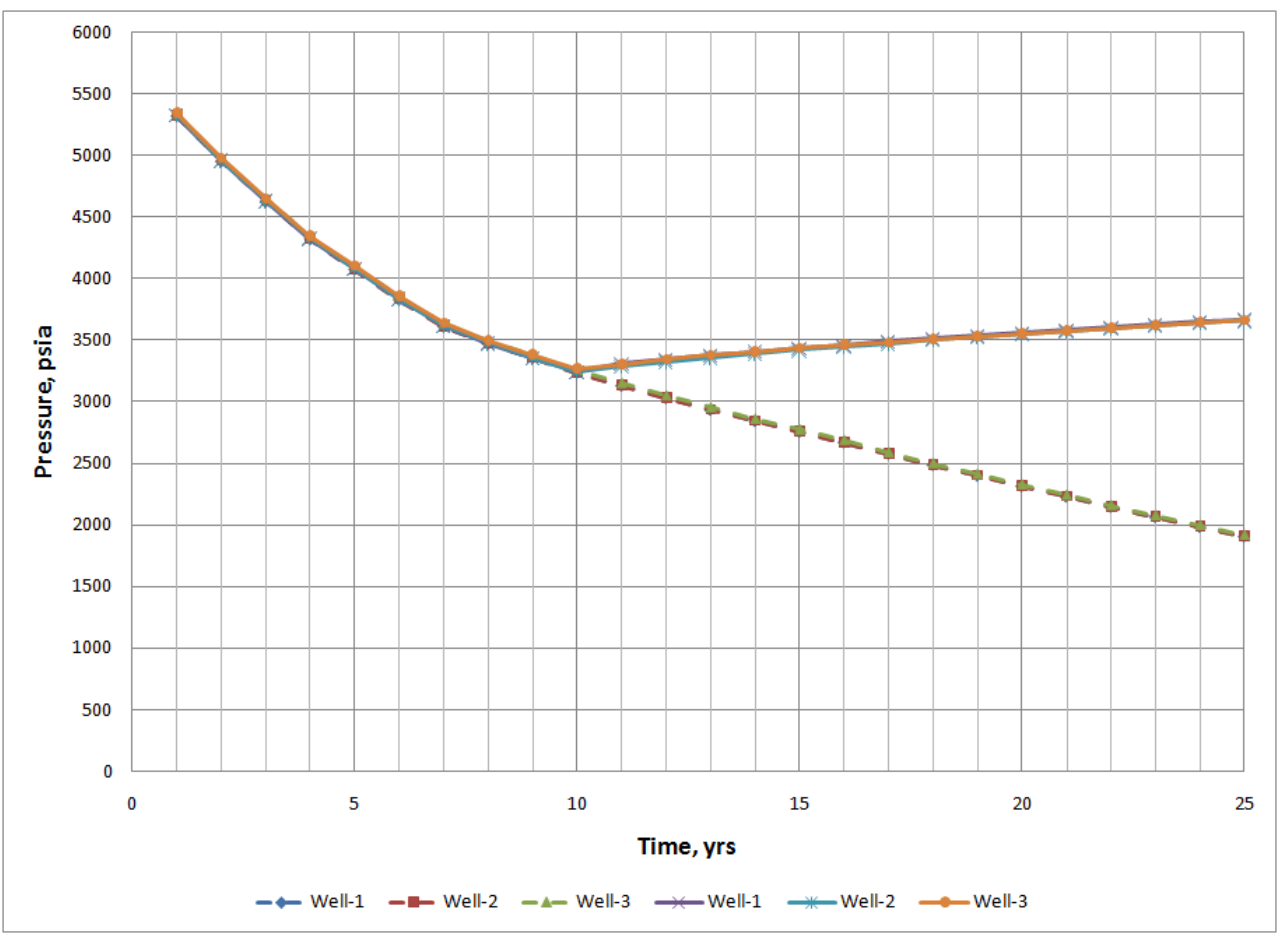

Figure 4-11 Well block pressure comparison between nitrogen injection (solid lines) and pressure depletion (dashed lines)

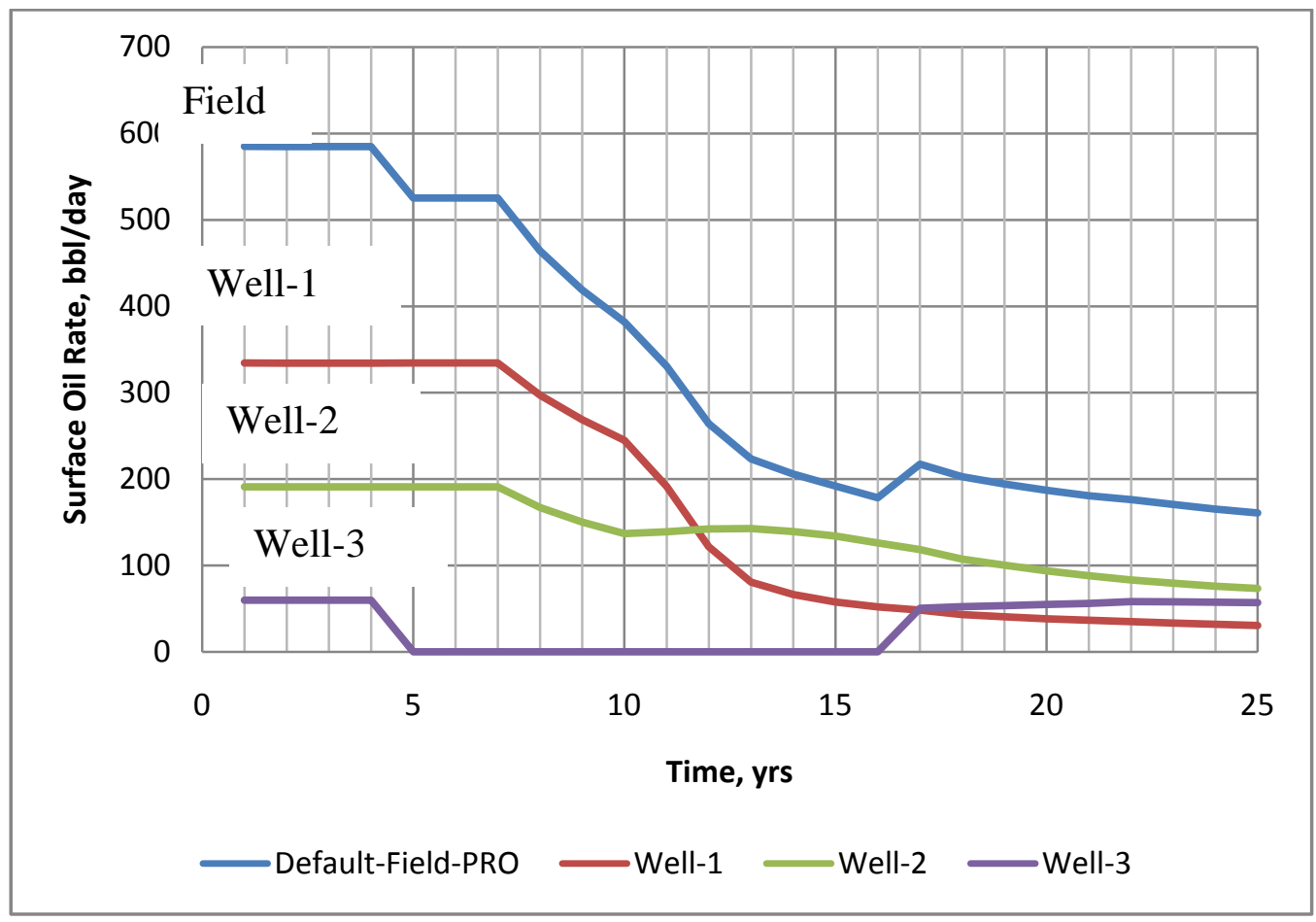

Figure 4-12 Surface production rates for field under nitrogen injection 


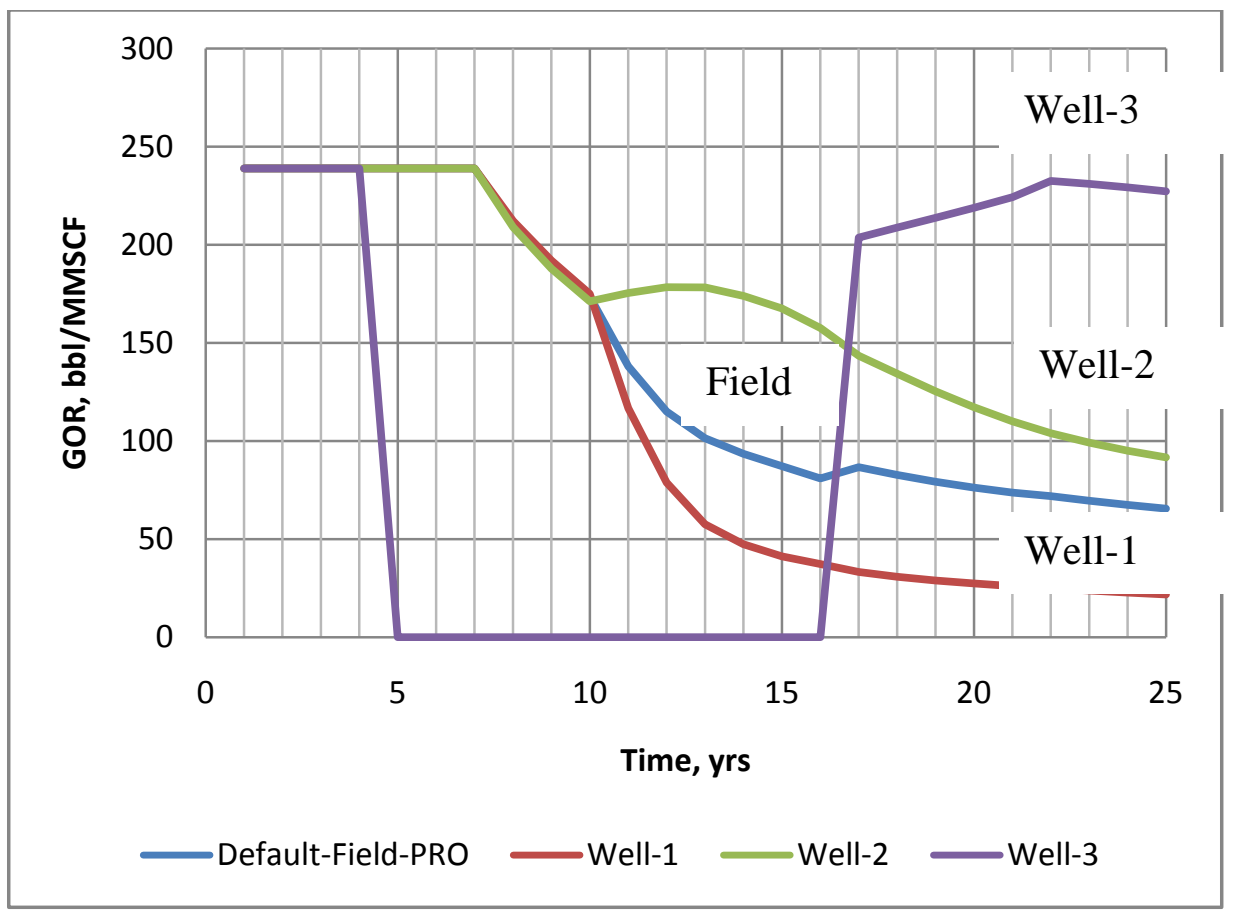

Figure 4-13 Surface gas oil ratios for reservoir when nitrogen is injected

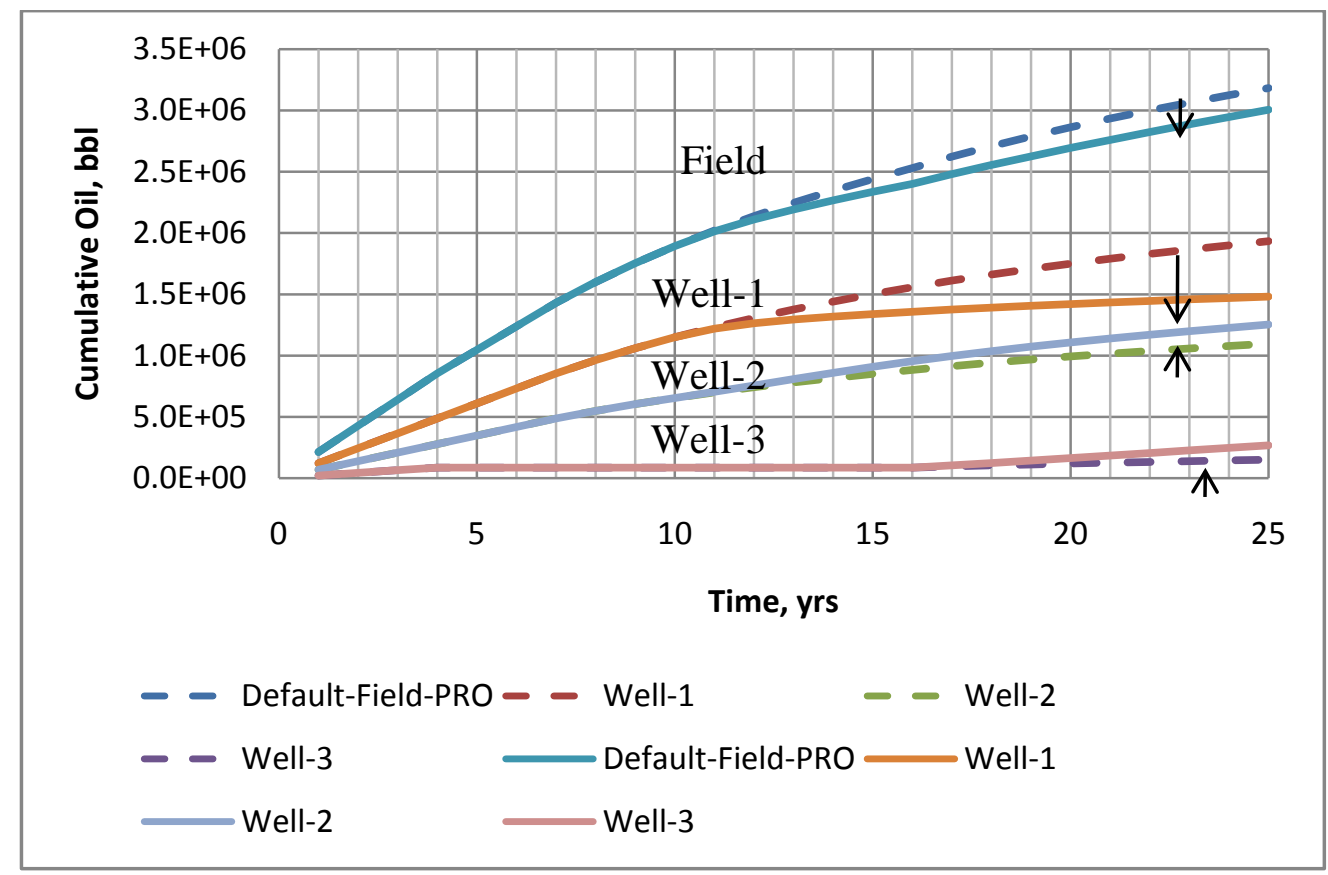

Figure 4-14 Cumulative surface condensate production comparison between nitrogen injection (solid lines) and pressure depletion (dashed lines) 


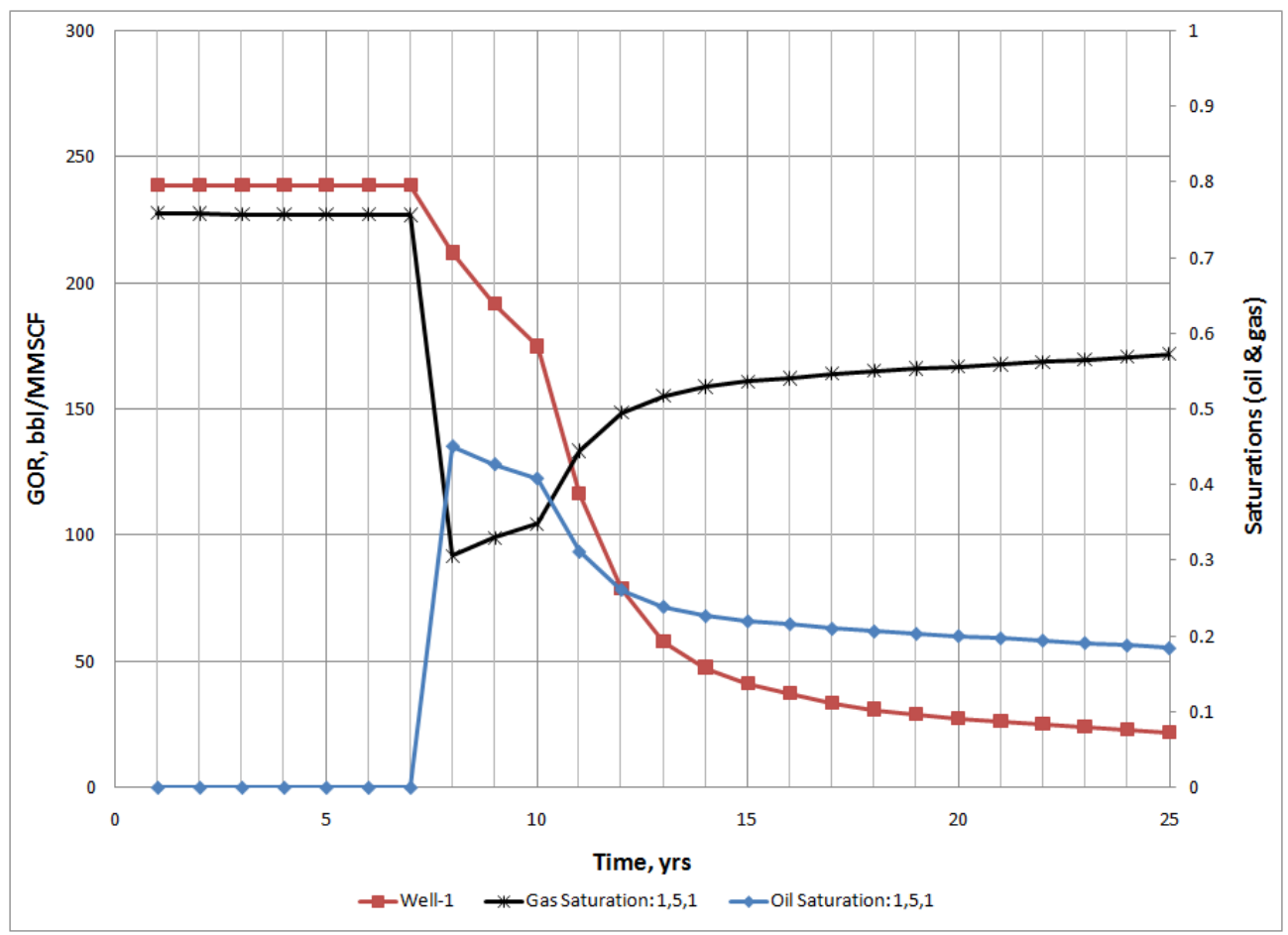

Figure 4-15 GOR and block saturations for Well-1

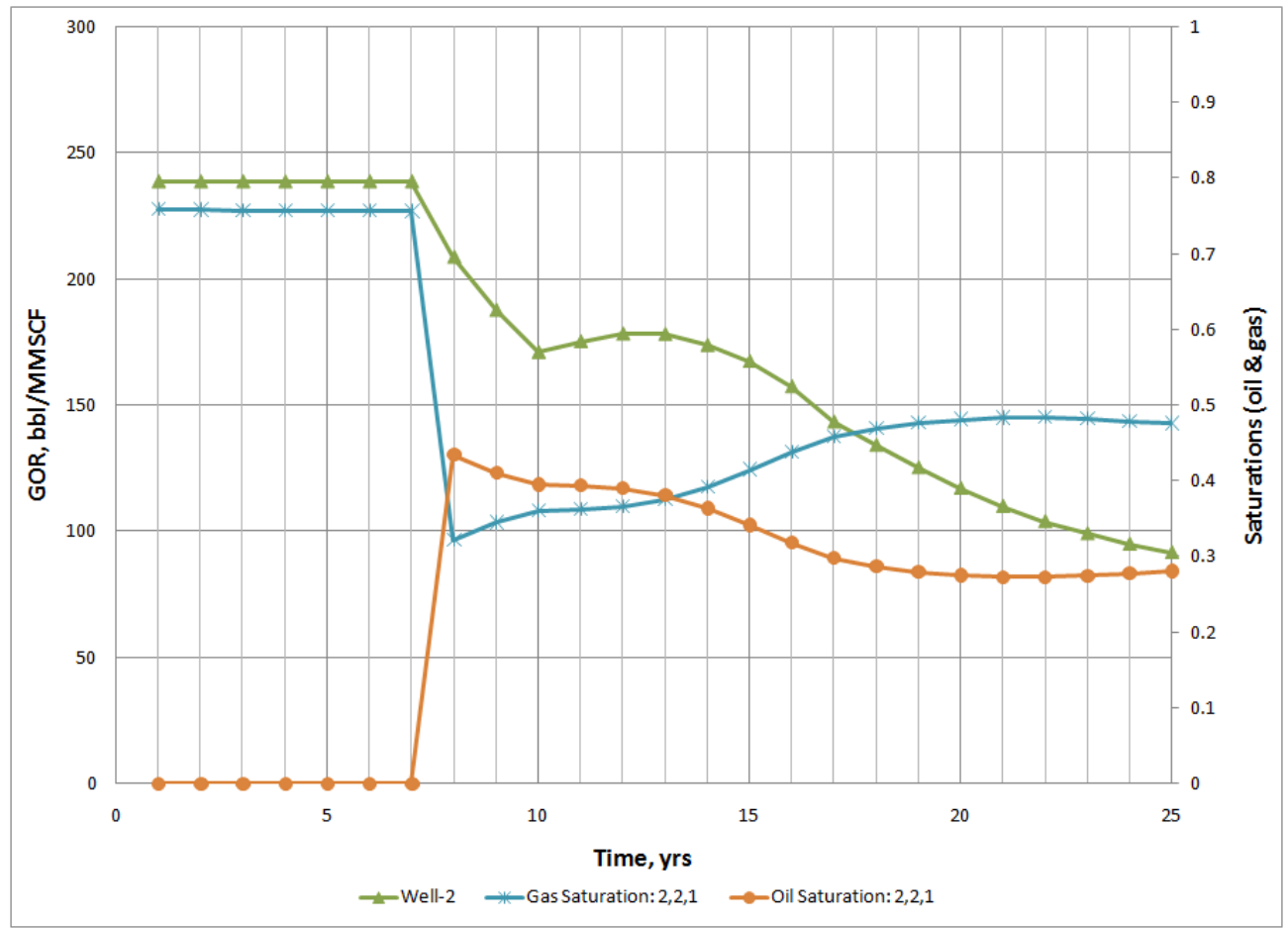

Figure 4-16 GOR and block saturations for Well-2 


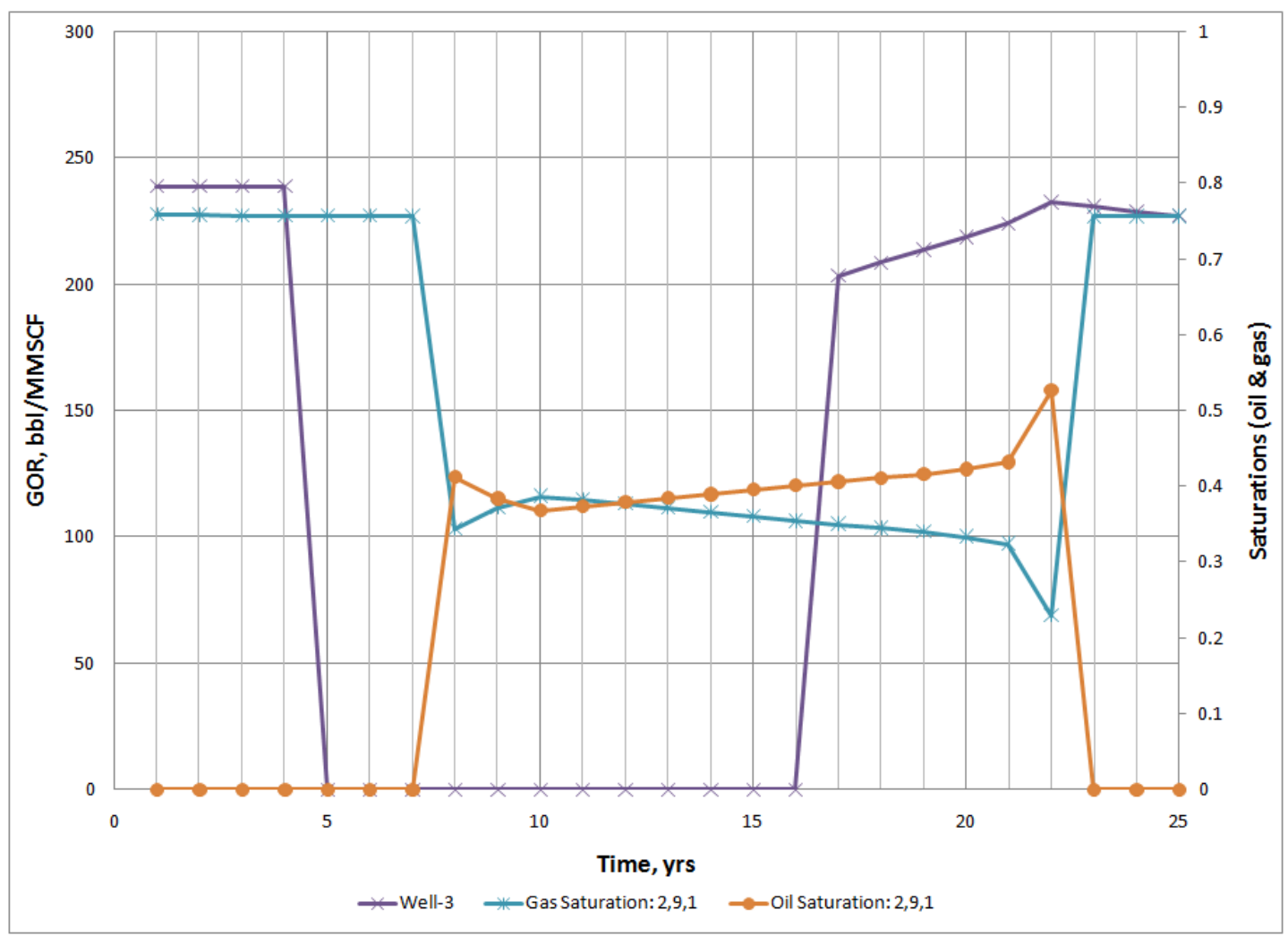

Figure 4-17 GOR and block saturations for Well-3

\subsection{Alternative Models}

Several cases were considered as alternative plans for the model was based on. These were,

1. Defining the reservoir as a two-layer model with production from both layers and injection to the top layer only.

2. Varying the starting time of nitrogen injection.

3. Varying the location of the injection point in the model.

4. Including an additional producer well in the reservoir model. 


\subsubsection{Two-layer Model}

In the two-layer model, each layer had a height of $45 \mathrm{ft}$ and the model was kept homogeneous. The reservoir was perforated through both layers for the three (3) producers but the injection was to the top layer only. The figures below show the simulation results for production by pressure depletion and by nitrogen injection.

When comparing Figures 4-6 through 4-10 to Figures 4-18 through 4-23 it is seen that defining the reservoir model as a two-layer model does not significantly affect the production results. However when comparing the block saturations for the one and twolayer model it is seen that there is a significant difference in saturations between top and bottom layer, as the liquid formed tends to settle to the bottom of the reservoir model. This is due to gravitational affects causing settling of the condensate liquid to the lower layer. However when the average of the top and bottom layers was taken, the values matched the single layer block saturations. An example of this is shown in the Appendix D.

When nitrogen injection was started the displacement of reservoir liquid to the corners of the lower layers was clearly seen (Figure 4-24 to Figure 4-27). At the end of the production period, the top layer had returned to the original gas saturation of $76 \%$. The lower layers varied from $75 \%$ to $0 \%$ with the highest gas saturation at the point of injection in the centre and getting progressively lower as you move towards the outer corner blocks. 


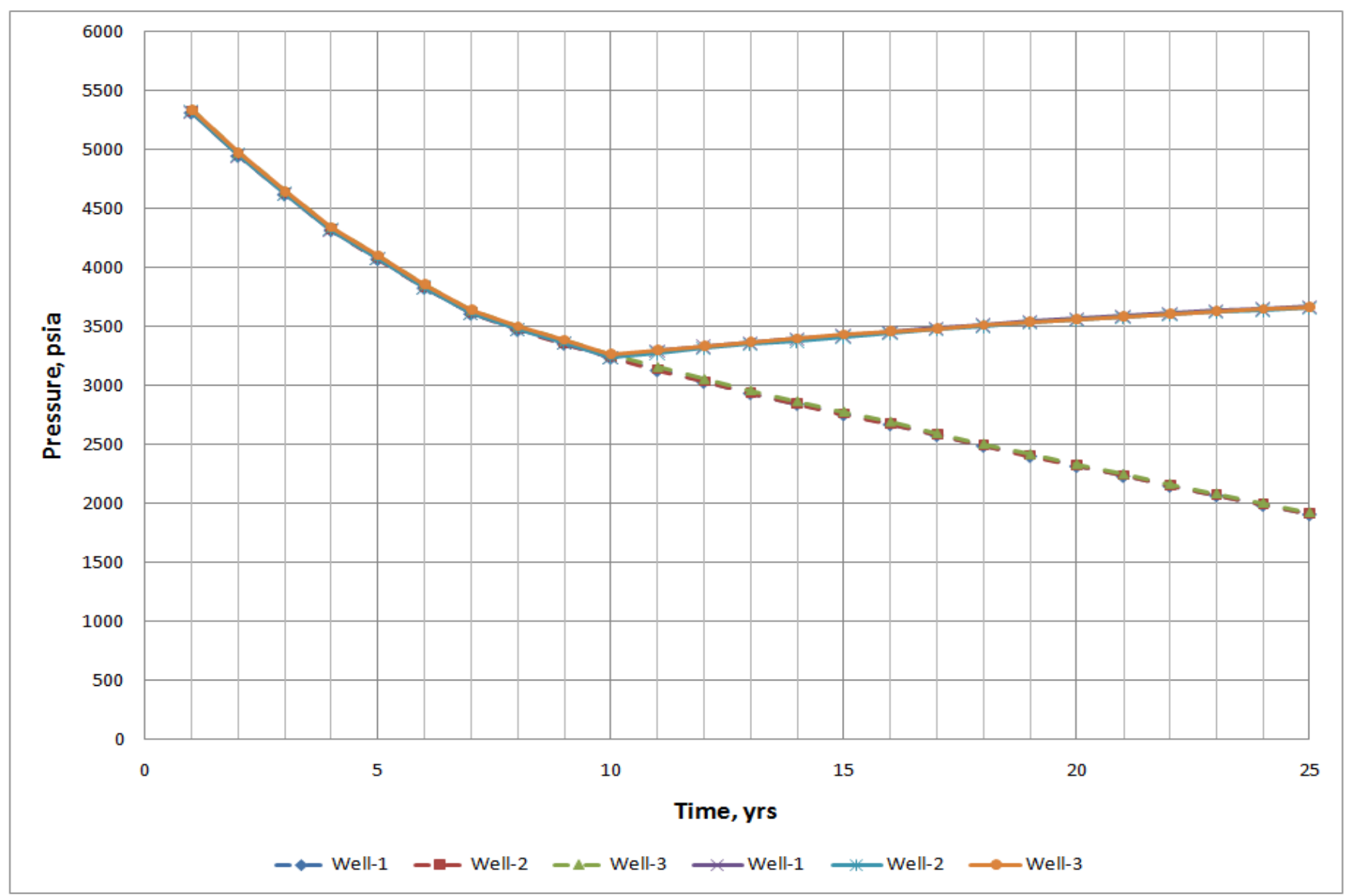

Figure 4-18 Well block pressures for two-layer model comparing production with nitrogen injection (solid lines) and pressure depletion (dashed lines) 


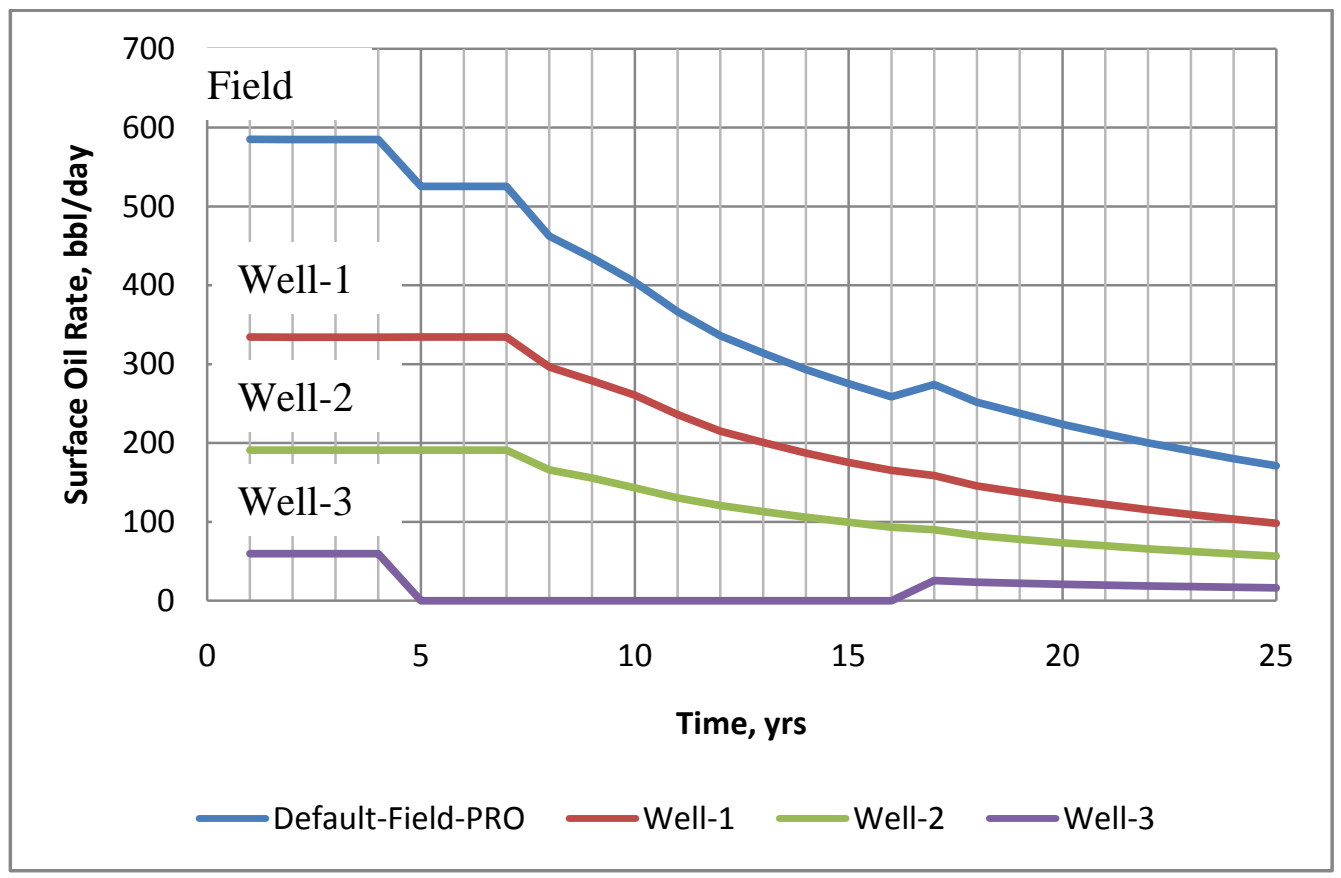

Figure 4-19 Surface condensate production rates for two-layer model under pressure depletion

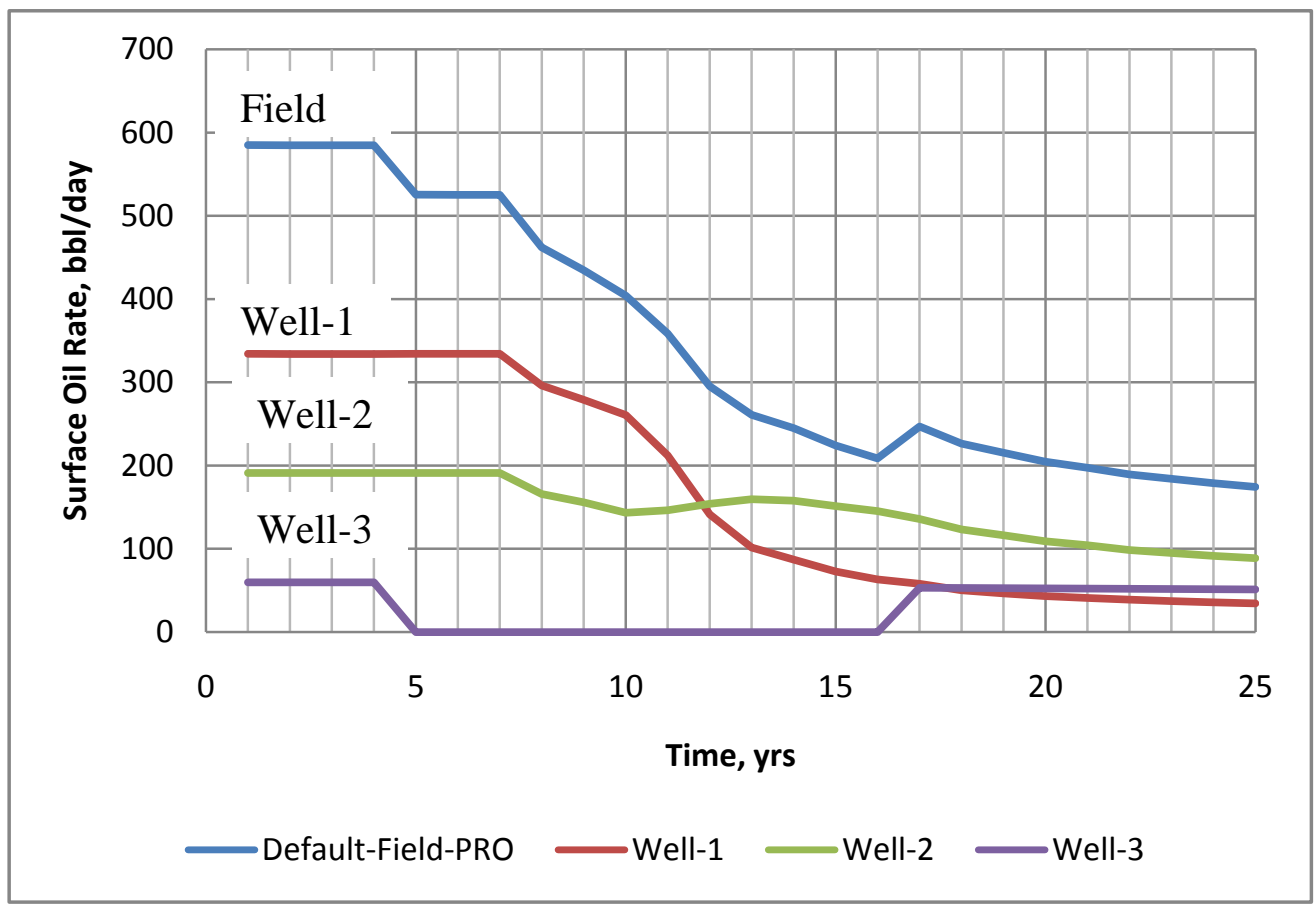

Figure 4-20 Surface condensate production rates for two-layer model with nitrogen injection 


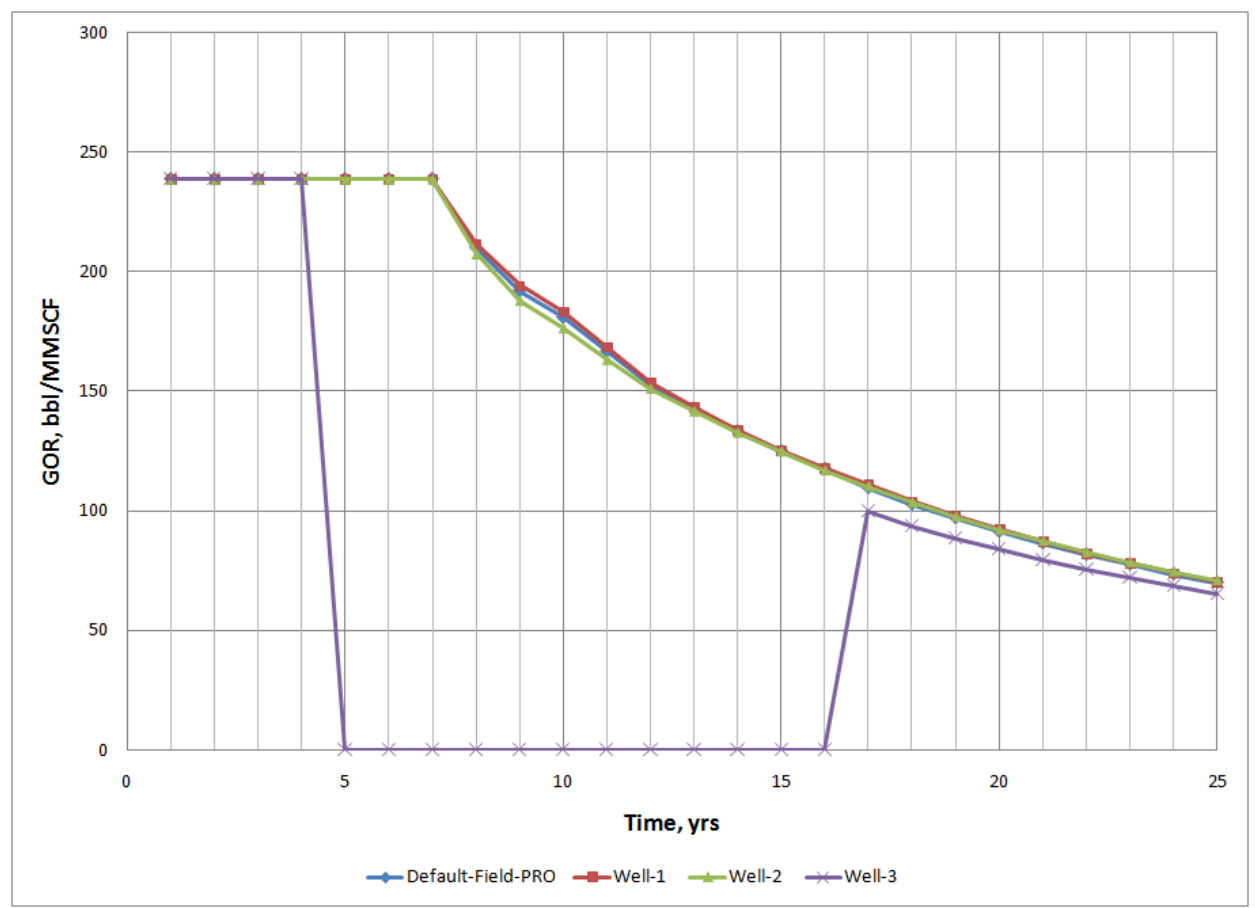

Figure 4-21 Surface gas-oil-ratios for two-layer model under pressure depletion

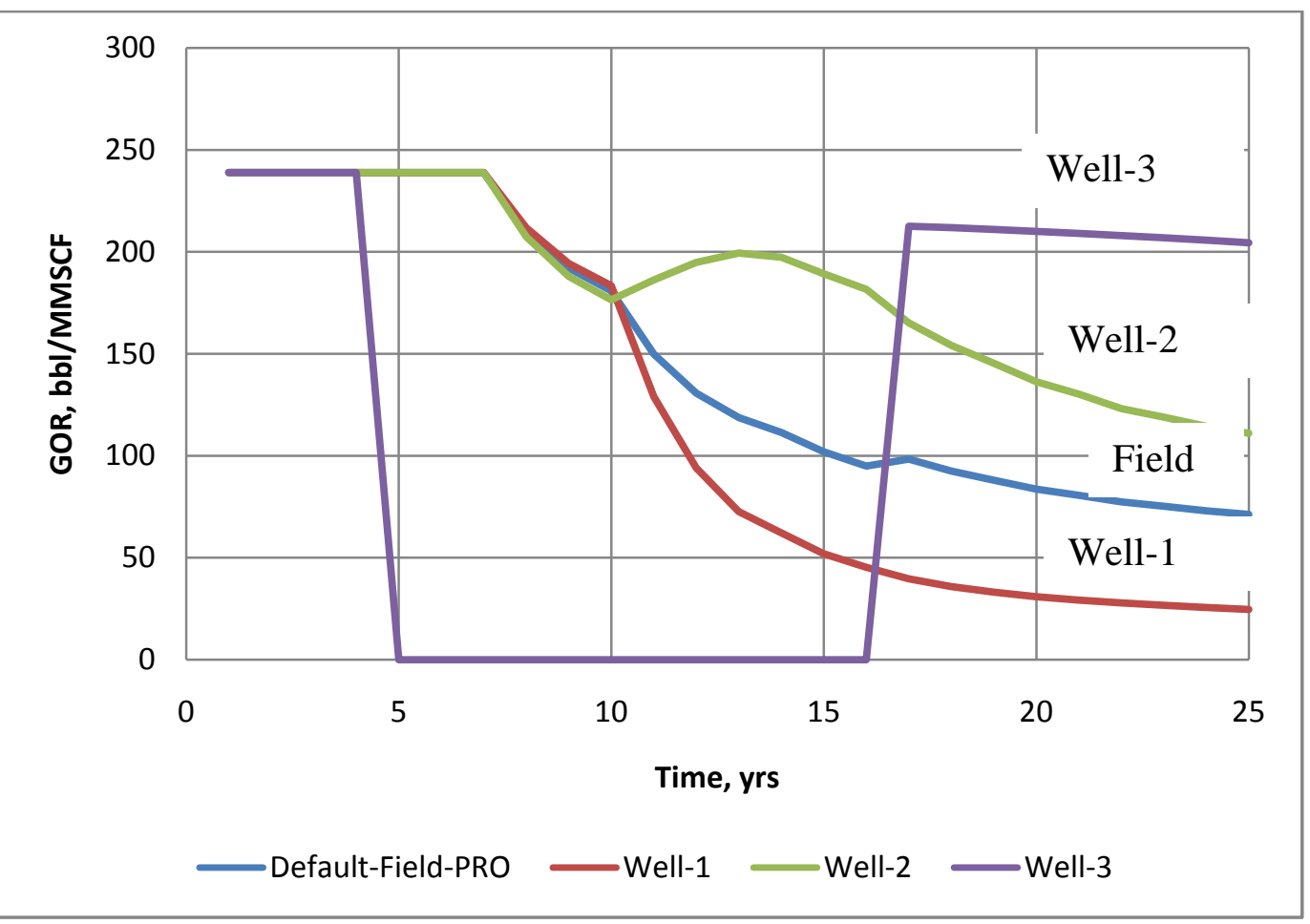

Figure 4-22 Surface gas-oil-ratios for two-layer model with nitrogen injection 


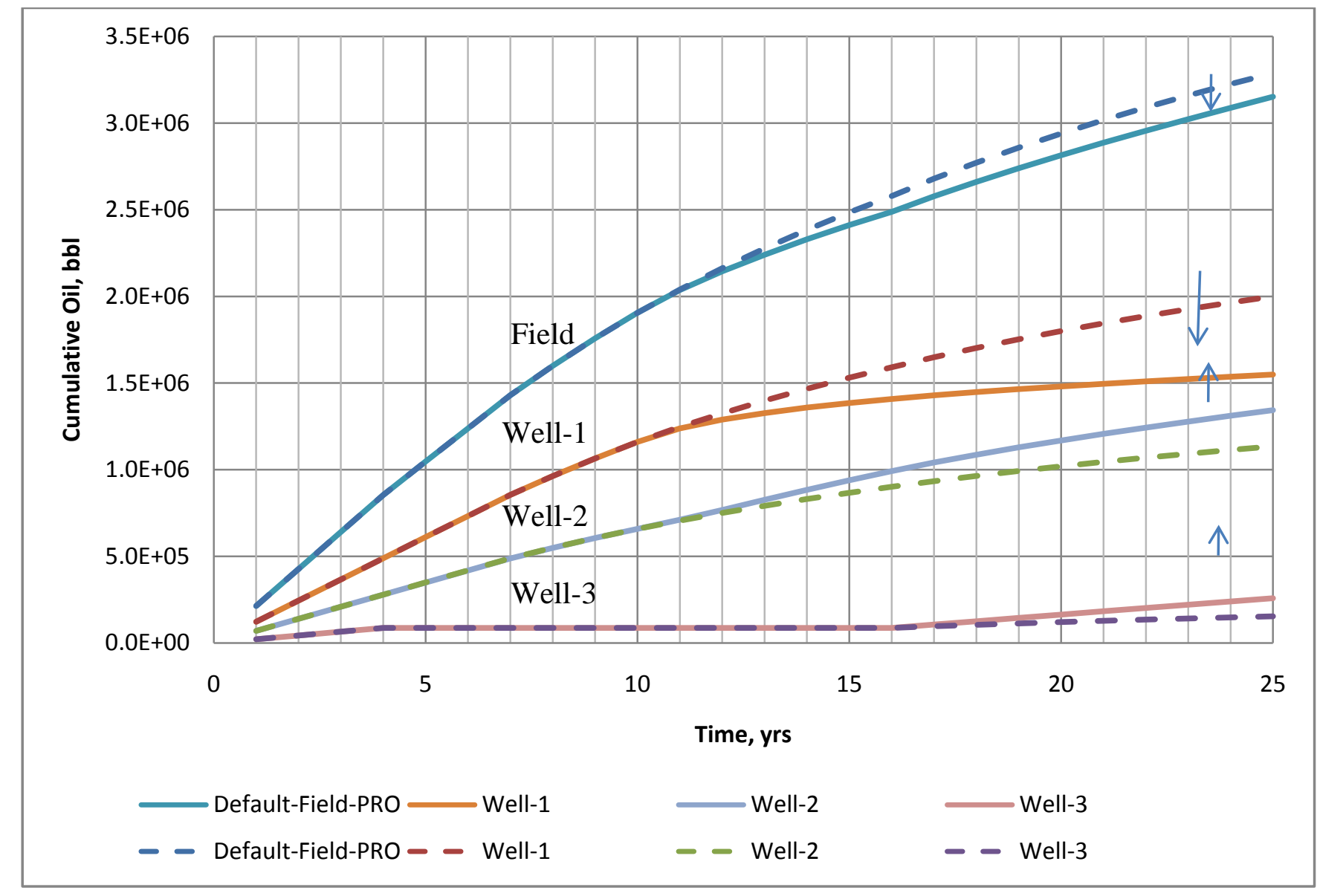

Figure 4-23 Cumulative condensate productions for two-layer model comparing production with nitrogen injection (solid lines) and under pressure depletion (dashed lines) 


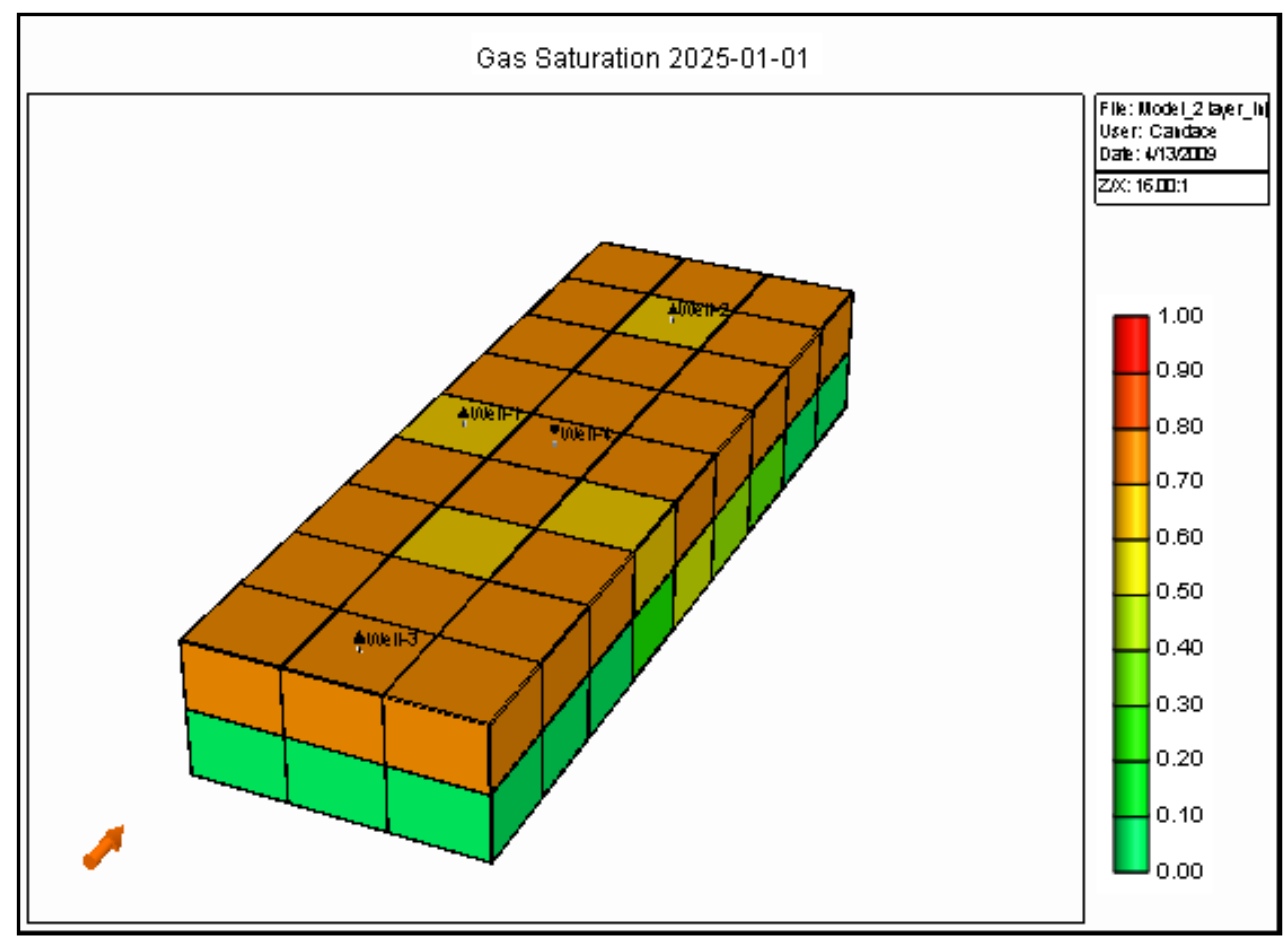

Figure 4-24 CMG Results top layer gas saturation profile after 25 years

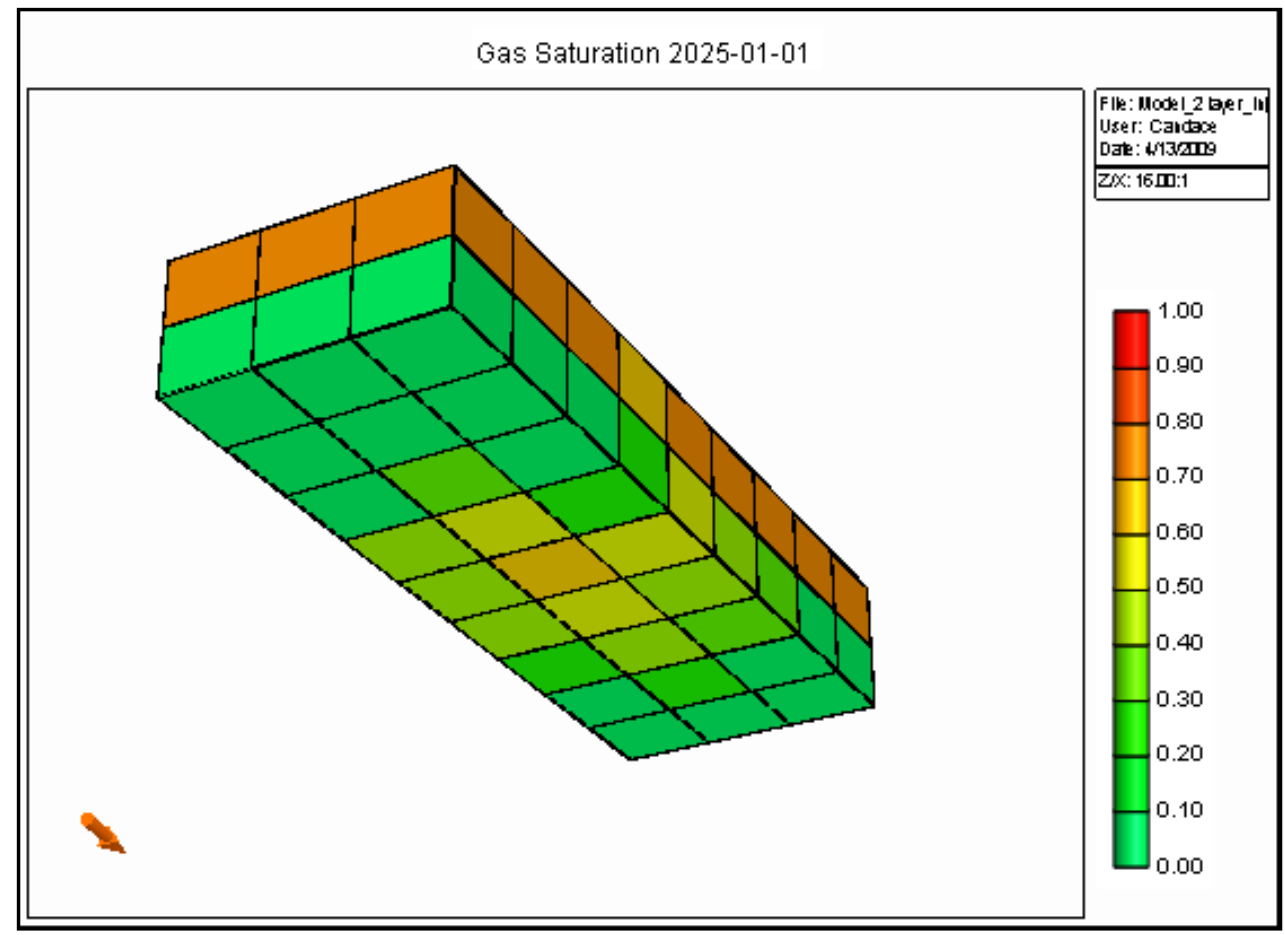

Figure 4-25 CMG Results bottom layer gas saturation profile after 25 years 


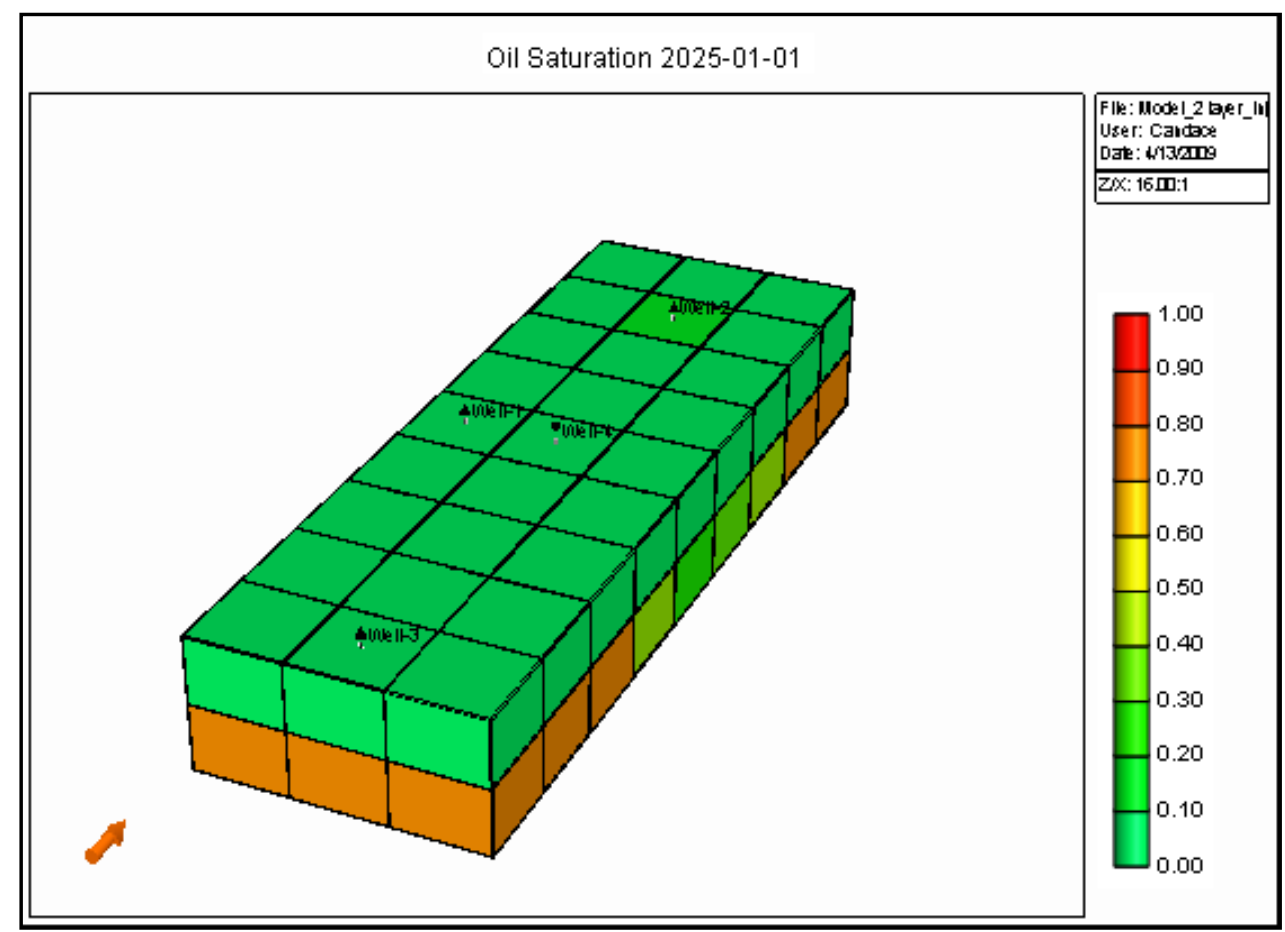

Figure 4-26 CMG Results top layer oil saturation profile after 25 years

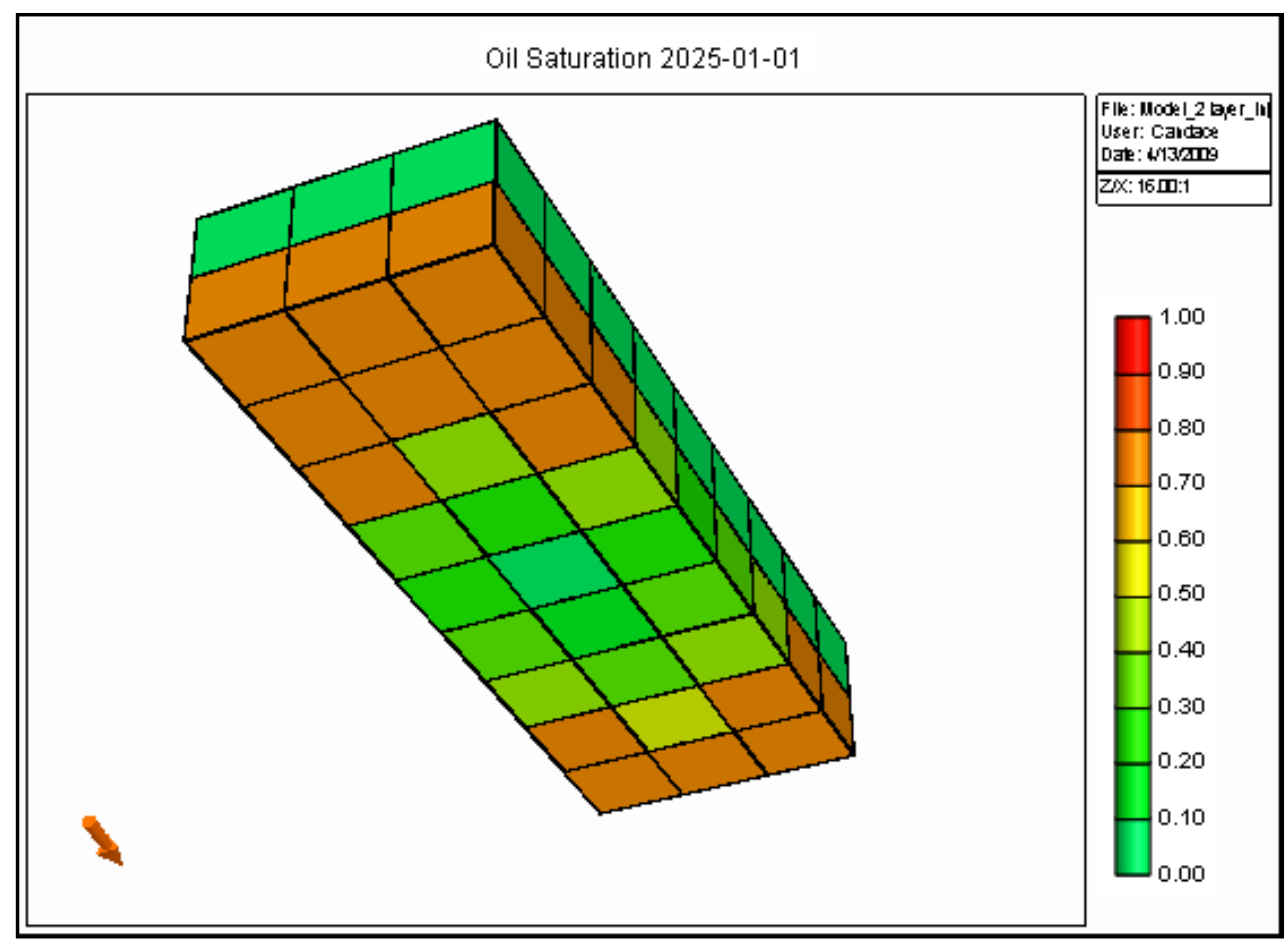

Figure 4-27 CMG Results bottom layer oil saturation profile after 25 years 


\subsubsection{Nitrogen Injection Starting Time}

Injection was started after ten (10) years for the deep gas condensate field and the nitrogen injection plan was modeled after this. However different starting times were investigated to determine any change in the effects the nitrogen injection had on the reservoir fluid production behavior.

Nitrogen was injected at the start of year 7, before the reservoir pressure dropped below the dew point. The production results are shown in Figure 4-28 to Figure 4-31.

Nitrogen injection was also delayed till year 13. The total condensate production was 3.05 MMbbl and the production results for each well are shown in Figure 4-32 to Figure 4-35.

In general it is seen that the earlier nitrogen injection is started the less condensate is produced. This result corresponds with what is seen when comparing pressure depletion and depletion with injection starting at year 10, i.e., under the selected injection rate and well layout, nitrogen injection does not help the production of condensate. Thus the less nitrogen injected into the reservoir, the more condensate is produced. 


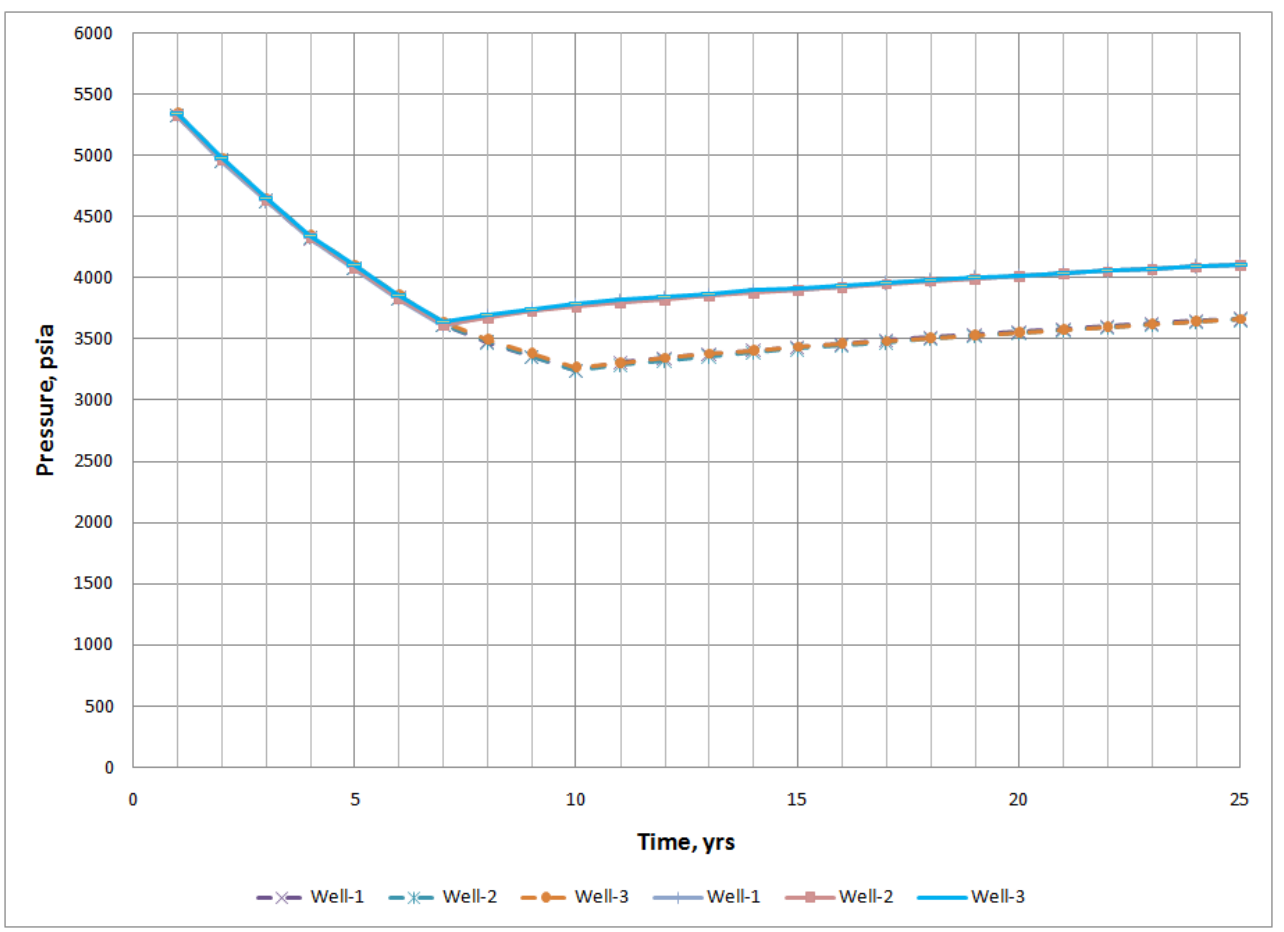

Figure 4-28 Well block pressures comparison between injection starting at year 7 (solid lines) and year 10 (dashed lines)

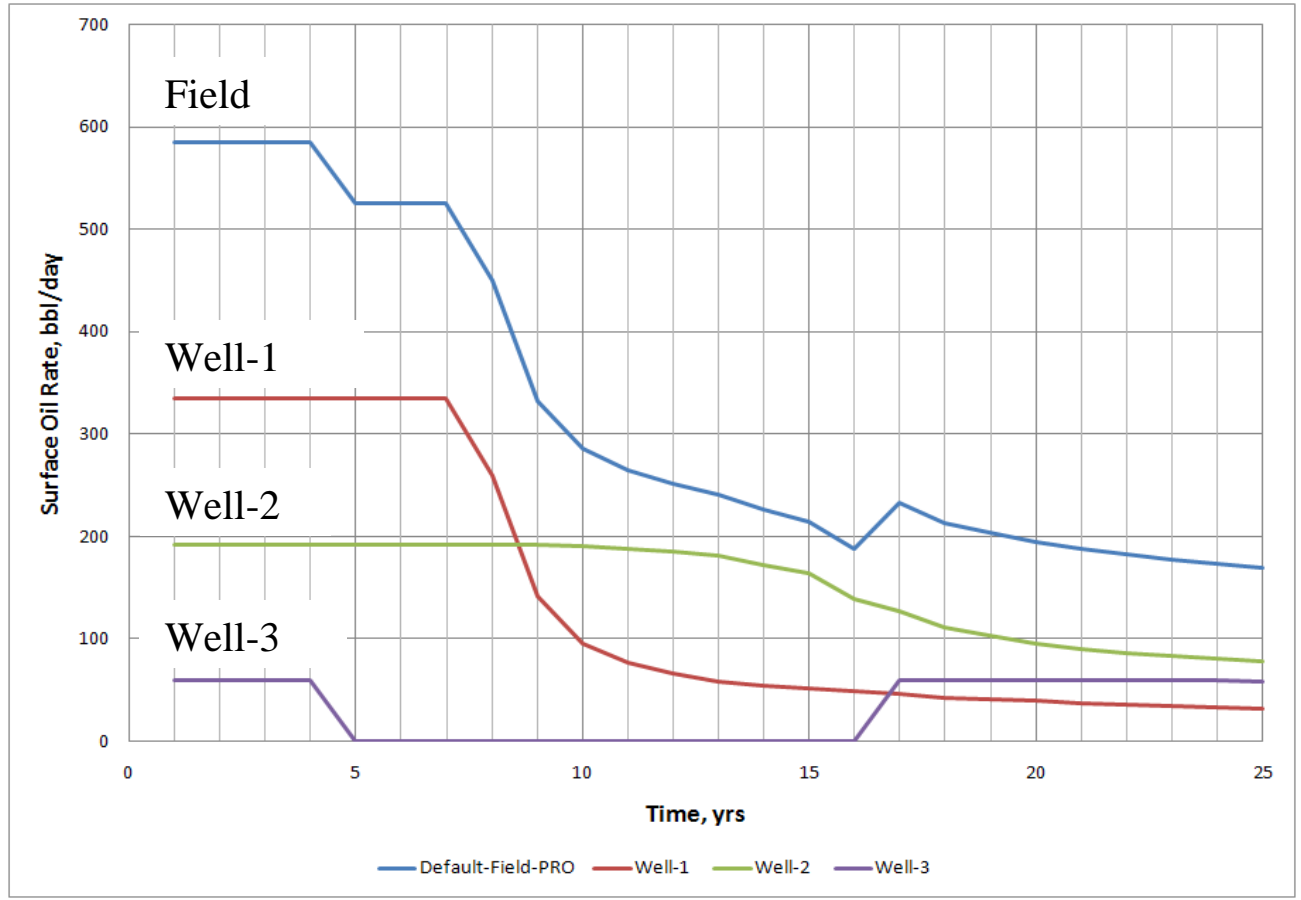

Figure 4-29 Surface condensate production rates for injection plan starting at year 7 


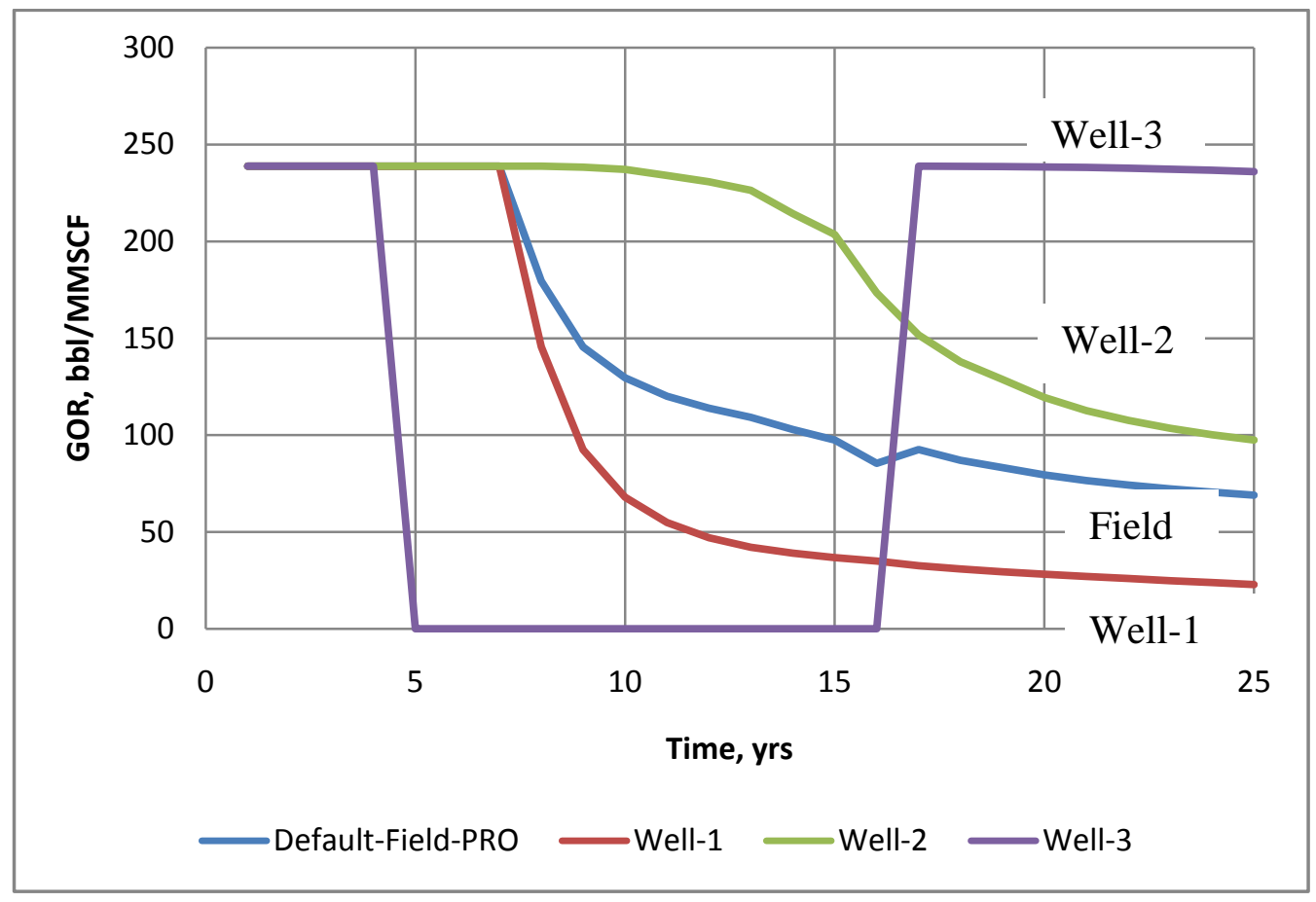

Figure 4-30 Gas-oil-ratios for injection plan starting at year 7

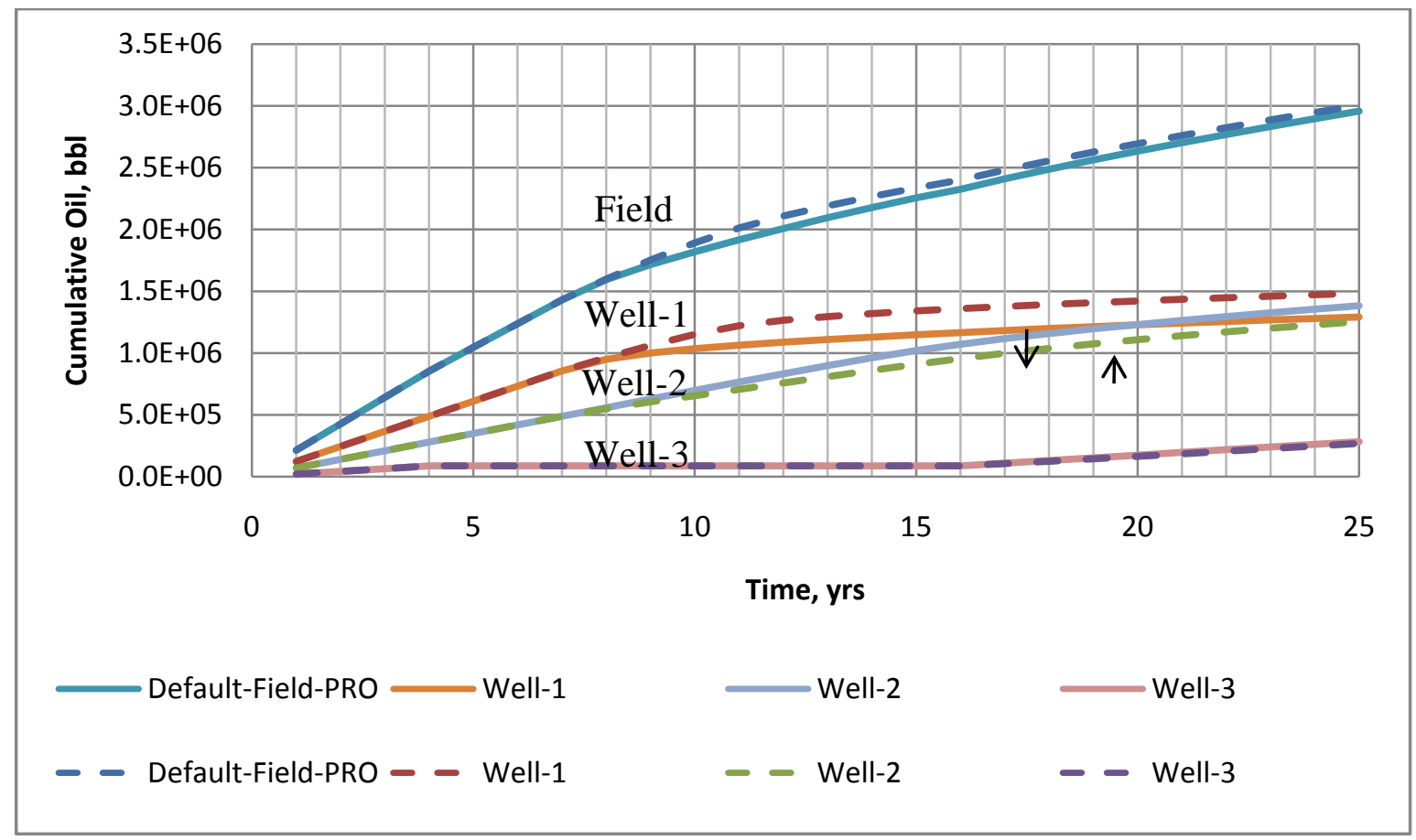

Figure 4-31 Cumulative condensate productions comparison between injection starting at year 7 (solid lines) and year 10 (dashed lines) 


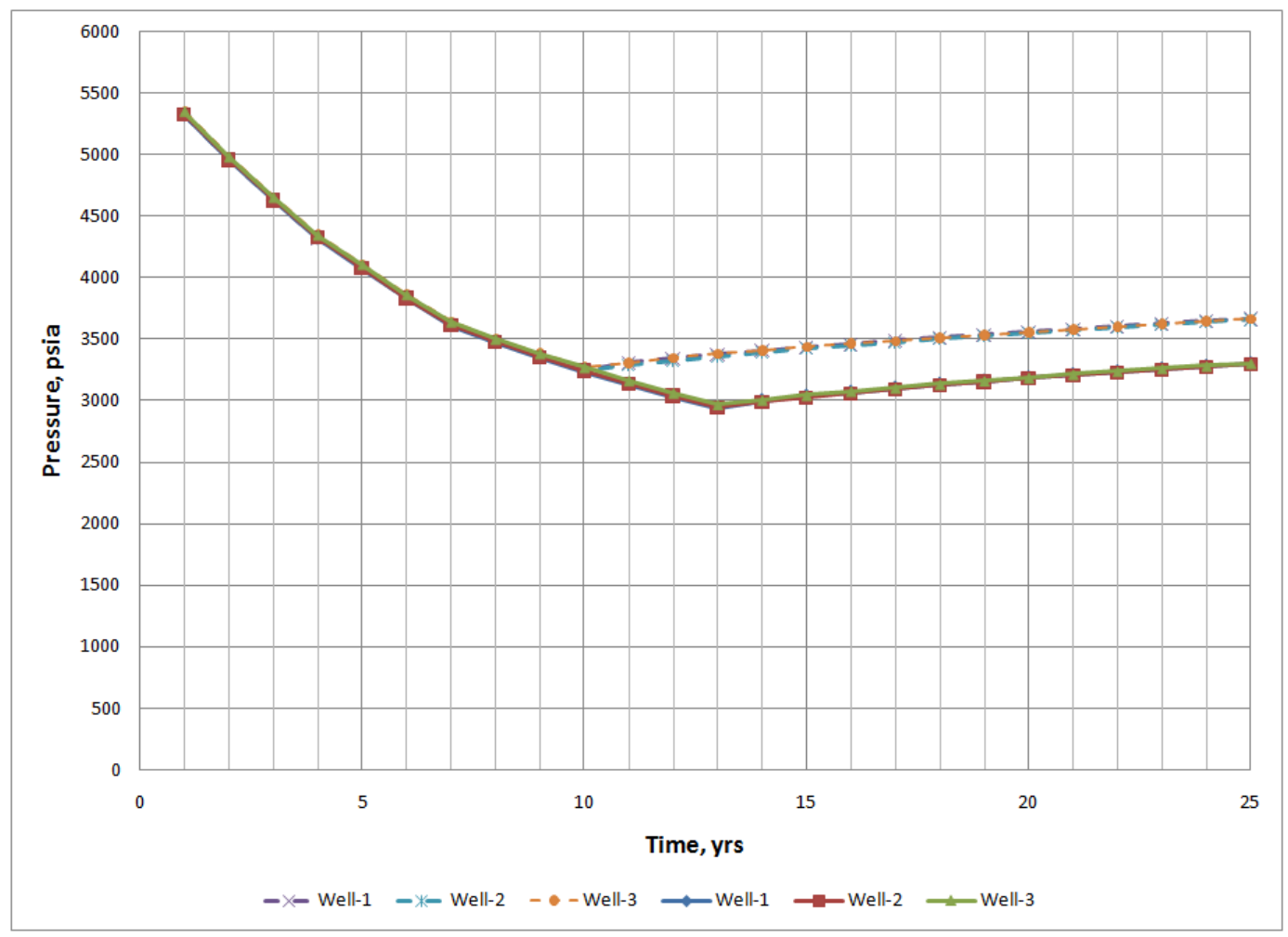

Figure 4-32 Well block pressures comparison between injection starting at year 13 (solid lines) and year 10 (dashed lines)

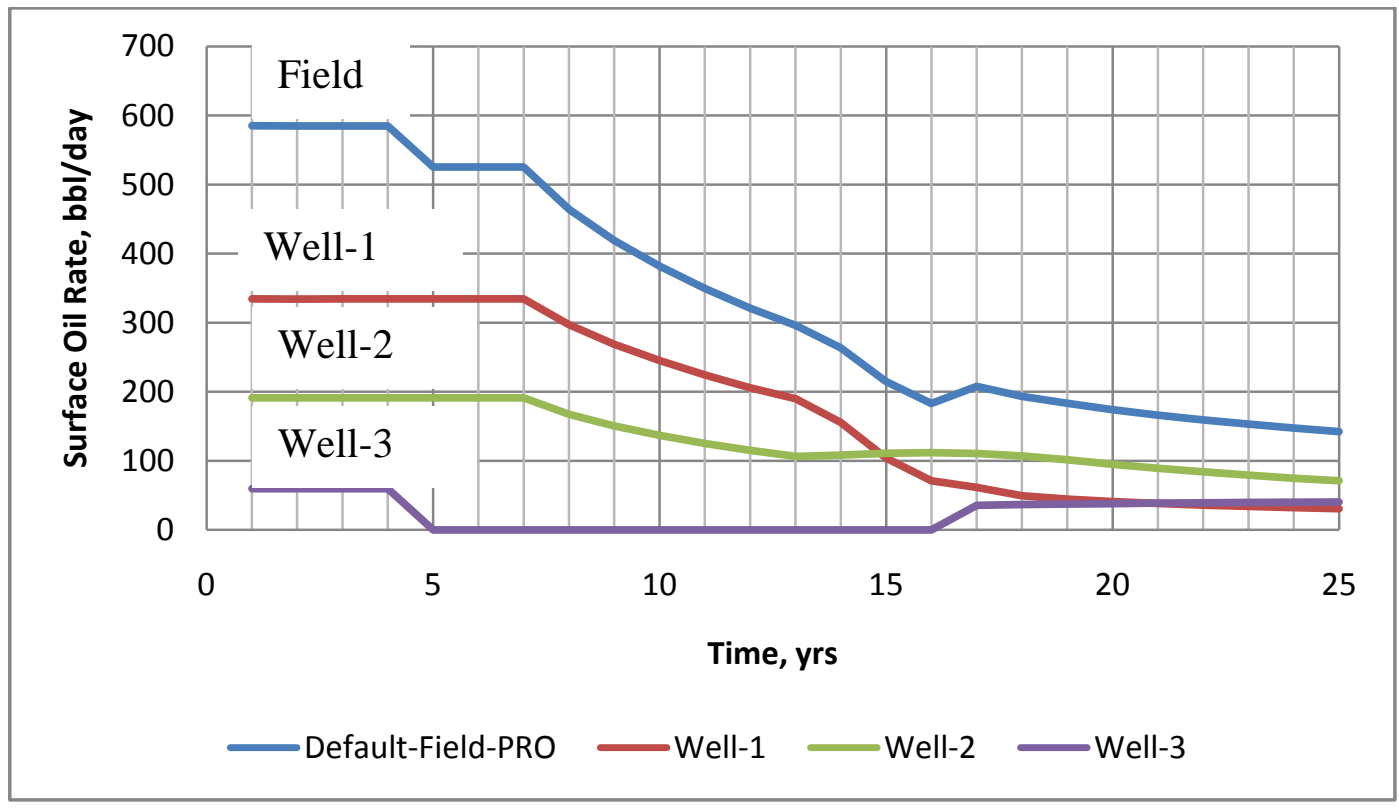

Figure 4-33 Surface condensate production rates for injection plan starting at year 13 


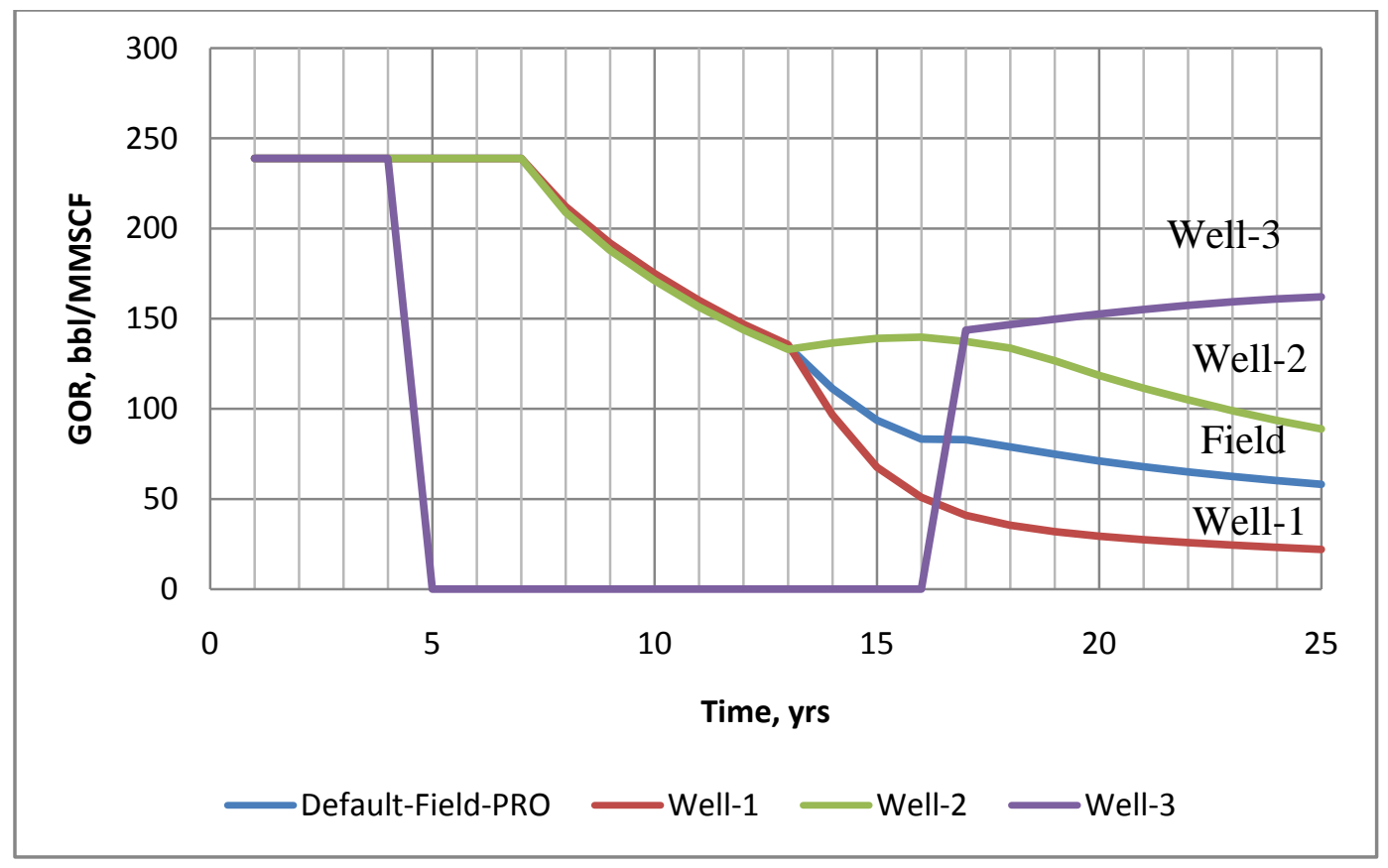

Figure 4-34 Gas-oil-ratios for injection plan starting at year 13

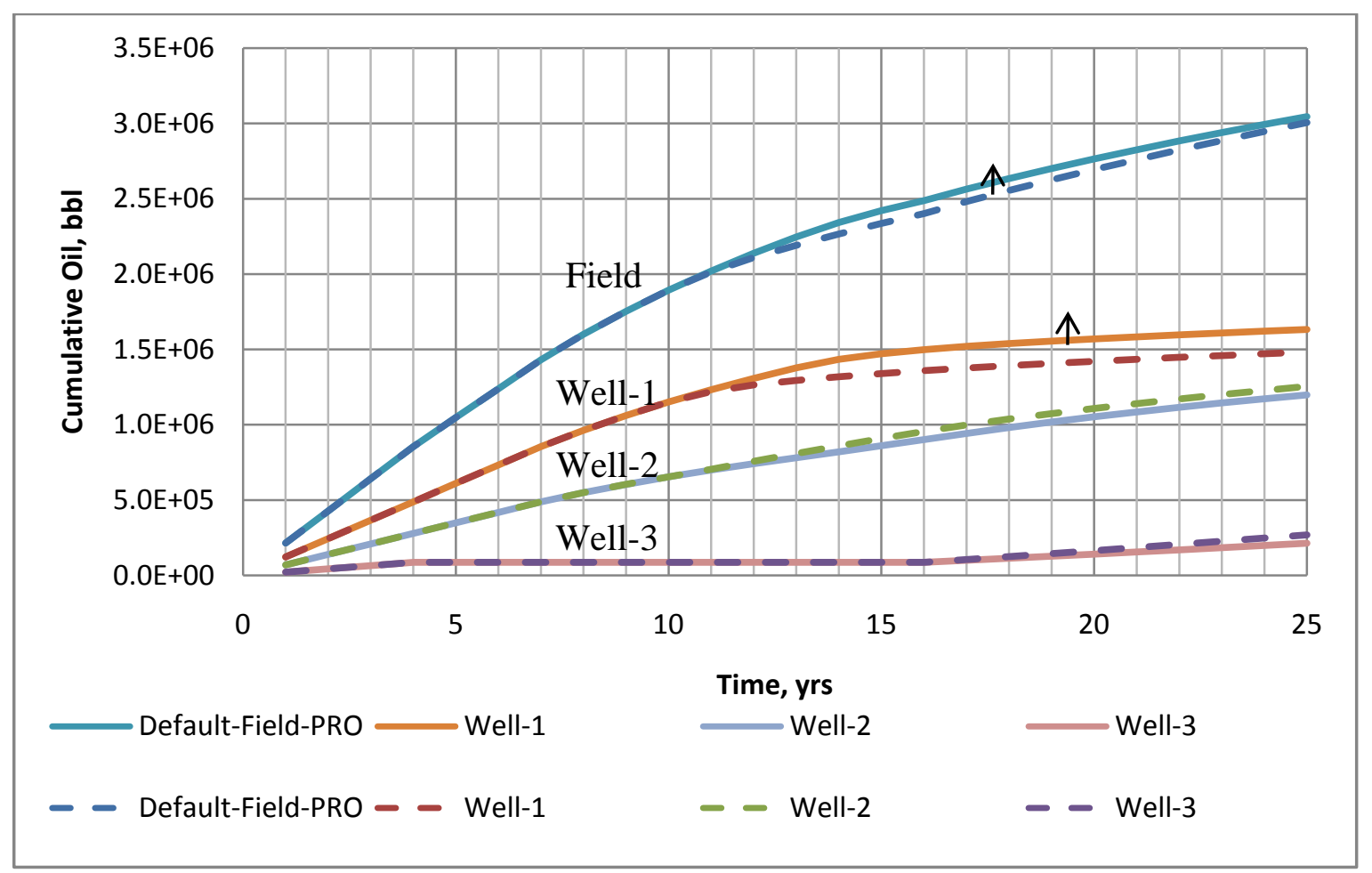

Figure 4-35 Cumulative condensate productions comparison between injection starting at year 13 (solid lines) and year 10 (dashed lines) 


\subsubsection{Location of Injection Point}

The injector well was set in the centre of the model in grid-block 2,5,1 which corresponds to where the injection well was drilled in the deep gas condensate field. Once injection was started it was seen that the nitrogen gas pushed the reservoir liquid to the outer limits of the model thus giving higher liquid saturations at Well-2 and Well-3. Two alternatives were looked at which involved moving the injector closer to Well-2 (Grid-block 2,4,1) and moving the injector closer to Well-3 (Grid-block 2,7,1). The effects of relocating the injector well are expressed using the GORs and cumulative condensate production comparison. The results for both cases are shown in Figures 4-36 to 4-39.

There was no net effect of moving the injection point closer to Well-2. The increase in condensate production from Well-1 and decrease in Well-2 production nullified any change in the total field production.

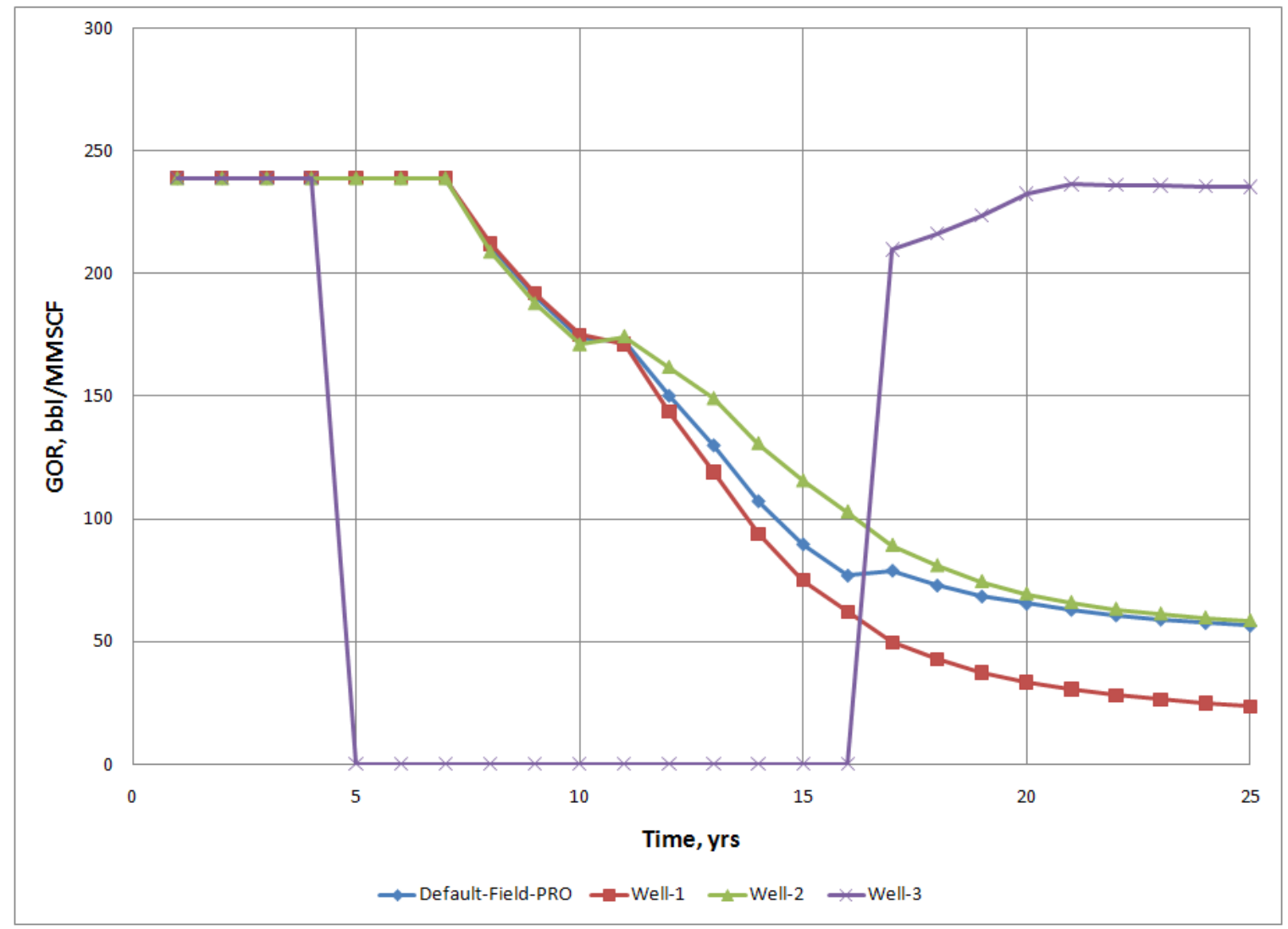

Figure 4-36 Gas-oil-ratios for injection at grid-block 2,4,1 


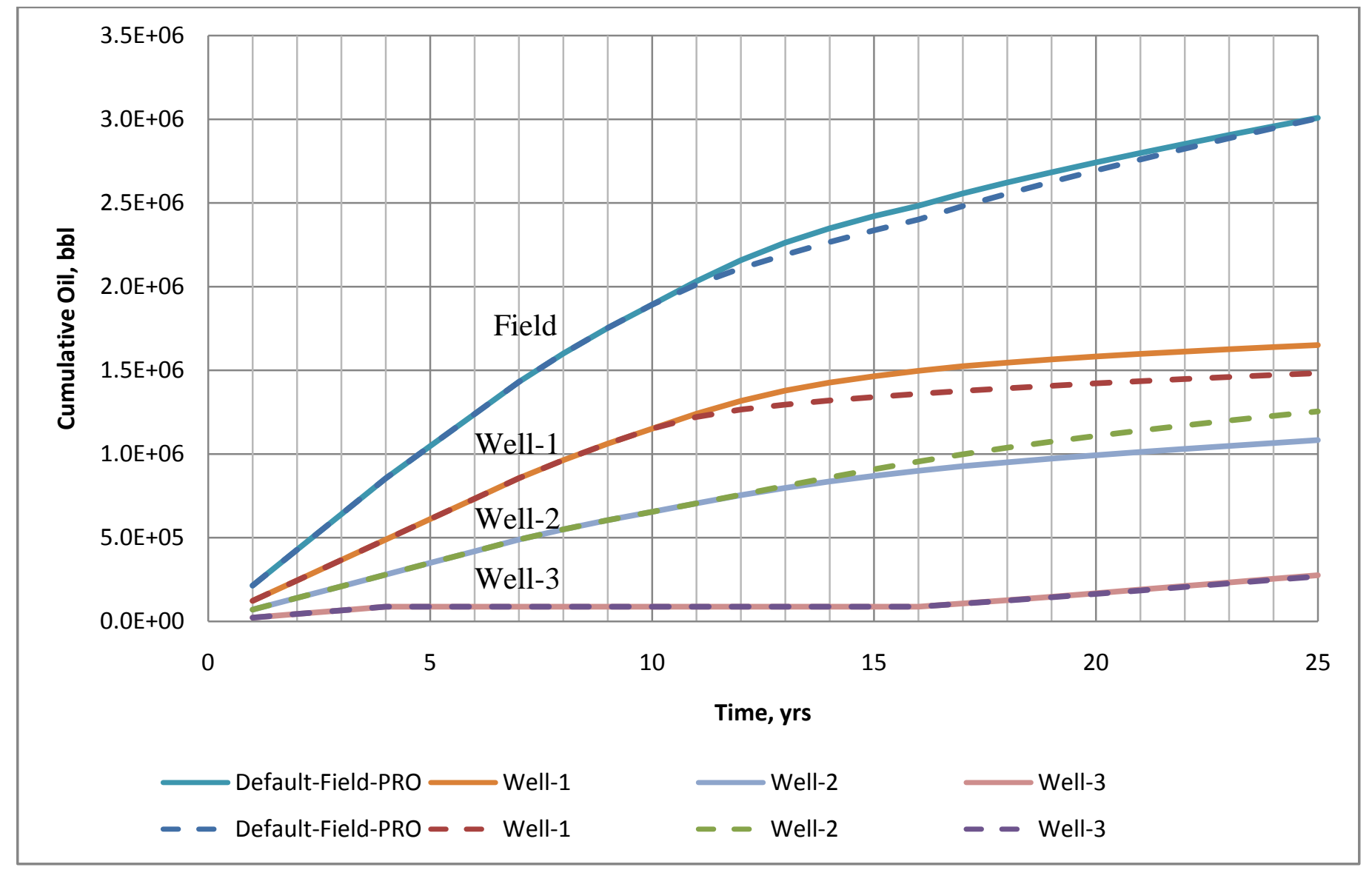

Figure 4-37 Cumulative condensate productions comparison between injection at grid-block 2,4,1 (solid lines) and grid-block 2,5,1 (dashed lines) 


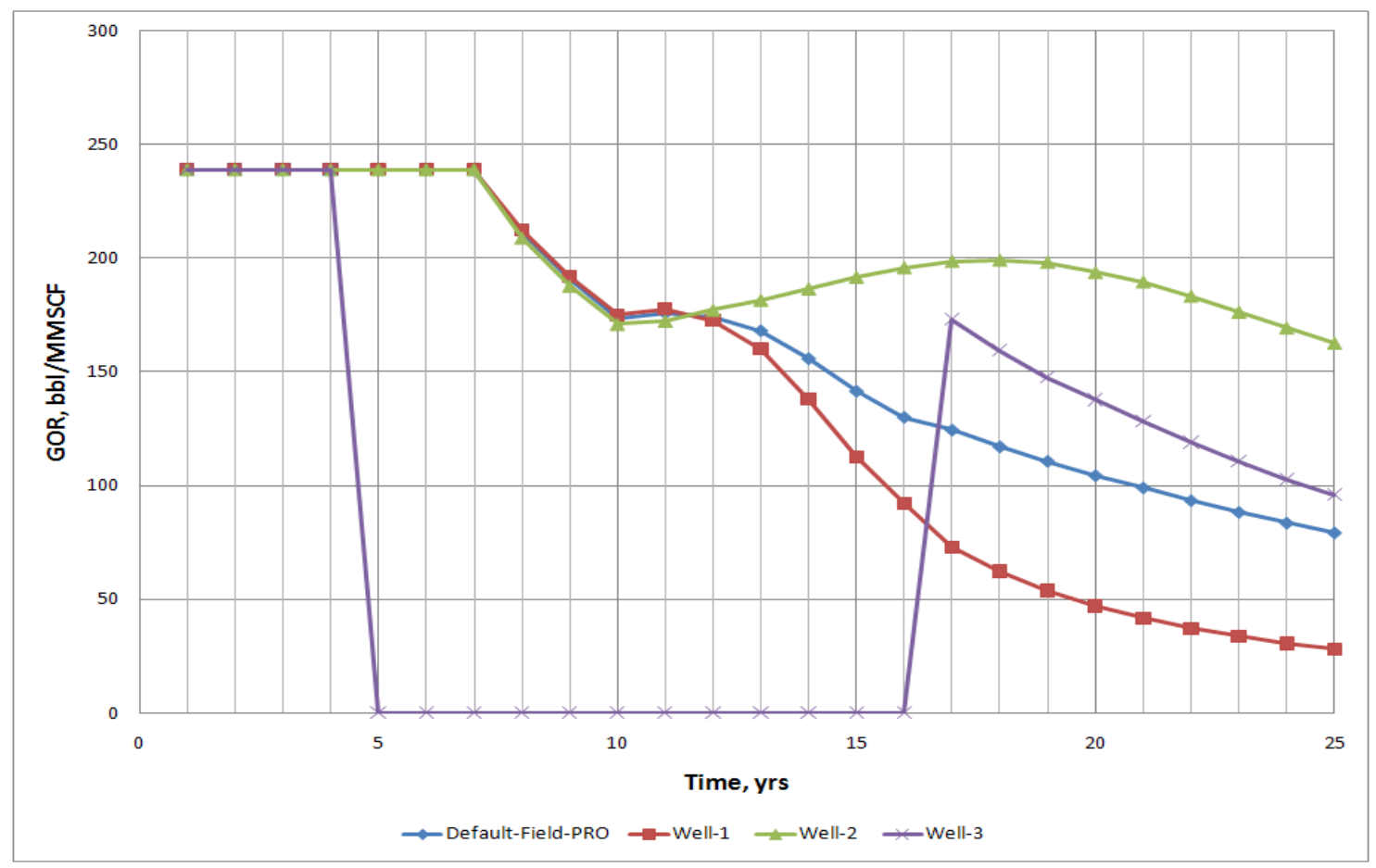

Figure 4-38 Gas-oil-ratios for injection at grid-block 2,7,1

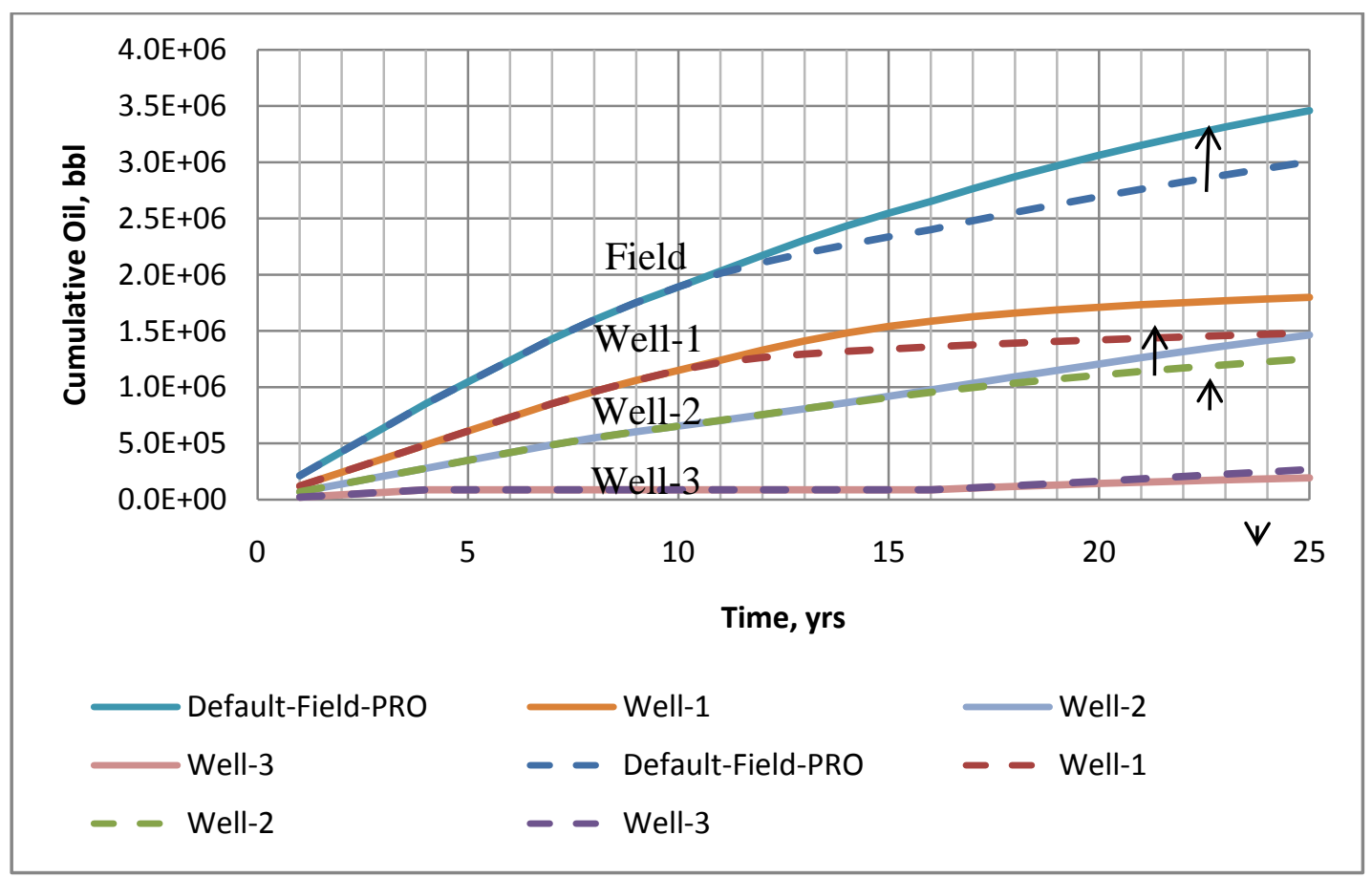

Figure 4-39 Cumulative condensate productions comparison between injection at gridblock 2,7,1 (solid lines) and grid-block 2,5,1 (dashed lines) 
Moving the injection well away from Well-1 and Well-2 had a positive effect on the total production of condensate from the reservoir as seen in Figure 4-39. Further investigation was done on the injection well location, trying various grid-blocks (shown in Figure 440) and noting the total condensate cumulative production. Table 4-1 shows a summary of the result.

Table 4-2 Cumulative condensate productions for different locations of injection well,

Well-4

\begin{tabular}{|c|c|}
\hline $\begin{array}{c}\text { Injection Well Grid } \\
\text { Location }\end{array}$ & $\begin{array}{c}\text { Total Condensate Production } \\
\text { (MMbbl) }\end{array}$ \\
\hline $1,8,1$ & 3.49 \\
\hline $2,3,1$ & 3.03 \\
\hline $2,4,1$ & 3.01 \\
\hline $2,5,1$ (original location) & 3.01 \\
\hline $2,7,1$ & 3.46 \\
\hline $2,8,1$ & 3.67 \\
\hline $3,5,1$ & 3.38 \\
\hline $3,8,1$ & 3.96 \\
\hline $3,9,1$ & 405 \\
\hline
\end{tabular}

The best production was obtained when Well-4 was placed in grid-block 3,9,1. The GORs and cumulative condensate productions are shown in Figures 4-41 and 4-42. It is seen that the placement of the injection point this close to Well-3 (grid-block 2,9,1) basically stops the production of condensate once Well-3 was re-opened. However the distance created between the two (2) higher producers, Wells 1 and 2, and the injection point significantly increases the amount of production from each of these wells. 


\begin{tabular}{|c|c|c|}
\hline & $\begin{array}{c}\text { Well } 2 \\
0\end{array}$ & \\
\hline & $\begin{array}{c}\Delta \\
2,3,1\end{array}$ & \\
\hline & $\begin{array}{c}\Delta \\
2,4,1\end{array}$ & \\
\hline $\begin{array}{c}\text { Well } 1 \\
0\end{array}$ & $\begin{array}{c}\text { Well } 4 \\
\Delta\end{array}$ & $3,5,1$ \\
\hline & $\begin{array}{c}\Delta \\
2,7,1\end{array}$ & \\
\hline $\begin{array}{c}\Delta \\
1,5,1\end{array}$ & $\begin{array}{c}\Delta \\
2,8,1\end{array}$ & $\begin{array}{c}\Delta \\
3,8,1\end{array}$ \\
\hline & $\begin{array}{c}\text { Well } 3 \\
\mathrm{O}\end{array}$ & $\begin{array}{c}\Delta \\
3,9,1\end{array}$ \\
\hline
\end{tabular}

Figure 4-40 Location of investigated injection points 


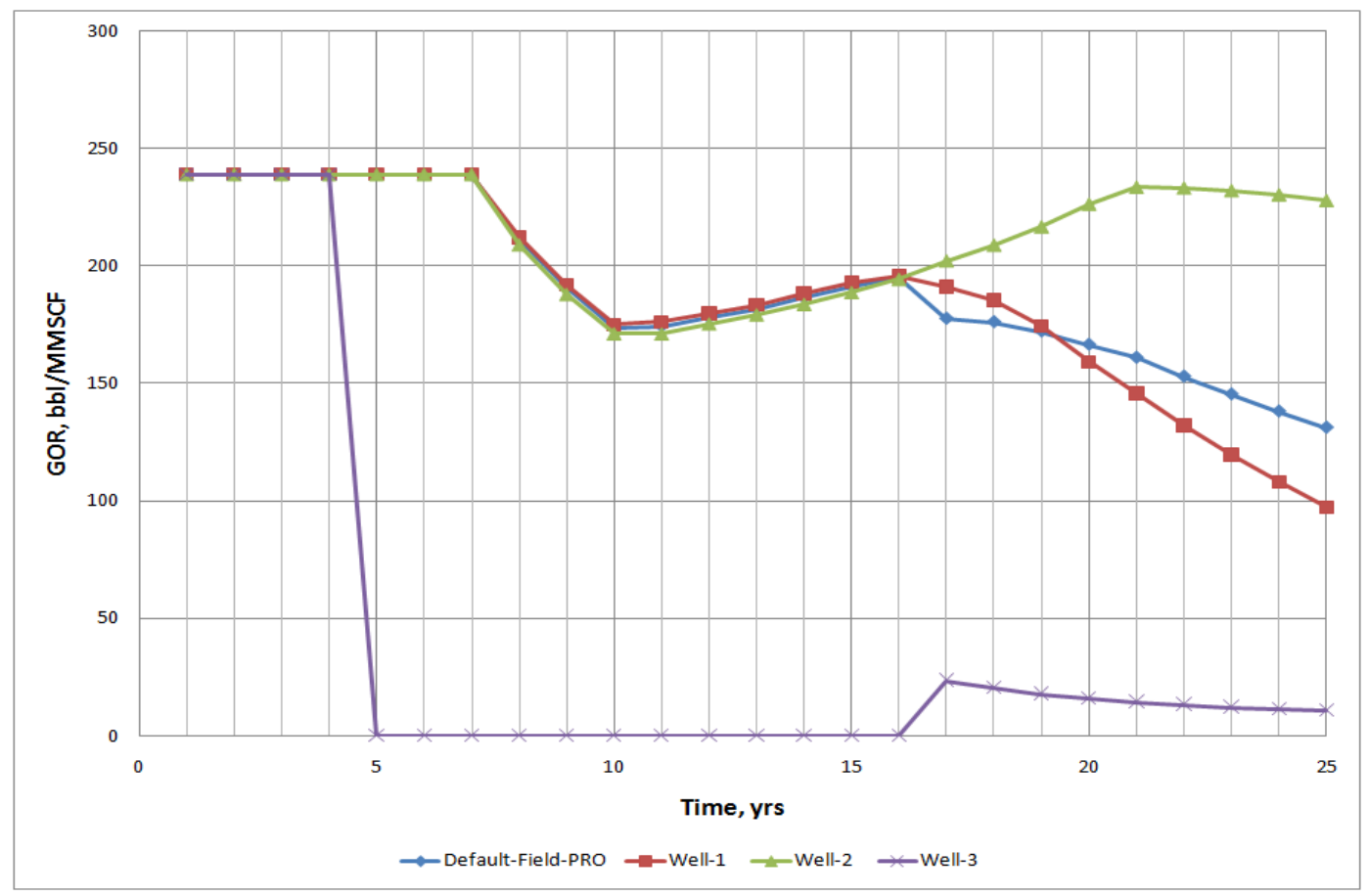

Figure 4-41 Gas-oil-ratios for injection at grid-block 3,9,1

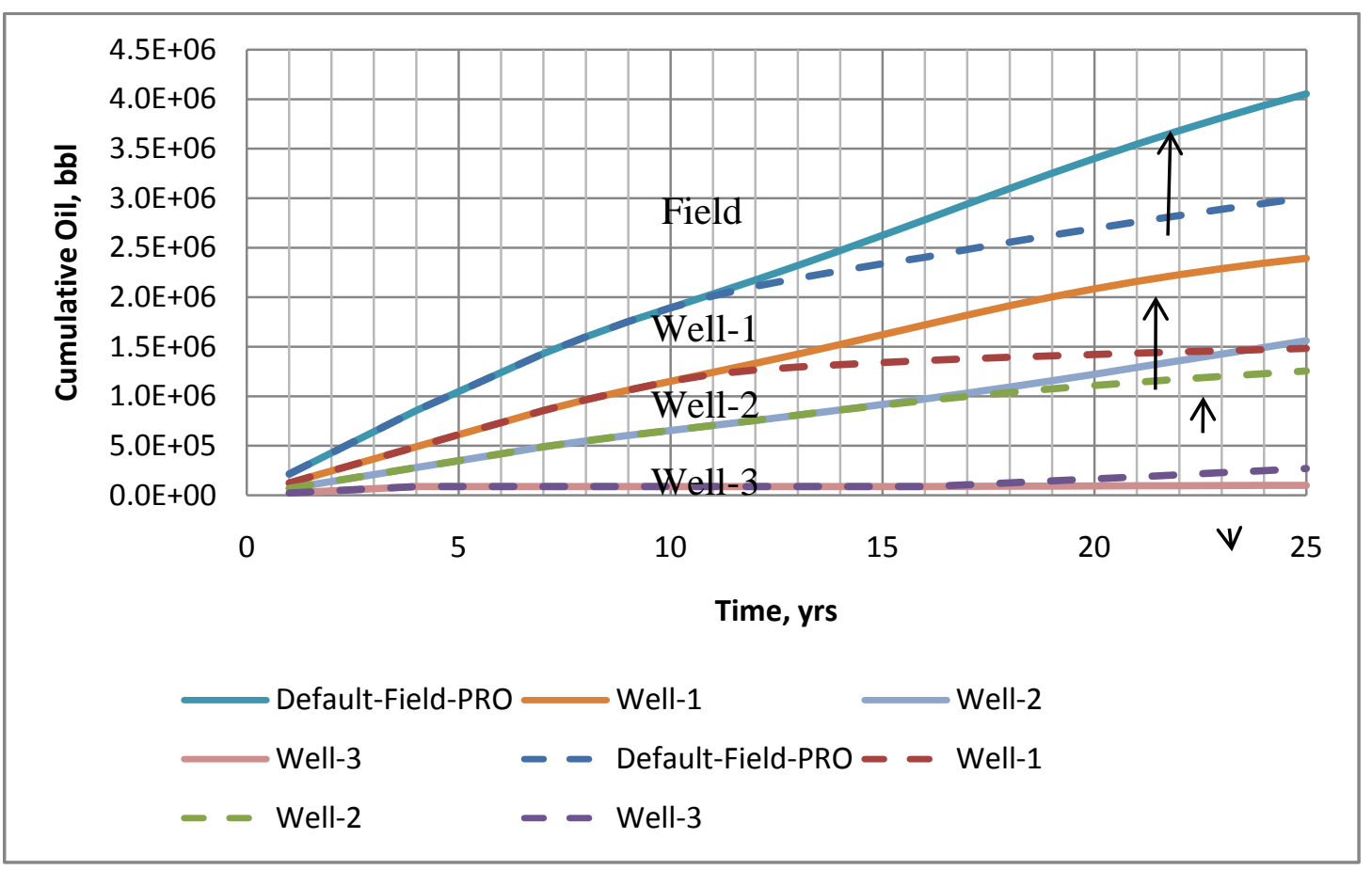

Figure 4-42 Cumulative condensate productions comparison between injection at gridblock 3,9,1 (solid lines) and grid-block 2,5,1 (dashed lines) 


\subsubsection{Additional Producer}

In an effort to improve condensate recovery an additional production well (Well-5) was added to the model in grid-block 2,7,1 (Figure 4-43). The well was assumed to produce 1 MMSCFD and was allowed to produce for the 25 year period.

Producing the field from the four (4) producers and with no nitrogen being injected, the total condensate produced was 3.72 $\mathrm{MMbbl}$ as compared to 3.58 $\mathrm{MMbbl}$ when nitrogen was injected. In this case as well, nitrogen injected does not aide the condensate yield.

A second trial was done with Well-5 moved further away from the injection point (gridblock 2,8,1 - Figure 4-44).

At this location condensate produced was $3.72 \mathrm{MMbbl}$, which is equal to the amount produced when Well-5 was located at grid-block 2,7,1. This shows that an additional production well would be beneficial if placed away from the point of nitrogen injection.

The use of Well-3 as an additional producer was also investigated. Well-3, which was the well furthest away from the nitrogen injection point and was initially set to produce 0.25 MMSCFD, was increased to 1 MMSCFD and was kept open throughout the twenty-five (25) year production period. In this case the condensate recovery increased to 3.69 MMbbl. Well-3 had the highest condensate production for the field as shown in Figure 445. 


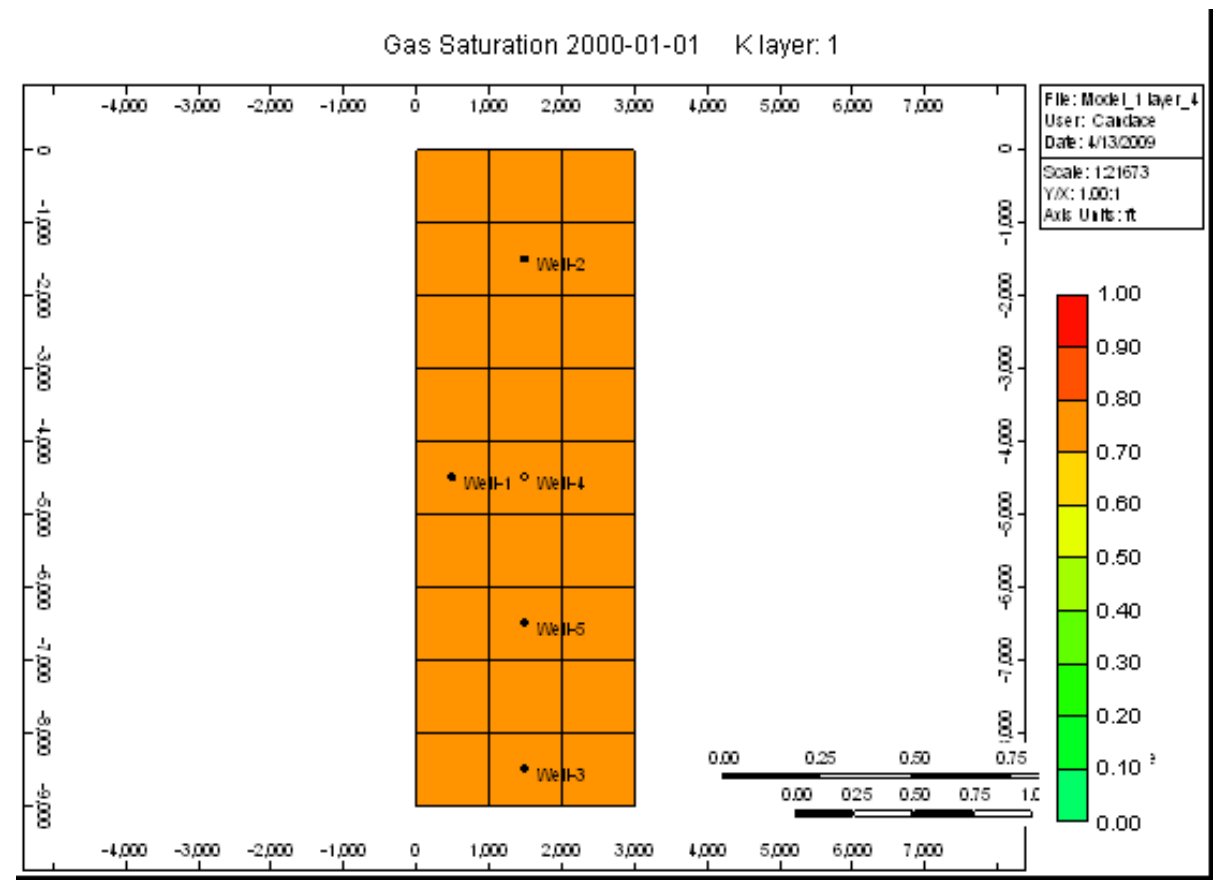

Figure 4-43 Location of additional production well, Well-5

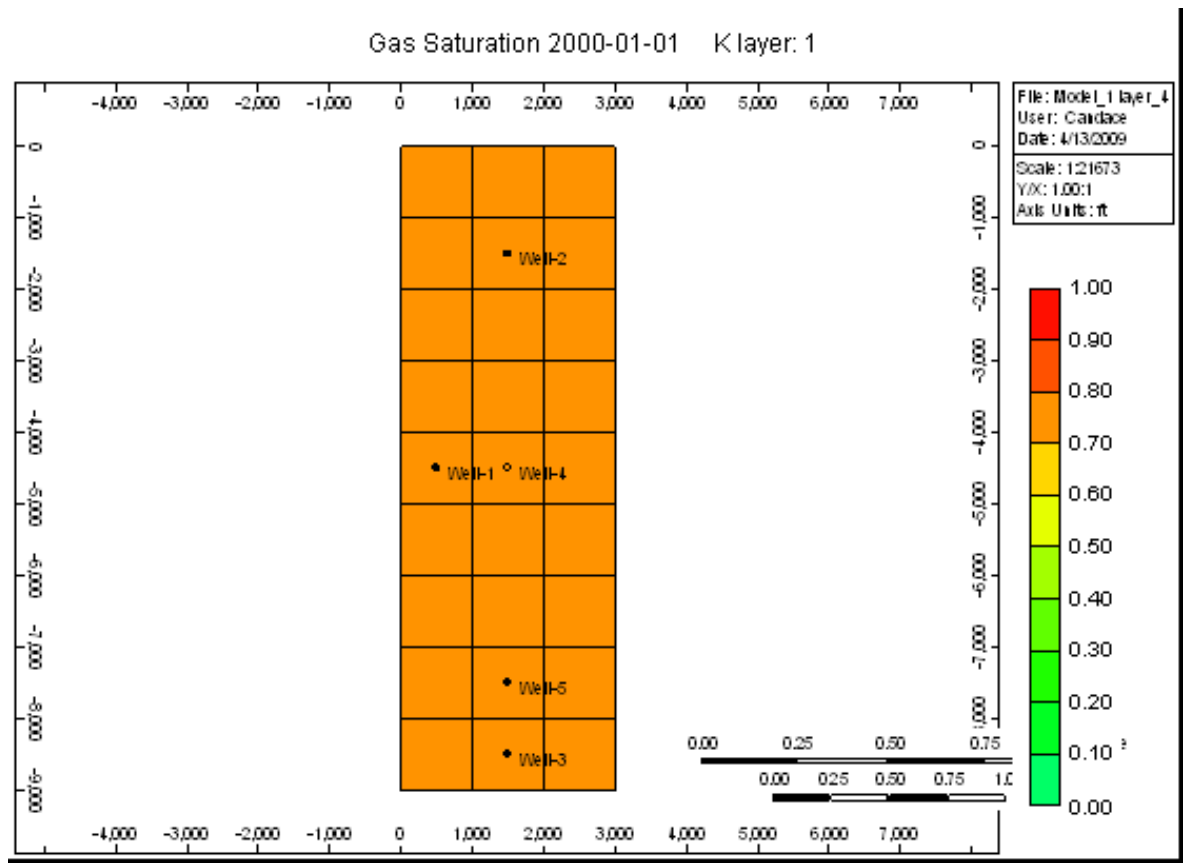

Figure 4-44 Alternate location of additional production well, Well-5 


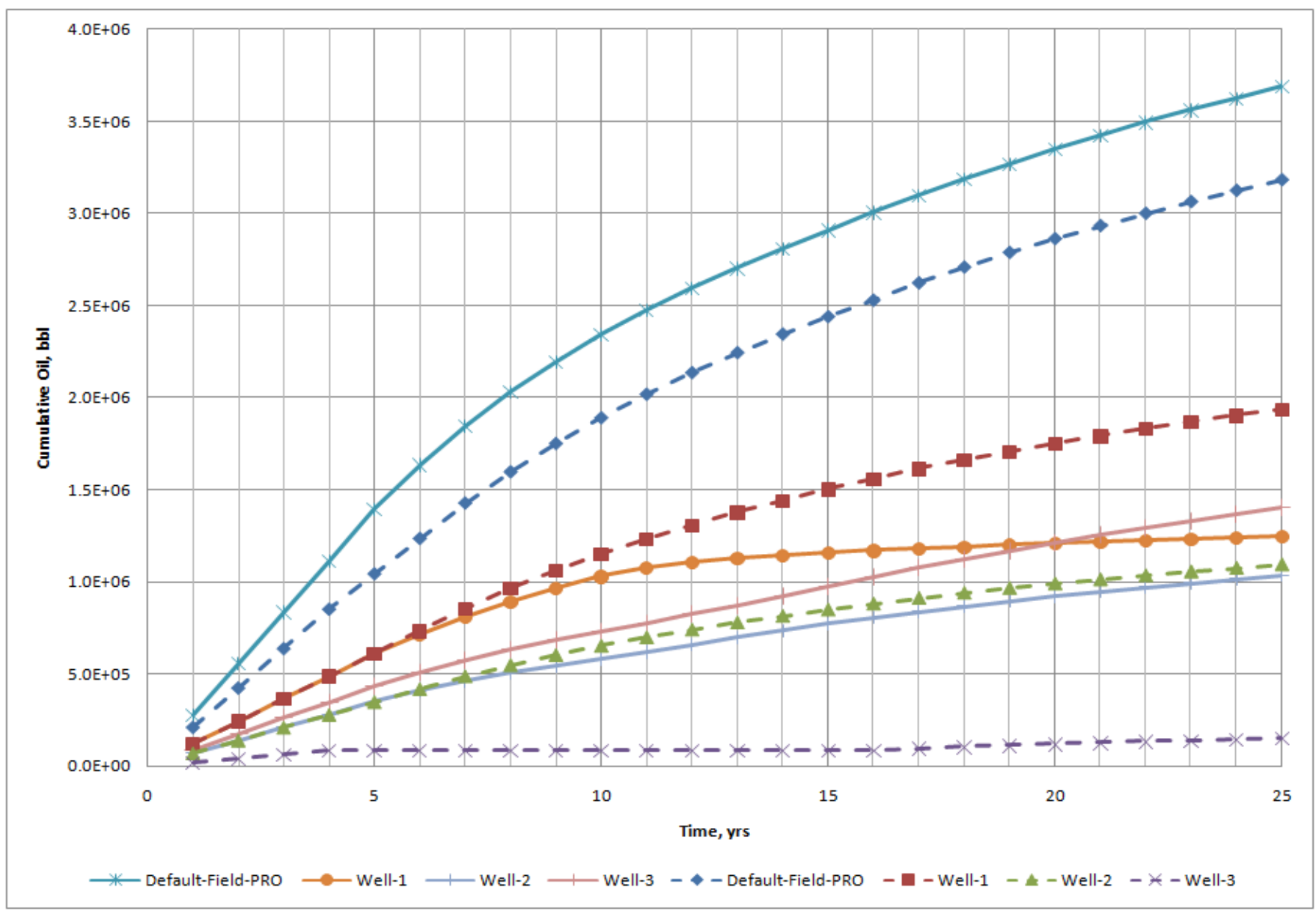

Figure 4-45 Cumulative surface condensate production for field under nitrogen injection where Well-3 surface gas rate was increased to 1 MMSCFD (solid lines) compared to pressure depletion with Well-3 as a low producer (dashed line) 


\subsection{Summary}

The results of the study show that nitrogen injection can enhance the condensate recovery from the reservoir by having the production take place away from the injection point, i.e., away from the mixing of the nitrogen and reservoir fluid where the dew point pressure is higher leading to subsequent more liquid drop-out in the reservoir. The affect of mixing was also seen when it was found that nitrogen injection into the original well pattern reduced the condensate recovery and the reduction was more significant the longer nitrogen was injected. Thus the production was adversely affected by the mixing of the two (2) fluids with the original well pattern.

Well-1 showed a large decline in condensate recovery which lead to a decline in overall field recovery. Well-1 was the nearest production well to the injection point and thus would have experienced the full mixing effects of nitrogen injection as it was in the region of highest liquid drop-out (and largest spike in dew point pressure). When Well-3 surface gas rate was increased to 1 MMSCFD and the well was allowed to stay open for the twenty-five (25) years, it showed the largest increase in condensate recovery. This supports the findings that the addition of another production well and the location relative to the injection point can enhance condensate recovery. Applying these conditions give the advantage of having nitrogen injection elevate the reservoir pressure but at a distance away not to be adversely affected by the liquid drop-out caused by the mixing of the fluids. 


\section{CONCLUSIONS AND RECOMMENDATIONS}

The main focus of this research was to develop a model to determine the positive and negative effects that injection of nitrogen has on the production from gas condensate reservoir. Based on the results, the following conclusions and recommendations were made.

1. When nitrogen comes into contact with reservoir fluid the dew point is elevated at the point of contact. However due to the uneven mixing within the reservoir resulting from well placement, the effect of nitrogen on the dew point is not uniform.

2. With respect to a reservoir modeled from the deep, high pressure gas condensate field, nitrogen injection causes a reduction in the total condensate recovery.

3. For the original reservoir model, injecting nitrogen earlier on in the production time period further reduces the recovery of condensate.

4. Definition of the reservoir model as a two-layer grid does not affect the simulation's production output, however it allows a more detailed look into the gas and oil saturation changes throughout the reservoir not just on the $\mathrm{x}$ and $\mathrm{y}$ plane but on the vertical plane as well.

5. The effectiveness of a nitrogen injection plan is dependent on the location of the injection well to the production wells. The larger the distance between the producer and injector, i.e., the further away from the nitrogen/reservoir fluid displacement front, the greater the condensate recovery.

6. The addition of another production well can increase the recovery of condensate; however the extent of the increase depends on the location of the well to the injection point. 
The model was designed to be a homogeneous reservoir, with each grid-block having similar properties. It is recommended that nitrogen injection be applied to reservoir models with varying heterogeneity to determine whether this changes the impact of nitrogen injection.

It is also recommended that an aquifer be associated with the reservoir model to determine how this would change the impact of nitrogen injection. 


\section{REFERENCES}

1. Bourblaux B. J., "Parametric Study of Gas-Condensate Reservoir Behavior During Depletion: A Guide for development Planning”, paper SPE 28848 presented at the European petroleum Conference, London, U.K., 25-27 October 1994.

2. Calvin J. W. and Vogel J. L., “An Evaluation of Nitrogen Injection as a Method of Increasing Gas Cap Reserves and Accelerating Depletion - Ryckman Creek Field, Uinta County, Wyoming” paper SPE 8384 presented at the $54^{\text {th }}$ SPE Annual Fall Technical Conference and Exhibition, Las Vegas, Nevada, 23-26 September 1979.

3. Clark T. J., “The Application of a 2-D Compositional, Radial Model to Predict Single-Well Performance in a Rich Gas Condensate Reservoir”, paper SPE 14413 presented at the $60^{\text {th }}$ Annual Technical Conference and Exhibition, Las Vegas, Nevada, 22-25 September, 1985.

4. Donohoe C. W. and Buchanan Jr. R. D., "Economic Evaluation of Cycling GasCondensate Reservoirs with Nitrogen”, Journal of Petroleum Technology, February 1981.

5. Elsharkawy A. M., "Characterization of the Plus Fraction and Prediction of the Dew point Pressure for Gas Condensate Reservoirs”, paper SPE 68776 presented at the 2001 SPE Western Regional Meeting, Bakersfield, California, 26-30 March 2001.

6. Farley R. W., Weinaug C. F. and Wolfe J.F., "Predicting Depletion Behavior of Condensate”, paper SPE 2273 presented at 43 ${ }^{\text {rd }}$ Annual Fall Meeting, Houston, Texas, 29 Spet-2 Oct 1969.

7. Firoozabadl A., "Reservoir-Fluid Phase Behavior and Volumetric Prediction with Equations of State”, SPE Distinguished Author Series, Journal of Petroleum Technology, April 1988. 
8. Hagoort J., Brinkhorst J. W. and Van der Kleyn P. H., "Development of an Offshore Gas-Condensate Reservoir by nitrogen Injection vs. Pressure Depletion”, Journal of Petroleum Technology, April 1988.

9. Hamoud A.A. and Al-Marhoun M.A., “A New Correlation for Gas-condensate Dew point Pressure Prediction”, paper SPE 68230 presented at the 2001 SPE Middle East Oil Show, Bahrain, 17-20 March 2001.

10. Ikoku C. U., "Natural Gas Rerservoir Engineering”, Krieger Publishing Company, Malabar, Florida, 1992, pp 53-94.

11. Katz D. L., Herzog R. A. and Hakim Y., "Predicting Yield of Revaporized Condensate in Gas Storage”, paper SPE 10166 presented at the $56^{\text {th }}$ Annual Fall Technical Conference and Exhibition, San Antonio, Texas, 5-7 October 1981.

12. Lino U. R. A, "Compositional and Phase Behavior Experimental and Theoretical Work on Hydrocarbon Mixtures and Several Solvents (Carbon Dioxide, Nitrogen and Flue Gases)”, paper SPE 59343 presented at the 2000 SPE/DOE Improved Oil Recovery Symposium, Tulsa, Oklahoma, 3-5 April 2000.

13. Marruffo I., Maita J., Him H. and Rojas G., "Statistical Forecast Models to Determine Retrograde Dew Pressure and C7= percentage of Gas Condensate on Basis of Production Test Data of Eastern Venezuelan Reservoirs”, paper SPE 69393 presented at the SPE Latin American and Caribbean Petroleum Engineering Conference, Buenos Aires, Argentina, 25-28 March 2001.

14. Niemstschik G. E. and Poettmann F. H., "Correlation for Determining Gas Condensate Composition”, paper SPE 26183 presented at the SPE Gas Technology Symposium, Calgary, Alberta, Canada, 28-30 June 1993.

15. Ovalie A. P., Lenn C. P. and McCain Jr. W. D., "Tools to Manage Gas/Condensate Reservoirs: Novel Fluid-Property Correlations Based on Commonly Available Field Data”, paper IPTC 10320 presented at the International petroleum Technology Conference, Doha, Qatar, 21-23 November 2005. 
16. Palasthy G. and Kristof P., "Alternatices of Gas Injection as an Enhanced Recovery Method in Advanced Gas Market Environment”, paper SPE 75203 presented at the SPE/DOE Improved Oil Recovery Symposium, Tulsa, Oklahoma, 13-17 April 2002.

17. Rayes D. G., Plper L. D., McCain Jr. W. D. and Poston S. W., "Two-Phase Compressibility Factors for Retrograde Gases”, SPE Formation Evaluation, March 1992.

18. Ring J. N., Heffner T. A., Elliott M. W. and Zack J. G., "Improving Reservoir performance of the Painter Reservoir Unit, paper SPE 55635 presented at the 1999 SPE Rocky Mountain Regional Meeting, Gillette, Wyoming, 15-18 May 1999.

19. Siregar S., Hagoort J. and Ronde H., "Nitrogen Injection vs. Gas Cycling in Rich Retrograde Condensate-Gas Reservoirs” paper SPE 22360 presented at the SPE International Meeting on petroleum Engineering, Beijing, China, 24-27 March 1992.

20. Zeidouni M., Movazi G. H. and Pourghasem B., "Performance Prediction of a Rich Gas/Condensate Reservoir Through Material Balance and PVT Behaviour: A Case Study”, paper SPE 99830 presented at the 2006 SPE Gas Technology Symposium, Calgary, Alberta, Canada, 15-17 May 2006. 


\section{APPENDIX}

\section{APPENDIX A - Laboratory data}

\begin{tabular}{|c|c|c|c|c|c|c|c|c|}
\hline & & & Reser & oir Fluid $C$ & mposition & & & \\
\hline & & Basis of & combination & $18,573 \mathrm{scf}$ & p gas / bbls & condensate & & \\
\hline & $\begin{array}{l}\text { Component } \\
\text { (S,modi Name) }\end{array}$ & $\begin{array}{c}\text { Separator } \\
\text { Gas } \\
\text { (moless; }\end{array}$ & $\begin{array}{l}\text { Soparator } \\
\text { Liquid } \\
\text { imolo } \% \text { (w) }\end{array}$ & $\begin{array}{c}\text { Soparator } \\
\text { Liquid } \\
\text { (woght :5) }\end{array}$ & $\begin{array}{c}\text { Molecular } \\
\text { Woight }\end{array}$ & $\begin{array}{c}\text { Spocific } \\
\text { Gravity } \\
\text { waver }=1.0\}\end{array}$ & $\begin{array}{c}\text { Ressorvoir } \\
\text { Fluild } \\
\text { (moles } \$ \text { ) }\end{array}$ & $\begin{array}{l}\text { Rosorvoir } \\
\text { Fluid } \\
\text { (whegrt } \mathrm{N} \text { ) }\end{array}$ \\
\hline$N$ & Nrogen & 64611 & 4296 & 1.227 & 2801 & 0.809 & 61667 & 58.149 \\
\hline$\infty$ & Carten Clande & 0.124 & 0.057 & 0026 & 4409 & 0.818 & 0.121 & 0179 \\
\hline $\mathrm{H}: \mathrm{S}$ & Hyorogen Sulfide & 0.000 & 0000 & 0.000 & 000 & 0000 & 0.000 & 0000 \\
\hline c) & Methane & 25488 & 5,797 & $0.9 \times 9$ & 1604 & 0.196 & 24527 & 19.244 \\
\hline $\mathrm{C} 2$ & Erane & 5.247 & 5.623 & 1.724 & 3007 & 0.380 & 5265 & 5.329 \\
\hline $\mathrm{Ca}^{2}$ & Propene & 2721 & 8003 & 3625 & 44.10 & 0.507 & 2.383 & 4427 \\
\hline CA & i-Butane & 0.581 & 3586 & 2126 & 58.12 & 0563 & 0.728 & 1.424 \\
\hline $\mathrm{nC}_{4}$ & n. Butane & 0649 & 5535 & 3281 & so 12 & 0.524 & 0887 & 1,736 \\
\hline $\mathrm{cs}$ & i-Pentane & 0.197 & 3602 & 2659 & 72.15 & 0624 & 0.363 & 0882 \\
\hline nCs & n.Pentane & $0.14 \mathrm{~B}$ & 3.180 & 2340 & 72.15 & oes1 & 0.294 & $0: 114$ \\
\hline$C 6$ & Hexanes & 0.104 & 5979. & $s 255$ & 5618 & oeet & 0.391 & 1,39 \\
\hline $\mathrm{Ct}$ & Heptanes & 0076 & 16080 & 10. 183 & 9311 & 0716 & 0.594 & +.863 \\
\hline $\mathrm{ce}$ & Octanes & 0044 & $14265 !$ & 15.374 & 10535 & 0.743 & 0739 & 2.621 \\
\hline $\mathrm{cs}$ & Noranes & 0.007 & 7 mas: & 9783 & 120.03 & 0.764 & 0.397 & 1603 \\
\hline C10 & Decanes & 0.005 & 5161 & 7005 & 134.53 & ores & 0.257 & 1.182 \\
\hline C11 & Undecanes & & 3335 & 5,000 & 14700 & orro & 0163 & 0.806 \\
\hline $\mathrm{C}_{12}$ & Dodecanes & & 2345 & 3851 & 16100 & 0789 & 0.114 & 0.620 \\
\hline $\mathrm{C}_{13}$ & Teidecanes & & 2230 & 3940 & 17500 & 0800 & 0.109 & 0,641 \\
\hline $\mathrm{C}_{14}$ & Tetradecanes & & 1584 & 3204 & 19000 & 0811 & 0.082 & 0.526 \\
\hline Cis & Pentadecones & & 1387 & 2014 & 20600 & 0.821 & 0000 & 0.469 \\
\hline $\mathrm{C}_{16}$ & Hexadecanes & & 096 & 2142 & 222.00 & 0.828 & 0.046 & 0345 \\
\hline c17 & Heptasecanes & & 0.773 & 1950 & 297.00 & 0835 & 0.008 & 0.301 \\
\hline C18 & Octasecanes & & 0603 & . 775 & 25100 & osel & 0.034 & 0.236 \\
\hline C19 & Nondecanes & & 0.512 & 1373 & 203.00 & 0.46 & 0.025 & 0.221 \\
\hline $\mathrm{cos}$ & Eicosanes & & 0.376 & ioss & 275.00 & 0.551 & 0.018 & 0170 \\
\hline$c_{21}$ & Hensicosanes & & 0.307 & 0911 & 281.00 & 0856 & 0.015 & 0.147 \\
\hline $\mathrm{C} 22$ & Docosanes & & 0243 & 0.755 & 30500 & 0851 & 0.012 & 0.122 \\
\hline$C_{23}$ & Trcosanes & & 0.202 & 0.656 & 31800 & 0.856 & 0010 & 0.100 \\
\hline $\mathrm{CO}_{24}$ & Tetracosares & & 0.164 & 0553 & 331,00 & 0870 & 0.008 & 0030 \\
\hline c.25 & Pentacesanes & & 0157 & 0.552 & 34500 & 0.873 & 0.058 & 0039 \\
\hline cos & Hexacosanes & & 0.116 & 0.423 & 35000 & 0.877 & 0005 & 0.088 \\
\hline $\mathrm{C}_{27}$ & Mequocesanes & & 0.096 & 0.367 & 374.00 & 0.821 & 0,005 & 0059 \\
\hline $\mathrm{C} 28$ & Octoccsanes & & 0.080 & 0.316 & 58600 & 0.824 & 0.004 & 0081 \\
\hline $\mathrm{c29}$ & Nanacosanes & & 0.063 & 0257 & 40200 & 0.887 & 0.003 & 0041 \\
\hline $030+$ & Thcomienes Phe & & 0416 & 2374 & 56022 & 0.922 & 0.020 & 0382 \\
\hline Total & & 100.000 & 100000 & 100600 & & & 100000 & 100000 \\
\hline Mabccul & os Werght & 2521 & 9805 & & & & 2971 & \\
\hline $\begin{array}{ll}7 \mathrm{sen} \\
\Rightarrow \mathrm{con}\end{array}$ & $\begin{array}{l}\text { following page for } L \\
\text { Tossitons grouging }\end{array}$ & $\begin{array}{l}\text { Araysis param } \\
\text { don nombet to }\end{array}$ & $\begin{array}{l}\text { is, separatbor ga } \\
\text { omal carton dist }\end{array}$ & $\begin{array}{l}\text { ropertes, } n \\
\text { usen. }\end{array}$ & wher. & & & \\
\hline & Compositional & pings of Res: & voir Fluld & & & & & \\
\hline & Group & Mole \% & Woight \% & $\mathrm{MW}$ & SG & $T_{8}$ & & \\
\hline & Total Flued & 100000 & 100000 & 29.71 & & $N / \mathrm{h}$ & & \\
\hline & c7. & 2774 & 12789 & 13697 & 0776 & 790 & & \\
\hline & $c 10$. & 1044 & 6702 & 19076 & 0.813 & 947 & & \\
\hline & $\mathrm{c} 20^{\circ}$ & 0106 & 1.324 & 363.24 & 0 os & 1273 & & \\
\hline & c 35. & 0020 & 0.382 & 56022 & $0 \$ 222$ & 1497 & & \\
\hline & & & & & & "Tb dor Commeten & & \\
\hline
\end{tabular}

Figure A-1 Reservoir fluid composition based on separator fluids recombination 


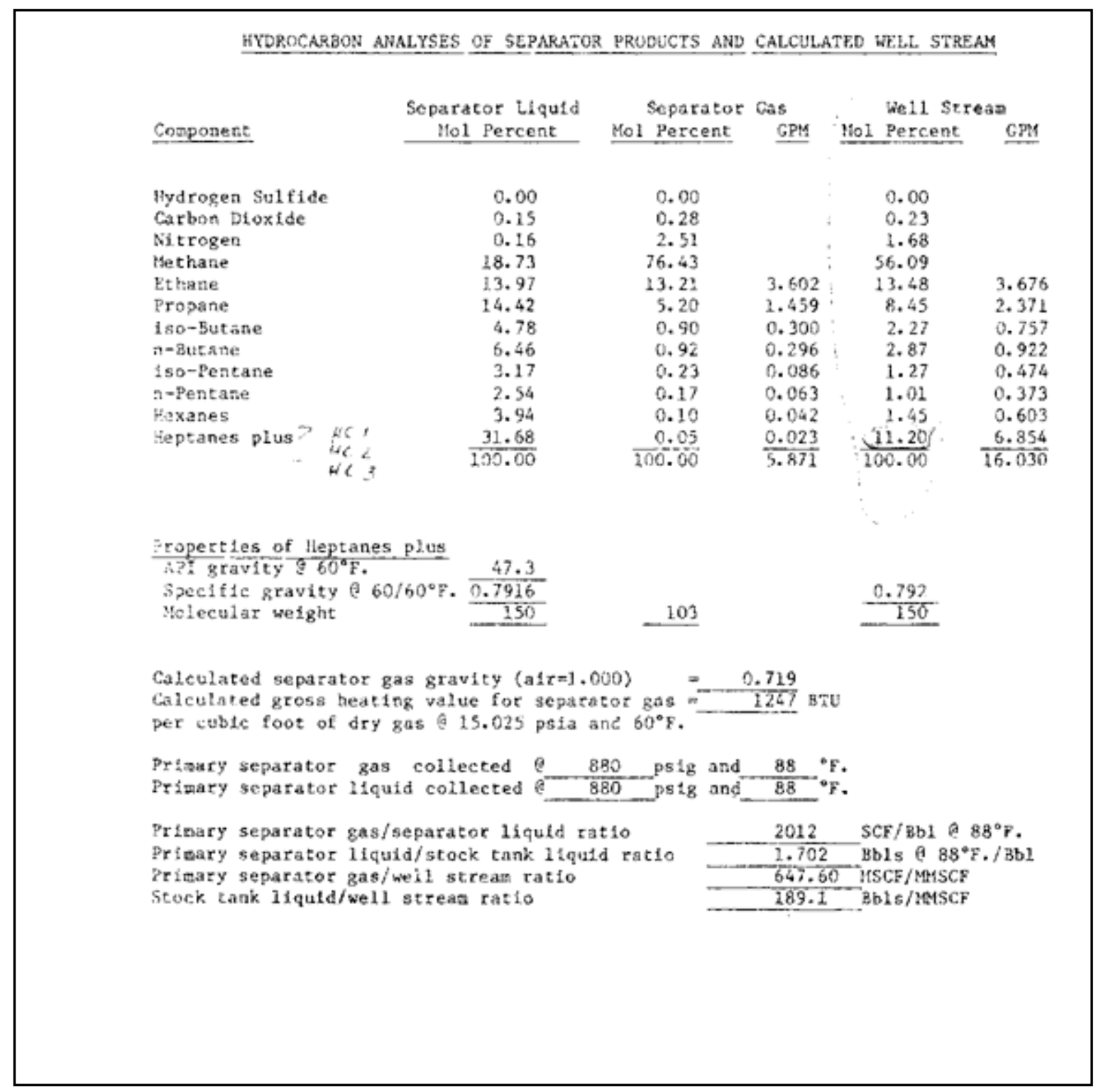

Figure A-2 Hydrocarbon analysis of separator products and calculated well stream 


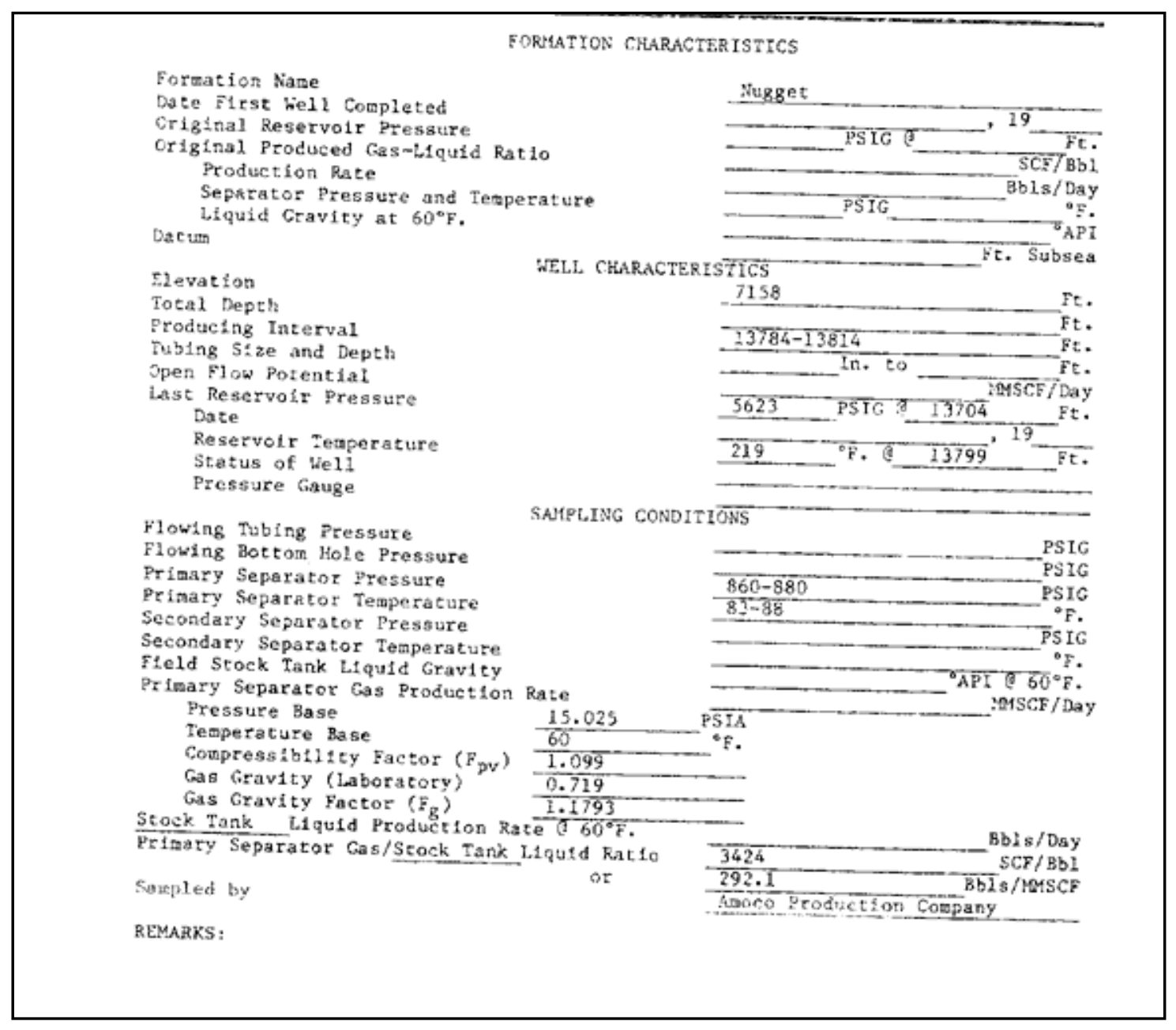

Figure A-3 Well Data 


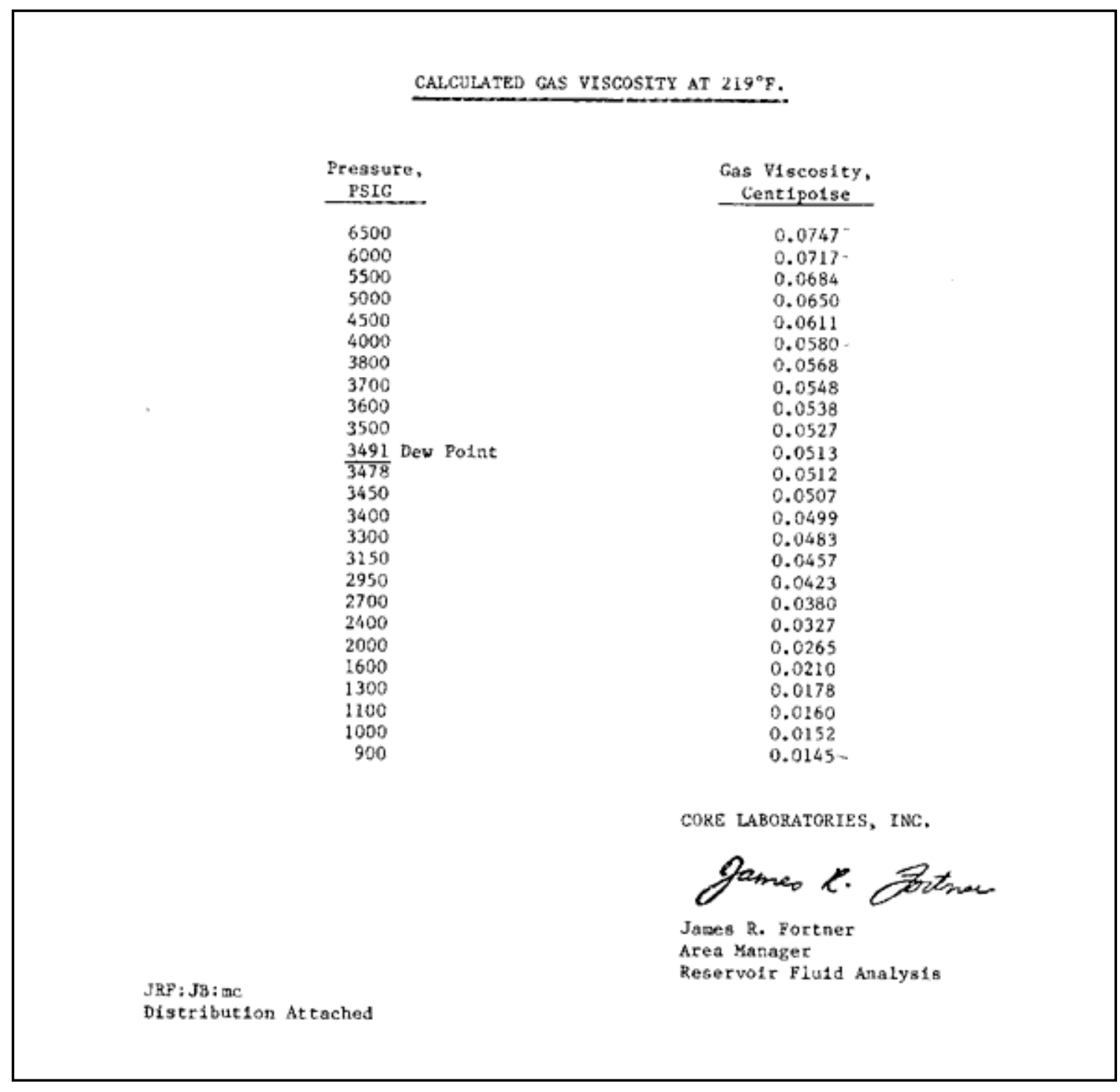

Figure A-4 Calculated gas viscosity at $219^{\circ} \mathrm{F}$ 


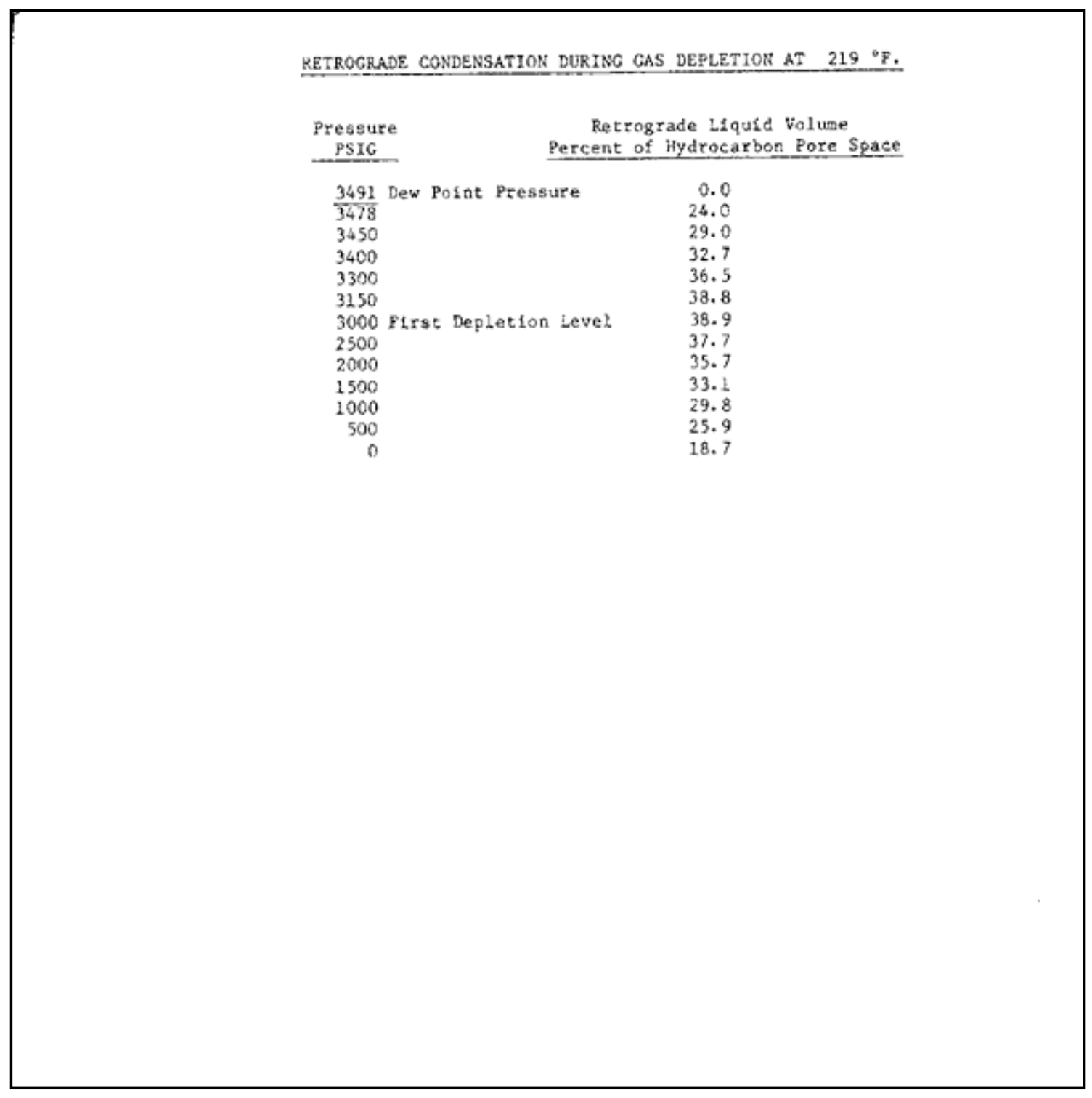

Figure A-5 Retrograde condensation during gas depletion at $219^{\circ} \mathrm{F}$ 


\section{APPENDIX B - Gas Cap Composition}

Table B-1 Gas cap composition

\begin{tabular}{|c|c|}
\hline Component & Composition \\
\hline & $\%$ \\
\hline N2 & 1.68 \\
\hline CO2 & 0.23 \\
\hline C1 & 56.0906 \\
\hline C2 & 13.4804 \\
\hline C3 & 8.4503 \\
\hline IC4 & 2.2701 \\
\hline NC4 & 2.8701 \\
\hline IC5 & 1.27 \\
\hline NC5 & 1.01 \\
\hline NC6 & 1.45 \\
\hline NC7 & 2.4001 \\
\hline NC8 & 2.9841 \\
\hline NC9 & 1.602 \\
\hline NC10 & 1.036 \\
\hline FC11 & 0.657 \\
\hline FC12 & 0.462 \\
\hline FC13 & 0.439 \\
\hline FC14 & 0.332 \\
\hline FC15 & 0.273 \\
\hline NC16 & 0.186 \\
\hline FC17 & 0.152 \\
\hline FC18 & 0.137 \\
\hline FC19 & 0.101 \\
\hline C20toC30 & 0.437 \\
\hline
\end{tabular}




\section{APPENDIX C - Comparison of saturations of single layer and two-layer model average}

Oil and gas saturations $\left(\mathrm{S}_{\mathrm{o}}\right.$ and $\left.\mathrm{S}_{\mathrm{g}}\right)$ for single layer and two-layer models with production under pressure depletion are used to illustrate the insignificant difference between saturation values. All saturation values are given as fractions.

Table C-1 Average gas and oil saturations of top and bottom layer

\begin{tabular}{|c|c|c|c|c|c|c|c|c|}
\hline TIME & Well-1 & Well-1 & Well-4 & Well-4 & Well-2 & Well-2 & Well-3 & Well-3 \\
\hline & $\mathrm{S}_{\mathrm{g}}: 1,5,1$ & $\mathrm{~S}_{0}: 1,5,1$ & $S_{g}: 2,5,1$ & $\mathrm{~S}_{0}: 2,5,1$ & $S_{g}: 2,2,1$ & $\mathrm{~S}_{\mathrm{o}}: 2,2,1$ & $\mathrm{~S}_{\mathrm{g}}: 2,9,1$ & $S_{0}: 2,9,1$ \\
\hline (year) & $1,5,2$ & $1,5,2$ & $2,5,2$ & $2,5,2$ & $2,2,2$ & $2,2,2$ & $2,9,2$ & $2,9,2$ \\
\hline 0 & 0.76 & 0 & 0.76 & 0 & 0.76 & 0 & 0.76 & 0 \\
\hline 1 & 0.759423 & 0 & 0.759441 & 0 & 0.759433 & 0 & 0.759458 & 0 \\
\hline 2 & 0.758895 & 0 & 0.758913 & 0 & 0.758905 & 0 & 0.75893 & 0 \\
\hline 3 & 0.758423 & 0 & 0.758441 & 0 & 0.758434 & 0 & 0.758458 & 0 \\
\hline 4 & 0.757984 & 0 & 0.758001 & 0 & 0.757994 & 0 & 0.758017 & 0 \\
\hline 5 & 0.757629 & 0 & 0.757646 & 0 & 0.757635 & 0 & 0.757671 & 0 \\
\hline 6 & 0.757274 & 0 & 0.757291 & 0 & 0.757281 & 0 & 0.757316 & 0 \\
\hline 7 & 0.756955 & 0 & 0.756971 & 0 & 0.756961 & 0 & 0.756996 & 0 \\
\hline 8 & 0.298509 & 0.458243 & 0.353744 & 0.403023 & 0.314751 & 0.442007 & 0.335822 & 0.420969 \\
\hline 9 & 0.337157 & 0.419426 & 0.379624 & 0.376975 & 0.350172 & 0.406417 & 0.373332 & 0.383292 \\
\hline 10 & 0.344939 & 0.411469 & 0.423295 & 0.333128 & 0.356358 & 0.400055 & 0.392202 & 0.364245 \\
\hline 11 & 0.358447 & 0.397806 & 0.42517 & 0.331098 & 0.364791 & 0.391468 & 0.404423 & 0.351869 \\
\hline 12 & 0.375414 & 0.380694 & 0.426554 & 0.329568 & 0.37701 & 0.379103 & 0.414353 & 0.341791 \\
\hline 13 & 0.386044 & 0.369923 & 0.431036 & 0.324946 & 0.385273 & 0.3707 & 0.422513 & 0.333489 \\
\hline 14 & 0.399245 & 0.356589 & 0.435367 & 0.320481 & 0.395895 & 0.359945 & 0.430126 & 0.325743 \\
\hline 15 & 0.408247 & 0.347458 & 0.440422 & 0.315295 & 0.404088 & 0.351622 & 0.436854 & 0.318884 \\
\hline 16 & 0.41629 & 0.33929 & 0.445057 & 0.310536 & 0.413814 & 0.34177 & 0.443415 & 0.312197 \\
\hline 17 & 0.426726 & 0.328718 & 0.451792 & 0.303665 & 0.423776 & 0.331676 & 0.450117 & 0.305352 \\
\hline 18 & 0.435338 & 0.319975 & 0.457729 & 0.297596 & 0.432464 & 0.322856 & 0.455776 & 0.299561 \\
\hline 19 & 0.441824 & 0.313359 & 0.463723 & 0.291473 & 0.439323 & 0.315868 & 0.460988 & 0.294219 \\
\hline
\end{tabular}




\begin{tabular}{|c|c|c|c|c|c|c|c|c|}
\hline 20 & 0.450022 & 0.305036 & 0.468857 & 0.286212 & 0.446693 & 0.308372 & 0.46648 & 0.288602 \\
\hline 21 & 0.456387 & 0.298546 & 0.474742 & 0.280204 & 0.452945 & 0.301996 & 0.471609 & 0.283348 \\
\hline 22 & 0.464029 & 0.290782 & 0.479893 & 0.27493 & 0.45999 & 0.294829 & 0.476947 & 0.277888 \\
\hline 23 & 0.470163 & 0.284528 & 0.485561 & 0.269142 & 0.466059 & 0.288638 & 0.481966 & 0.272749 \\
\hline 24 & 0.47722 & 0.277352 & 0.490594 & 0.26399 & 0.472808 & 0.281771 & 0.487142 & 0.267453 \\
\hline 25 & 0.482953 & 0.2715 & 0.496016 & 0.25845 & 0.478732 & 0.275729 & 0.492066 & 0.262411 \\
\hline
\end{tabular}

Table C-2 Single layer model gas and oil saturations

\begin{tabular}{|c|c|c|c|c|c|c|c|c|}
\hline TIME & Well-1 & Well-1 & Well-4 & Well-4 & Well-2 & Well-2 & Well-3 & Well-3 \\
\hline (year) & $\mathrm{S}_{\mathrm{g}}: 1,5,1$ & $\mathrm{~S}_{\mathrm{o}}: 1,5,1$ & $\mathrm{~S}_{\mathrm{g}}: 2,5,1$ & $\mathrm{~S}_{\mathrm{o}}: 2,5,1$ & $\mathrm{~S}_{\mathrm{g}}: 2,2,1$ & $\mathrm{~S}_{\mathrm{o}}: 2,2,1$ & $\mathrm{~S}_{\mathrm{g}}: 2,9,1$ & $\mathrm{~S}_{\mathrm{o}}: 2,9,1$ \\
\hline 0 & 0.76 & 0 & 0.76 & 0 & 0.76 & 0 & 0.76 & 0 \\
\hline 1 & 0.759423 & 0 & 0.759441 & 0 & 0.759433 & 0 & 0.759458 & 0 \\
\hline 2 & 0.758894 & 0 & 0.758913 & 0 & 0.758905 & 0 & 0.75893 & 0 \\
\hline 3 & 0.758423 & 0 & 0.758441 & 0 & 0.758433 & 0 & 0.758457 & 0 \\
\hline 4 & 0.757984 & 0 & 0.758001 & 0 & 0.757994 & 0 & 0.758017 & 0 \\
\hline 5 & 0.757629 & 0 & 0.757645 & 0 & 0.757635 & 0 & 0.757671 & 0 \\
\hline 6 & 0.757274 & 0 & 0.75729 & 0 & 0.75728 & 0 & 0.757316 & 0 \\
\hline 7 & 0.756955 & 0 & 0.756971 & 0 & 0.756961 & 0 & 0.756996 & 0 \\
\hline 8 & 0.305657 & 0.451094 & 0.354169 & 0.402598 & 0.322227 & 0.43453 & 0.343829 & 0.412962 \\
\hline 9 & 0.329174 & 0.427398 & 0.380163 & 0.376428 & 0.345316 & 0.411264 & 0.372062 & 0.384558 \\
\hline 10 & 0.347853 & 0.408559 & 0.394777 & 0.361652 & 0.361312 & 0.395107 & 0.387583 & 0.368874 \\
\hline 11 & 0.363911 & 0.392349 & 0.405976 & 0.3503 & 0.374351 & 0.381916 & 0.399205 & 0.357097 \\
\hline 12 & 0.376462 & 0.379653 & 0.415552 & 0.340579 & 0.38497 & 0.371152 & 0.408989 & 0.347166 \\
\hline 13 & 0.386823 & 0.369154 & 0.424153 & 0.331839 & 0.394109 & 0.361874 & 0.417726 & 0.338289 \\
\hline 14 & 0.395742 & 0.360102 & 0.432026 & 0.323832 & 0.402669 & 0.35318 & 0.425703 & 0.330177 \\
\hline 15 & 0.404918 & 0.350796 & 0.439333 & 0.316395 & 0.411158 & 0.344562 & 0.433087 & 0.322663 \\
\hline 16 & 0.414237 & 0.341351 & 0.446178 & 0.309425 & 0.419536 & 0.336058 & 0.440002 & 0.315622 \\
\hline 17 & 0.427299 & 0.328155 & 0.453251 & 0.302216 & 0.430059 & 0.325402 & 0.447742 & 0.307738 \\
\hline 18 & 0.43566 & 0.319661 & 0.460047 & 0.295288 & 0.437901 & 0.317428 & 0.454137 & 0.30121 \\
\hline 19 & 0.443399 & 0.311793 & 0.466524 & 0.288682 & 0.445224 & 0.309976 & 0.460327 & 0.294891 \\
\hline
\end{tabular}




\begin{tabular}{|c|c|c|c|c|c|c|c|c|}
\hline 20 & 0.450436 & 0.30463 & 0.472727 & 0.282351 & 0.452021 & 0.303052 & 0.466322 & 0.288768 \\
\hline 21 & 0.45697 & 0.297971 & 0.478707 & 0.276246 & 0.458483 & 0.296465 & 0.472155 & 0.282811 \\
\hline 22 & 0.463413 & 0.291406 & 0.484458 & 0.270373 & 0.464777 & 0.290049 & 0.477811 & 0.277032 \\
\hline 23 & 0.469754 & 0.284943 & 0.49002 & 0.26469 & 0.470923 & 0.283781 & 0.483321 & 0.271401 \\
\hline 24 & 0.476341 & 0.278236 & 0.49539 & 0.259201 & 0.477172 & 0.277413 & 0.488702 & 0.2659 \\
\hline 25 & 0.483286 & 0.271173 & 0.500582 & 0.253889 & 0.483561 & 0.270905 & 0.493934 & 0.26055 \\
\hline
\end{tabular}


Table C-3 Numeric difference between two-layer and single layer models saturation

\begin{tabular}{|c|c|c|c|c|c|c|c|c|}
\hline TIME & Well-1 & Well-1 & Well-4 & Well-4 & Well-2 & Well-2 & Well-3 & Well-3 \\
\hline (year) & $S_{\mathrm{g}}: 1,5,1$ & $S_{0}: 1,5,1$ & $S_{\mathrm{g}}: 2,5,1$ & $S_{0}: 2,5,1$ & $\mathrm{~S}_{\mathrm{g}}: 2,2,1$ & $S_{0}: 2,2,1$ & $S_{\mathrm{g}}: 2,9,1$ & $S_{0}: 2,9,1$ \\
\hline 0 & 0.0000 & 0.0000 & 0.0000 & 0.0000 & 0.0000 & 0.0000 & 0.0000 & 0.0000 \\
\hline 1 & 0.0000 & 0.0000 & 0.0000 & 0.0000 & 0.0000 & 0.0000 & 0.0000 & 0.0000 \\
\hline 2 & 0.0000 & 0.0000 & 0.0000 & 0.0000 & 0.0000 & 0.0000 & 0.0000 & 0.0000 \\
\hline 3 & 0.0000 & 0.0000 & 0.0000 & 0.0000 & 0.0000 & 0.0000 & 0.0000 & 0.0000 \\
\hline 4 & 0.0000 & 0.0000 & 0.0000 & 0.0000 & 0.0000 & 0.0000 & 0.0000 & 0.0000 \\
\hline 5 & 0.0000 & 0.0000 & 0.0000 & 0.0000 & 0.0000 & 0.0000 & 0.0000 & 0.0000 \\
\hline 6 & 0.0000 & 0.0000 & 0.0000 & 0.0000 & 0.0000 & 0.0000 & 0.0000 & 0.0000 \\
\hline 7 & 0.0000 & 0.0000 & 0.0000 & 0.0000 & 0.0000 & 0.0000 & 0.0000 & 0.0000 \\
\hline 8 & -0.0071 & 0.0071 & -0.0004 & 0.0004 & -0.0075 & 0.0075 & -0.0080 & 0.0080 \\
\hline 9 & 0.0080 & -0.0080 & -0.0005 & 0.0005 & 0.0049 & -0.0048 & 0.0013 & -0.0013 \\
\hline 10 & -0.0029 & 0.0029 & 0.0285 & -0.0285 & -0.0050 & 0.0049 & 0.0046 & -0.0046 \\
\hline 11 & -0.0055 & 0.0055 & 0.0192 & -0.0192 & -0.0096 & 0.0096 & 0.0052 & -0.0052 \\
\hline 12 & -0.0010 & 0.0010 & 0.0110 & -0.0110 & -0.0080 & 0.0080 & 0.0054 & -0.0054 \\
\hline 13 & -0.0008 & 0.0008 & 0.0069 & -0.0069 & -0.0088 & 0.0088 & 0.0048 & -0.0048 \\
\hline 14 & 0.0035 & -0.0035 & 0.0033 & -0.0034 & $\begin{array}{l}-0.0068 \\
\end{array}$ & 0.0068 & 0.0044 & -0.0044 \\
\hline 15 & 0.0033 & -0.0033 & 0.0011 & -0.0011 & -0.0071 & 0.0071 & 0.0038 & -0.0038 \\
\hline 16 & 0.0021 & -0.0021 & -0.0011 & 0.0011 & -0.0057 & 0.0057 & 0.0034 & -0.0034 \\
\hline 17 & -0.0006 & 0.0006 & -0.0015 & 0.0014 & -0.0063 & 0.0063 & 0.0024 & -0.0024 \\
\hline 18 & -0.0003 & 0.0003 & -0.0023 & 0.0023 & -0.0054 & 0.0054 & 0.0016 & -0.0016 \\
\hline 19 & -0.0016 & 0.0016 & -0.0028 & 0.0028 & -0.0059 & 0.0059 & 0.0007 & -0.0007 \\
\hline 20 & -0.0004 & 0.0004 & -0.0039 & 0.0039 & -0.0053 & 0.0053 & 0.0002 & -0.0002 \\
\hline 21 & -0.0006 & 0.0006 & -0.0040 & 0.0040 & -0.0055 & 0.0055 & -0.0005 & 0.0005 \\
\hline 22 & 0.0006 & -0.0006 & -0.0046 & 0.0046 & -0.0048 & 0.0048 & -0.0009 & 0.0009 \\
\hline 23 & 0.0004 & -0.0004 & -0.0045 & 0.0045 & -0.0049 & 0.0049 & -0.0014 & 0.0013 \\
\hline 24 & 0.0009 & -0.0009 & -0.0048 & 0.0048 & -0.0044 & 0.0044 & -0.0016 & 0.0016 \\
\hline 25 & -0.0003 & 0.0003 & -0.0046 & 0.0046 & -0.0048 & 0.0048 & -0.0019 & 0.0019 \\
\hline
\end{tabular}




\section{APPENDIX D - PVT Output}

WinProp PVT Analysis output:

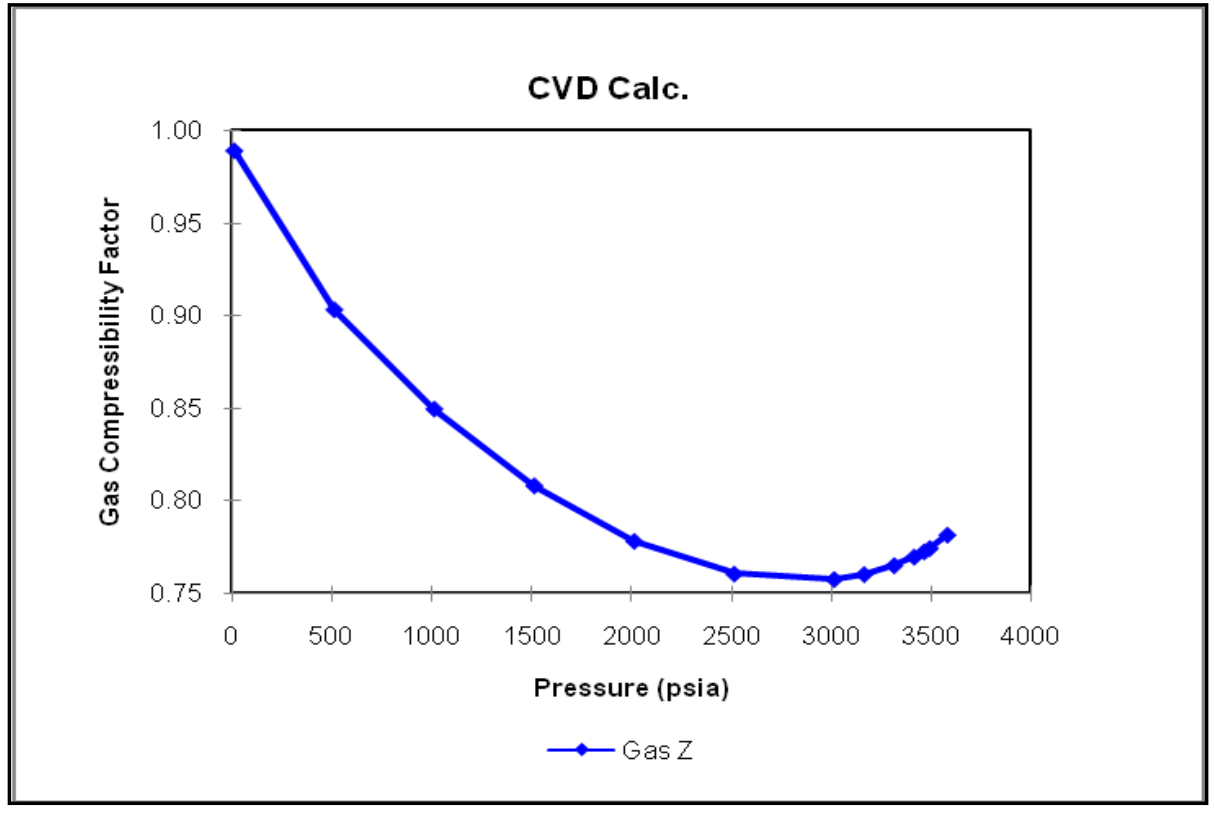

Figure D-1: WinProp CVD Simulation results for gas compressibility

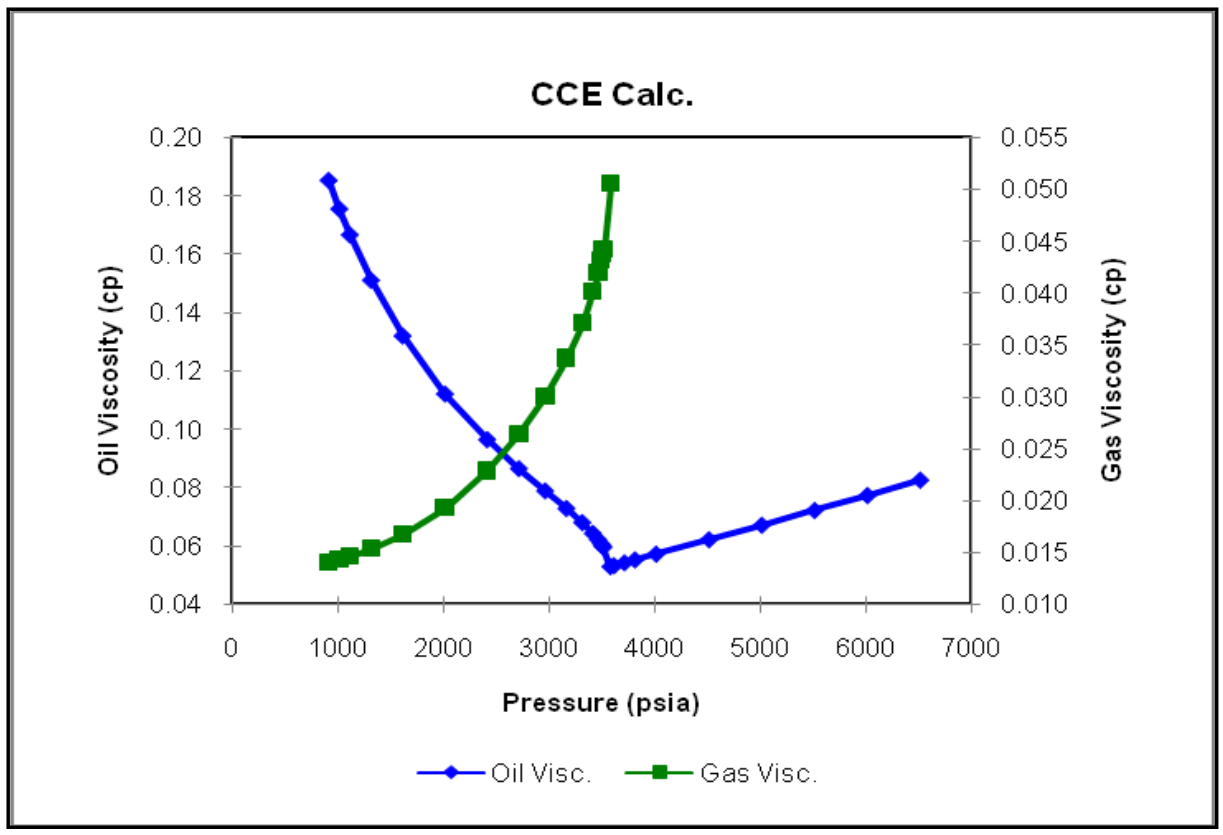

Figure D-2: WinProp CCE Simulation oil and gas viscosity predictions 


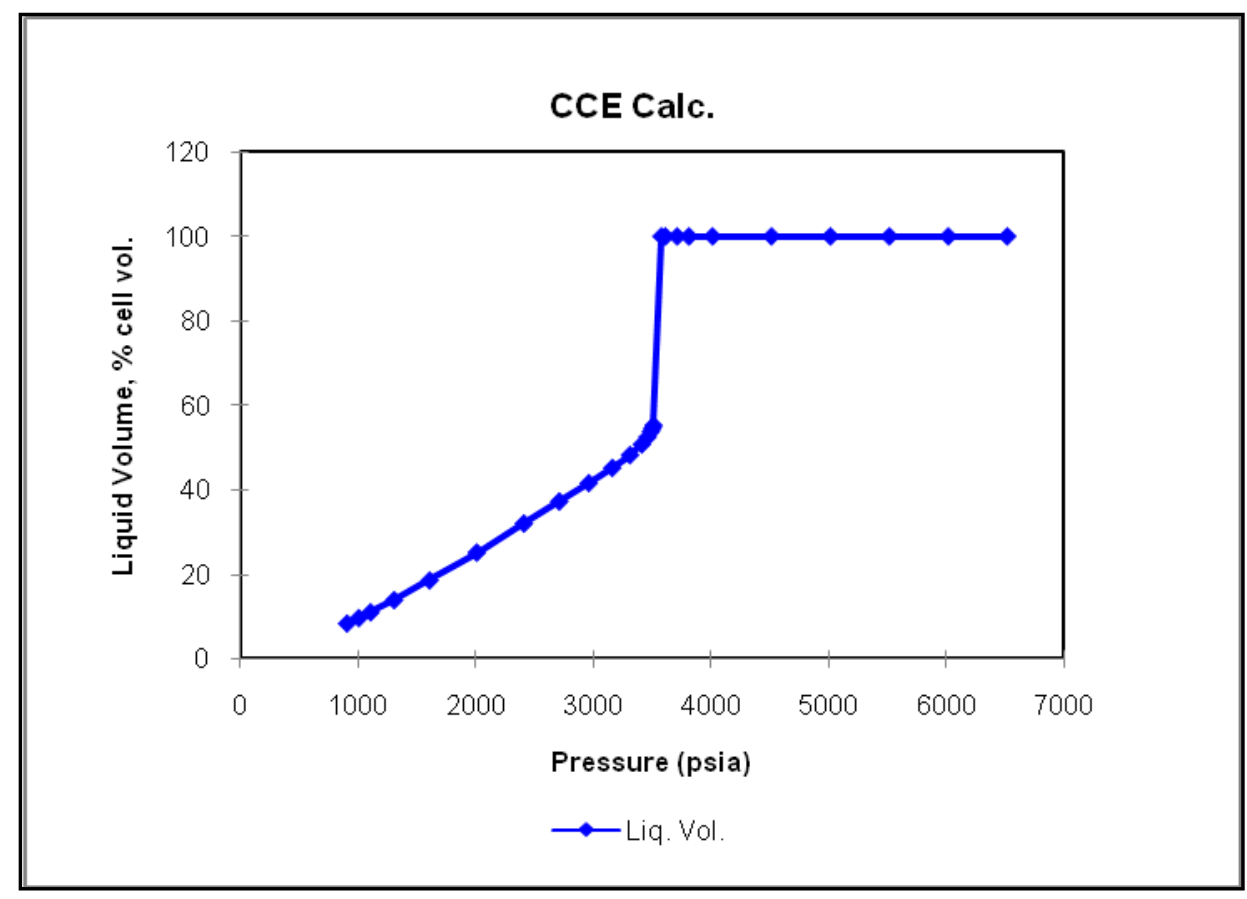

Figure D-3: WinProp CCE Simulation predictions for liquid volume percent

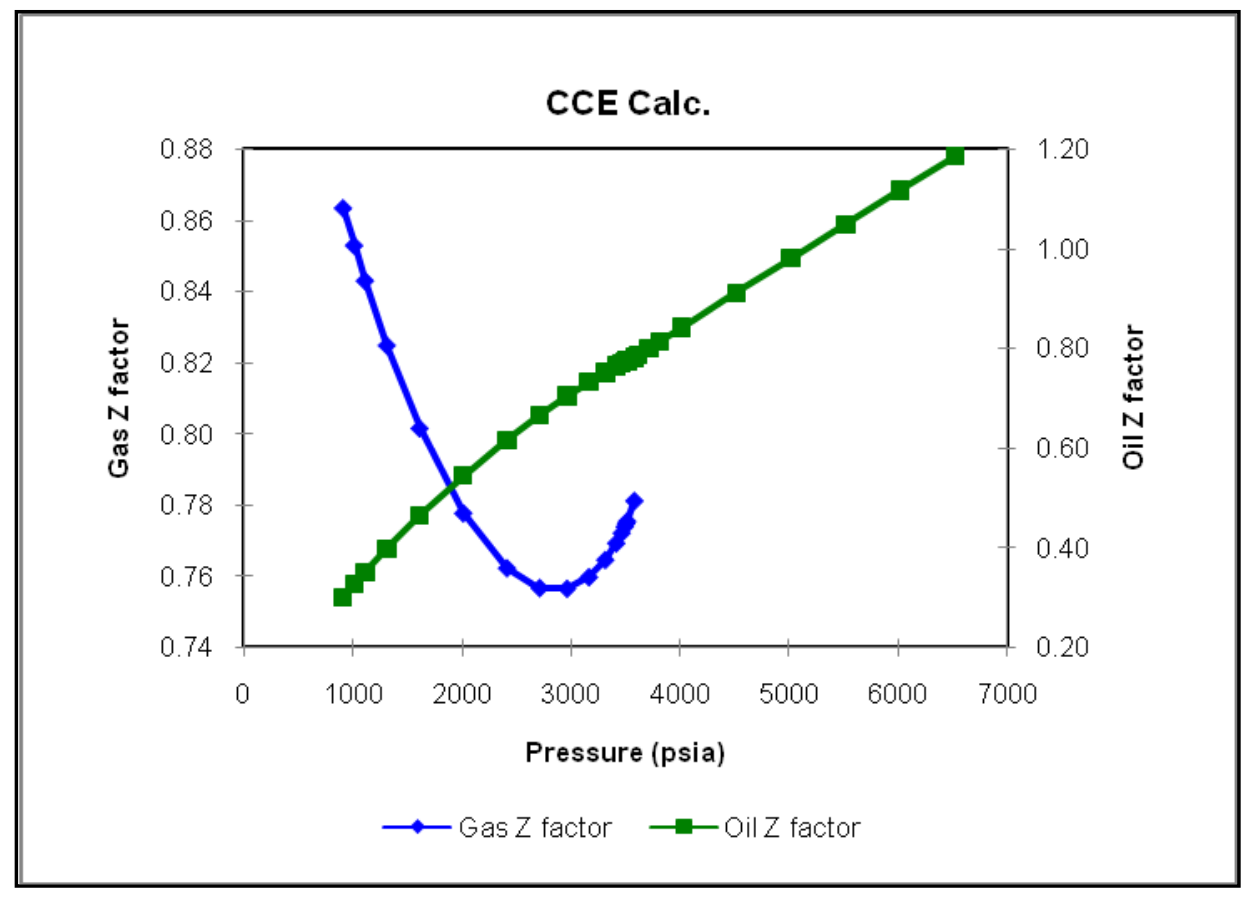

Figure D-4: WinProp CCE Simulation predictions for gas and oil z-factors 


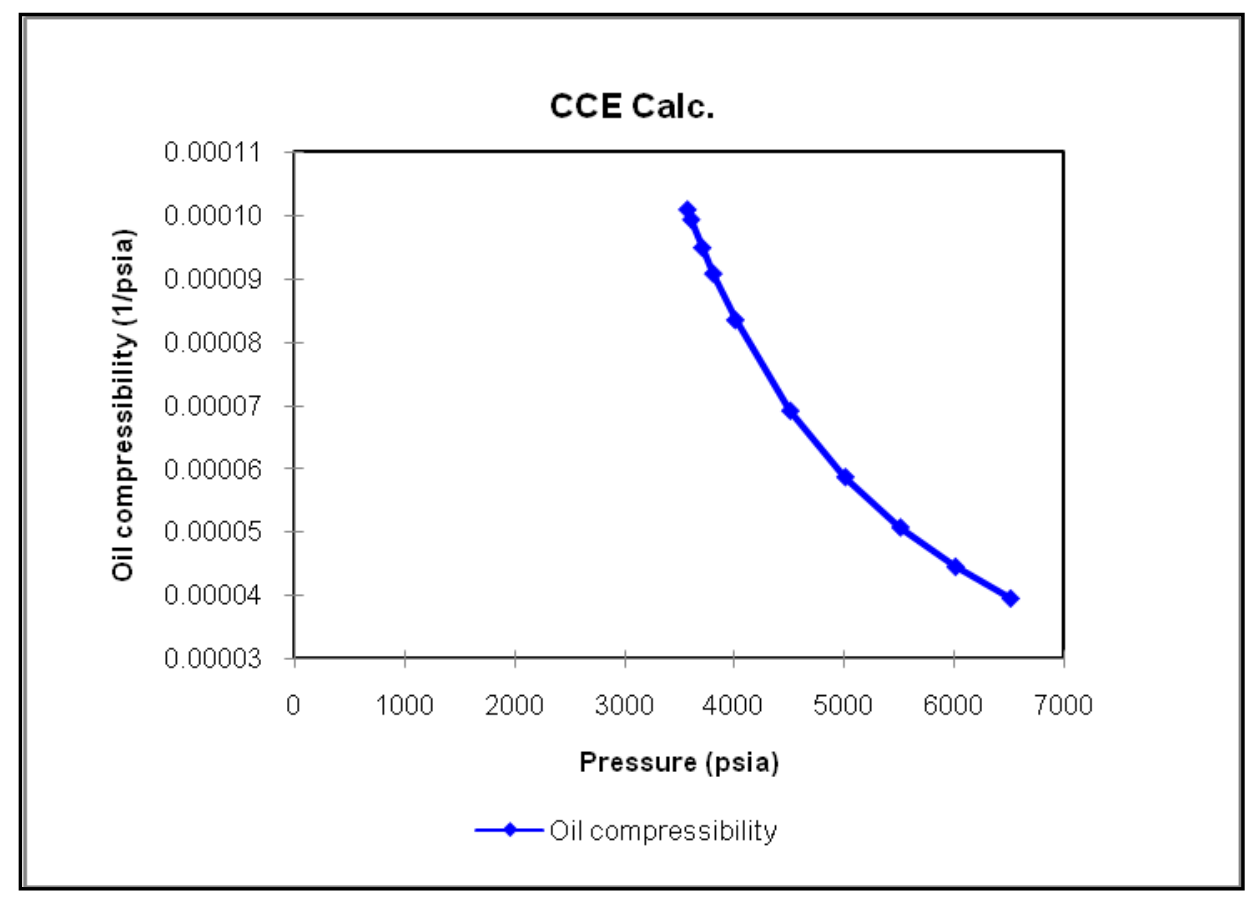

Figure D-5: WinProp CCE Simulation predictions for single phase oil compressibility

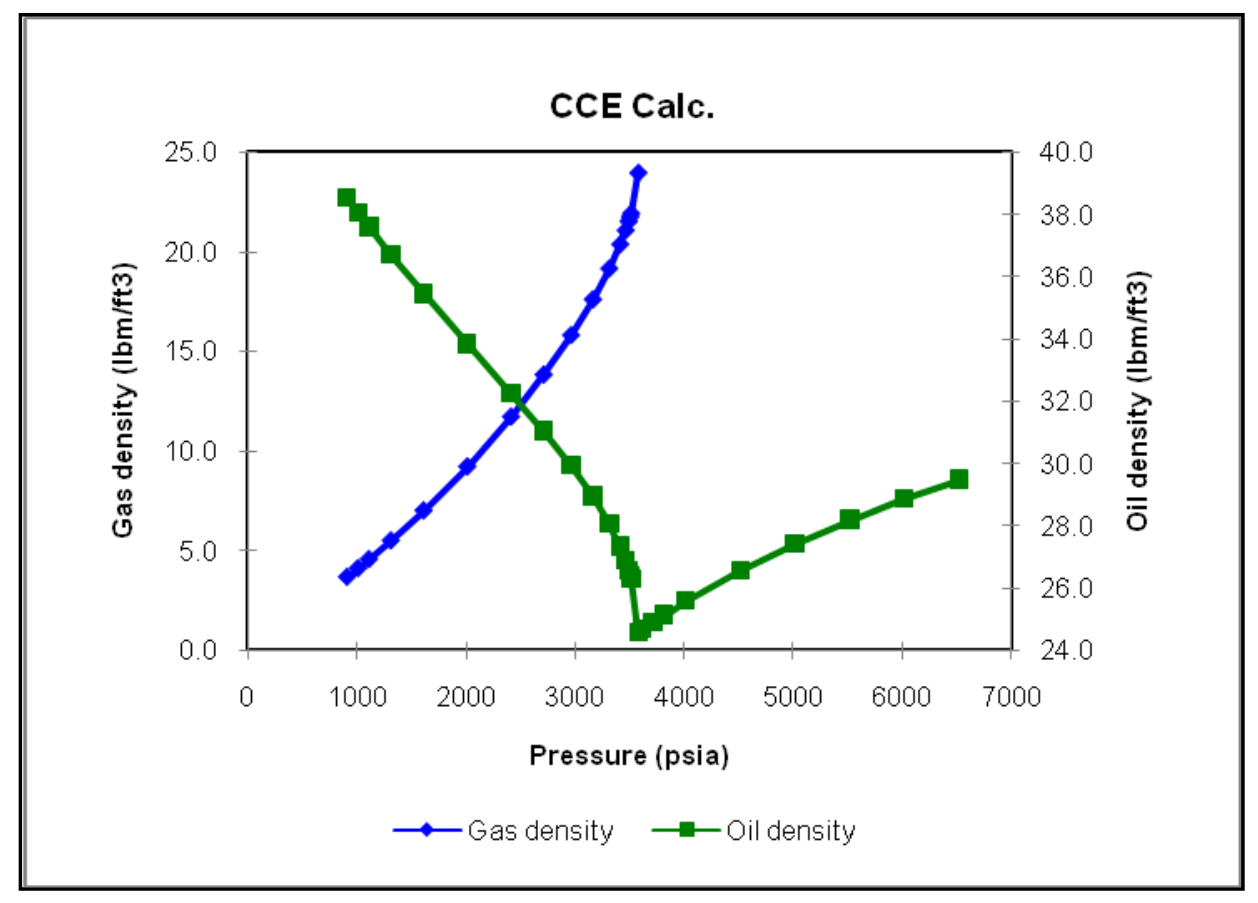

Figure D-6: WinProp CCE Simulation predictions for gas and oil densities 


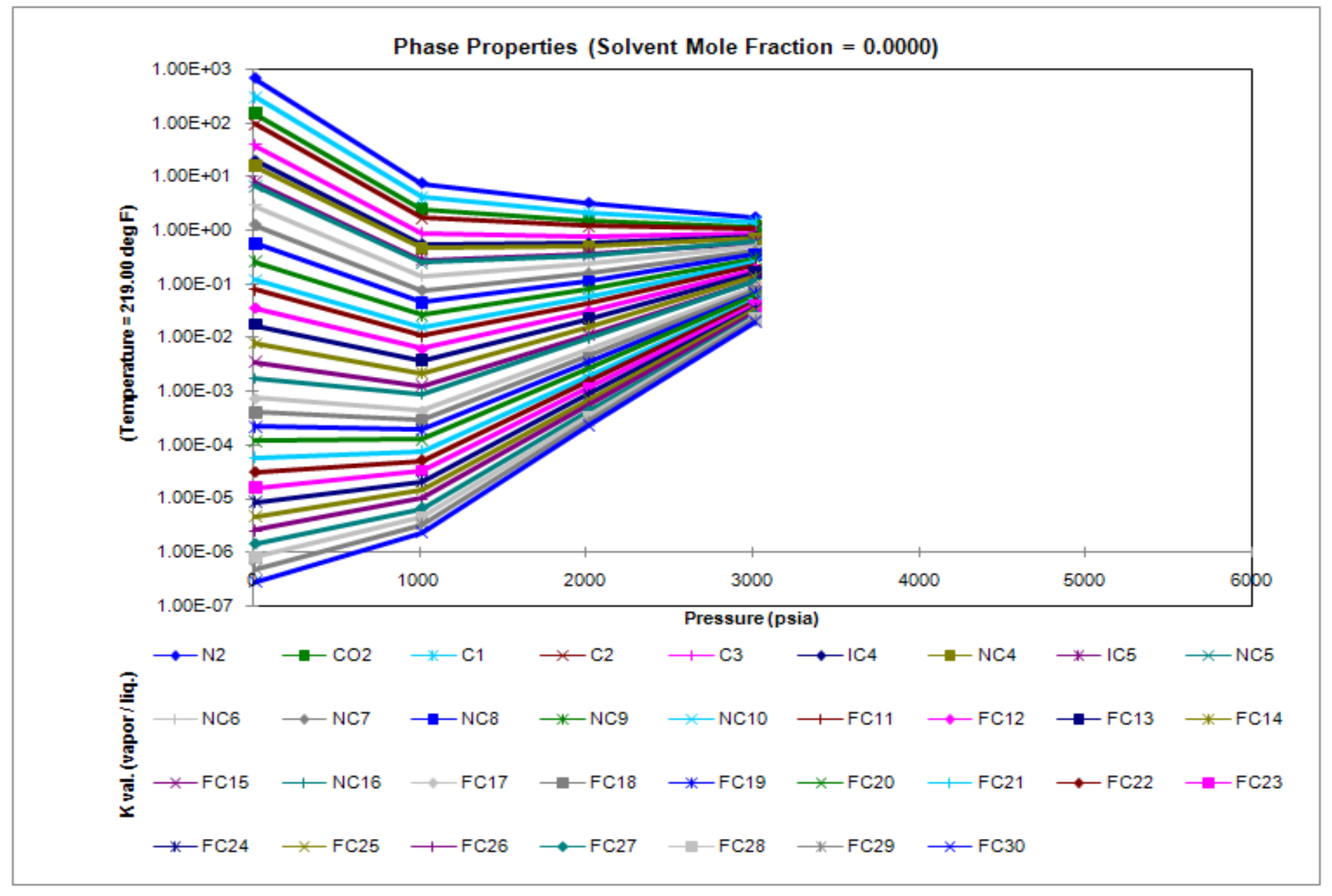

Figure D-7 WinProp generated P-T diagram showing individual component K-values 


\section{APPENDIX E - PHASE Program Example Input and Output Files}

The PHASE input file for a situation of a stream mix of $20 \%$ nitrogen and $80 \%$ reservoir fluid is shown below.

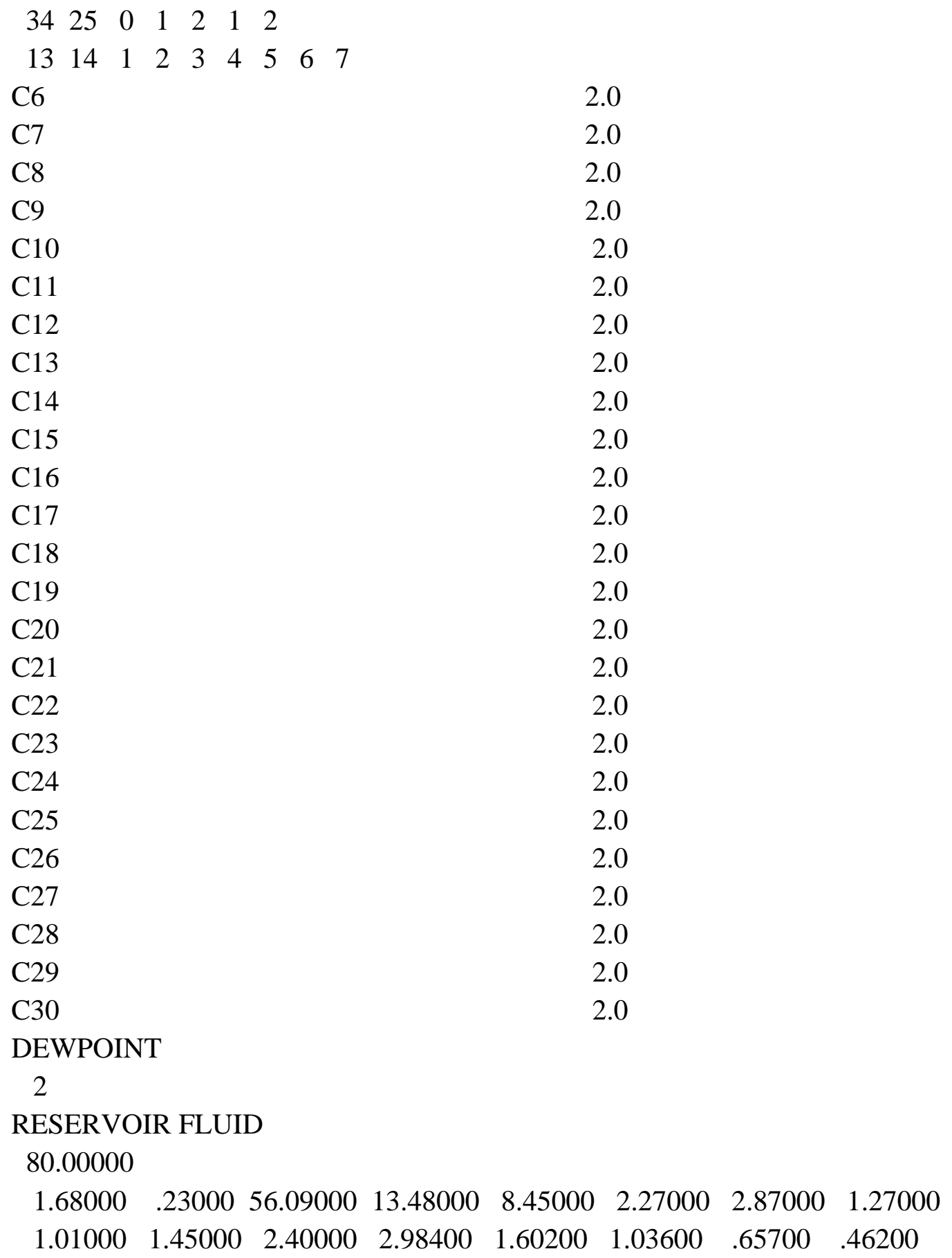

C30

2.0

DEWPOINT

2

RESERVOIR FLUID

80.00000

$\begin{array}{llllllll}1.68000 & 23000 & 56.09000 & 13.48000 & 8.45000 & 2.27000 & 2.87000 & 1.27000\end{array}$

$\begin{array}{llllllll}1.01000 & 1.45000 & 2.40000 & 2.98400 & 1.60200 & 1.03600 & .65700 & .46200\end{array}$ 


$\begin{array}{llllllll}.43900 & .33200 & .27300 & .18600 & .15200 & .13700 & .10100 & .07400 \\ .06000 & .04800 & .04000 & .03200 & .03100 & .02300 & .01900 & .01600 \\ .01200 & .08200 & & & & & & \end{array}$

INJECTION FLUID

$\begin{array}{lllllllll}20.00000 & & & & & & & \\ 99.90000 & .10000 & .00000 & .00000 & .00000 & .00000 & .00000 & .00000 \\ .00000 & .00000 & .00000 & .00000 & .00000 & .00000 & .00000 & .00000 \\ .00000 & .00000 & .00000 & .00000 & .00000 & .00000 & .00000 & .00000 \\ .00000 & .00000 & .00000 & .00000 & .00000 & .00000 & .00000 & .00000 \\ .00000 & .00000 & & & & & & \\ 4000.00000 & 219.00000 & & & & & & \\ \text { END }\end{array}$

The output file to determine the dew point estimate is given below,

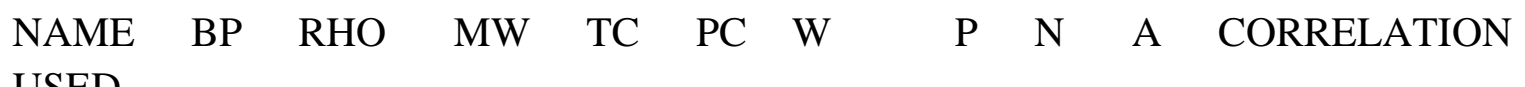
USED

DEG.F G/CC G/MOL DEG.F PSIA

$\begin{array}{llllllllll}\text { C6 } & 147.0 & .685 & 84.0 & 452.2 & 468.7 & .281 & .00 & \text { CAVETT'S } \\ \text { C7 } & 197.5 & .722 & 96.0 & 512.5 & 449.4 & .328 & .00 & \text { CAVETT'S } \\ \text { C8 } & 242.0 & .745 & 107.0 & 563.5 & 427.0 & .369 & .00 & \text { CAVETT'S } \\ \text { C9 } & 279.0 & .764 & 121.0 & 606.2 & 410.3 & .399 & .00 & \text { CAVETT'S } \\ \text { C10 } & 330.5 & .778 & 134.0 & 659.8 & 374.4 & .446 & .00 & \text { CAVETT'S } \\ \text { C11 } & 369.0 & .789 & 147.0 & 699.5 & 349.6 & .479 & .00 & \text { CAVETT'S } \\ \text { C12 } & 407.0 & .800 & 161.0 & 738.2 & 326.6 & .510 & .00 & \text { CAVETT'S } \\ \text { C13 } & 441.0 & .811 & 175.0 & 772.9 & 308.2 & .537 & .00 & \text { CAVETT'S } \\ \text { C14 } & 475.5 & .822 & 190.0 & 807.6 & 290.1 & .563 & .00 & \text { CAVETT'S }\end{array}$




$\begin{array}{lllllllll}\text { C15 } & 511.0 & .832 & 206.0 & 842.1 & 271.4 & .591 & .00 & \text { CAVETT'S } \\ \text { C16 } & 542.0 & .839 & 222.0 & 870.8 & 254.5 & .617 & .00 & \text { CAVETT'S } \\ \text { C17 } & 572.0 & .847 & 237.0 & 898.9 & 240.1 & .641 & .00 & \text { CAVETT'S } \\ \text { C18 } & 595.0 & .852 & 251.0 & 919.6 & 228.8 & .660 & .00 & \text { CAVETT'S } \\ \text { C19 } & 617.0 & .857 & 263.0 & 939.3 & 218.8 & .679 & .00 & \text { CAVETT'S } \\ \text { C20 } & 641.0 & .862 & 275.0 & 960.4 & 208.2 & .700 & .00 & \text { CAVETT'S } \\ \text { C21 } & 664.0 & .867 & 291.0 & 980.5 & 198.7 & .721 & .00 & \text { CAVETT'S } \\ \text { C22 } & 686.0 & .872 & 305.0 & 999.7 & 190.3 & .741 & .00 & \text { CAVETT'S } \\ \text { C23 } & 707.0 & .877 & 318.0 & 1018.0 & 182.9 & .761 & .00 & \text { CAVETT'S } \\ \text { C24 } & 727.0 & .791 & 331.0 & 991.8 & 134.5 & .846 & .00 & \text { CAVETT'S } \\ \text { C25 } & 747.0 & .795 & 345.0 & 1009.5 & 130.2 & .867 & .00 & \text { CAVETT'S } \\ \text { C26 } & 766.0 & .799 & 359.0 & 1026.3 & 126.5 & .887 & .00 & \text { CAVETT'S } \\ \text { C27 } & 786.0 & .893 & 374.0 & 1084.3 & 157.8 & .845 & .00 & \text { CAVETT'S } \\ \text { C28 } & 804.0 & .897 & 379.0 & 1099.4 & 153.1 & .866 & .00 & \text { CAVETT'S } \\ \text { C29 } & 821.0 & .899 & 402.0 & 1112.8 & 148.3 & .888 & .00 & \text { CAVETT'S } \\ \text { C30 } & 836.0 & .902 & 416.0 & 1125.2 & 144.7 & .907 & .00 & \text { CAVETT'S }\end{array}$

THE MOLAR RATE OF STREAM 1MIXED WAS 80.00000 HE NORMALIZED COMPOSITION OF THIS STREAM IS $1.6800 \quad$ 2300 56.0911

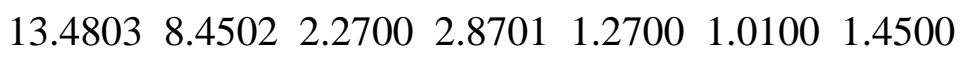

$$
\begin{aligned}
& \begin{array}{llllllllll}
2.4000 & 2.9841 & 1.6020 & 1.0360 & .6570 & .4620 & .4390 & .3320 & .2730 & .1860
\end{array} \\
& \begin{array}{llllllllll}
.1520 & .1370 & .1010 & .0740 & .0600 & .0480 & .0400 & .0320 & .0310 & .0230
\end{array} \\
& \begin{array}{llll}
.0190 & .0160 & .0120 & .0820
\end{array} \\
& \text { THE SOURCE OF THE ABOVE STREAM WAS RESERVOIR FLUID }
\end{aligned}
$$


THE MOLAR RATE OF STREAM 2MIXED WAS 20.00000

HE NORMALIZED COMPOSITION OF THIS STREAM IS 99.9000 $\quad .00000 .0000$ 00.000000 .000000 .000000 .000000 .000000 .000000 .0000 00.000000 .000000 .000000 .000000 .000000 .000000 .000000 .000000 .000000 .0000 00.000000 .000000 .000000 .000000 .000000 .000000 .000000 .000000 .000000 .0000 00.000000 .000000 .000000 .0000

THE SOURCE OF THE ABOVE STREAM WAS INJECTION FLUID

** THE NEW FEED COMPOSITION FORM ALL SOURCES IS ** $\begin{array}{lllllll}21.324027 & 204004 & 44.872897 & 10.784216 & 6.760135 & 1.816036 & 2.296046\end{array}$ $\begin{array}{lllll}1.016020 & 808016 & 1.160023 & 1.920038 & 2.387248\end{array}$

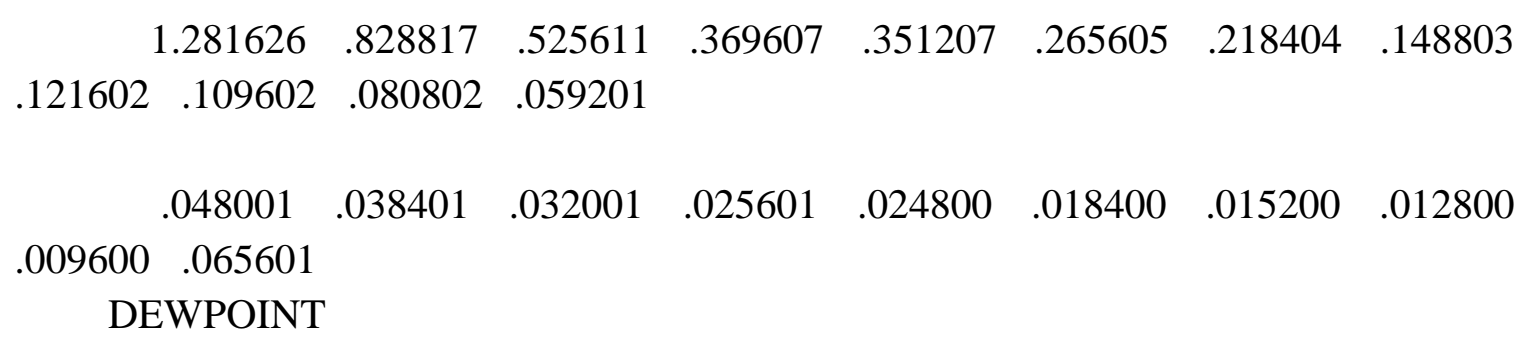

$\begin{array}{llllllll}1.281626 & .828817 & .525611 & .369607 & .351207 & .265605 & .218404 & .148803\end{array}$ $\begin{array}{lllll}.121602 & .109602 & 080802 & .059201\end{array}$

$\begin{array}{llllllll}.048001 & .038401 & .032001 & .025601 & .024800 & .018400 & .015200 & .012800\end{array}$ .009600 .065601

DEWPOINT

RETROGRADE DEW PT. PRESSURE DETERMINATION, INITIAL GUESS= 4014.70 PSIA

PRESSURE 5095.38PSIA TEMPERATURE 219.00DEGREE F

$\begin{array}{lccccccc}\text { N2 } & 21.32403 & 19.3816 & 21.32403 & 1.1002208 & .00 & .00 \\ \text { CO2 } & .20400 & .1990 & .20400 & 1.0252855 & .00 & .00 \\ \text { METH } & 44.87290 & 42.6251 & 44.87290 & 1.0527345 & .00 & .00 \\ \text { ETHN } & 10.78422 & 10.9160 & 10.78422 & .9879302 & .00 & .00 \\ \text { PROP } & 6.76014 & 7.1025 & 6.76014 & .9518025 & .00 & .00 \\ \text { 1-C4 } & 1.81604 & 1.9637 & 1.81604 & .9248045 & .00 & .00 \\ \text { N-C4 } & 2.29605 & 2.5227 & 2.29605 & .9101405 & .00 & .00 \\ \text { I-C5 } & 1.01602 & 1.1445 & 1.01602 & .8877149 & .00 & .00 \\ \text { N-C5 } & .80802 & .9192 & .80802 & .8790146 & .00 & .00 \\ \text { C6 } & 1.16002 & 1.3599 & 1.16002 & .8530302 & .00 & .00 \\ \text { C7 } & 1.92004 & 2.3286 & 1.92004 & .8245444 & .00 & .00 \\ \text { C8 } & 2.38725 & 2.9856 & 2.38725 & .7995775 & .00 & .00 \\ \text { C9 } & 1.28163 & 1.6469 & 1.28163 & .7782218 & .00 & .00\end{array}$




$\begin{array}{lllllll}\text { C10 } & .82882 & 1.1040 & .82882 & .7507150 & .00 & .00 \\ \text { C11 } & .52561 & .7198 & .52561 & .7302217 & .00 & .00 \\ \text { C12 } & .36961 & .5204 & .36961 & .7102860 & .00 & .00 \\ \text { C13 } & .35121 & .5072 & .35121 & .6924723 & .00 & .00 \\ \text { C14 } & .26561 & .3936 & .26561 & .6748584 & .00 & .00 \\ \text { C15 } & .21840 & .3321 & .21840 & .6577380 & .00 & .00 \\ \text { C16 } & .14880 & .2310 & .14880 & .6440394 & .00 & .00 \\ \text { C17 } & .12160 & .1928 & .12160 & .6308263 & .00 & .00 \\ \text { C18 } & .10960 & .1763 & .10960 & .6215822 & .00 & .00 \\ \text { C19 } & .08080 & .1318 & .08080 & .6129463 & .00 & .00 \\ \text { C20 } & .05920 & .0980 & .05920 & .6040879 & .00 & .00 \\ \text { C21 } & .04800 & .0806 & .04800 & .5957639 & .00 & .00 \\ \text { C22 } & .03840 & .0653 & .03840 & .5878598 & .00 & .00 \\ \text { C23 } & .03200 & .0551 & .03200 & .5802658 & .00 & .00 \\ \text { C24 } & .02560 & .0389 & .02560 & .6574164 & .00 & .00 \\ \text { C25 } & .02480 & .0380 & .02480 & .6528365 & .00 & .00 \\ \text { C26 } & .01840 & .0284 & .01840 & .6477986 & .00 & .00 \\ \text { C27 } & .01520 & .0275 & .01520 & .5531187 & .00 & .00 \\ \text { C28 } & .01280 & .0234 & .01280 & .5461764 & .00 & .00 \\ \text { C29 } & .00960 & .0178 & .00960 & .5406911 & .00 & .00 \\ \text { C30 } & .06560 & .1227 & .06560 & .5345600 & .00 & .00\end{array}$

MOLE RATES $\quad 100.00000 \quad 00.0000 \quad 100.00000$

MOLECULAR WEIGHT $36.443 \quad 40.899 \quad 36.443$

DENSITY (LB/CUFT) $\quad 28.234 \quad 25.608$

HEATING VALUE (BTU/CUFT) $\quad 1977.3 \quad 1722.5$

NO. OF INTERATIONS $=209$

END 